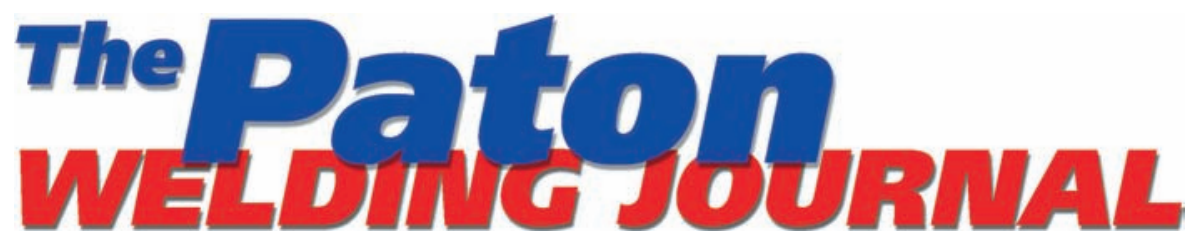

\section{J uly 2017 No. 7}

Published since 2000

\section{EDITORIAL BOARD \\ Editor-in-Chief B.E. Paton}

Scientists of PWI, Kiev S.I. Kuchuk-Yatsenko (vice-chief ed.), V.N. Lipodaev (vice-chief ed.)

Yu.S. Borisov, G.M. Grigorenko A.T. Zelnichenko, V.V. Knysh,

I.V. Krivtsun, Yu.N. Lankin, L.M. Lobanov, V.D. Poznyakov, I.A. Ryabtsev, K.A. Yushchenko

Scientists of Ukrainian Universities V.V. Dmitrik, NTU «KhPI», Kharkov V.V. Kvasnitsky, NTUU «KPl», Kiev V.D. Kuznetsov, NTUU «KPI», Kiev

\section{Foreign Scientists N.P. Alyoshin}

N.E. Bauman MSTU, Moscow, Russia Guan Qiao

Beijing Aeronautical Institute, China A.S. Zubchenko

DB «Gidropress», Podolsk, Russia M. Zinigrad

Ariel University, Israel V.I. Lysak

Volgograd STU, Russia

Ya. Pilarczyk

Welding Institute, Gliwice, Poland U. Reisgen

Welding and Joining Institute, Aachen, Germany G.A. Turichin

St. Petersburg SPU, Russia

Founders

E.O. Paton Electric Welding Institute, NASU International Association «Welding» Publisher

International Association «Welding» Translators

A.A. Fomin, O.S. Kurochko, I.N. Kutianova Editor

N.G. Khomenko

Electron galley

D.I. Sereda, T.Yu. Snegiryova Address

E.O. Paton Electric Welding Institute, International Association «Welding» 11 Kazimir Malevich Str. (former Bozhenko Str.), 03680, Kiev, Ukraine

Tel.: (38044) 20060 16, 2008277

Fax: (38044) 2008277,2008145

E-mail: journal@paton.kiev.ua

www.patonpublishinghouse.com

State Registration Certificate

KV 4790 of 09.01.2001

ISSN 0957-798X

doi.org/10.15407/tpwj2017.08.01

Subscriptions

$\$ 348,12$ issues per year

air postage and packaging included.

Back issues available. All rights reserved.

This publication and each of the articles contained herein are protected by copyright.

Permission to reproduce material contained in this ournal must be obtained in writing from the Publisher.

\section{CONTENTS}

\section{SCIENTIFIC AND TECHNICAL}

Tsybulkin G.A. Synthesis of structure of system for self-regulation of electrode melting rate

Markashova L.I., Poznyakov V.D., Berdnikova E.N., Alekseenko T.A., Kushnareva O.S. and Polovetsky E.V. Structure and service properties of welded joints of high-strength steels, aluminium and titanium alloys

Dmitrik V.V., Glushko A.V. and Sirenko T.O. Structural changes in metal of welded joints of steam pipelines

Berezhnaya E.V., Kuznetsov V.D., Kassov V.D. and Gavrish P.A. Investigation of microplastic deformation of metal deposited by electric resistance method

\section{INDUSTRIAL}

Korzhik V.N. Hybrid plasma-arc welding of thin-walled panels from aluminium alloy

Borisov Yu.S., Vojnarovich S.G., Kislitsa A.N., Kuzmych-lanchuk le.K., Masyuchok O.P. and Kalyuzhny S.N. Development of technology of microplasma spraying for restoration of local damages of enamel coating

Lebedev V.A., Zhuk G.V. and Lendel I.V. Application of adjustable electric drives with brushless electric motors in arc welding

Peremitko V.V. and Panfilov A.I. Arc surfacing of layers of metal of varying composition and hardness

Akhonin S.V., Vrzhizhevsky E.L., Belous V.Yu. and Petrichenko I.K. Influence of preheating parameters and local heat treatment on structure and properties of dispersion-strengthened joints of silicon-containing titanium alloys made by electron beam welding 


\title{
SYNTHESIS OF STRUCTURE OF SYSTEM FOR SELF-REGULATION OF ELECTRODE MELTING RATE
}

\author{
G.A. TSYBULKIN \\ E.O. Paton Electric Welding Institute, NASU \\ 11 Kazimir Malevich Str., 03680, Kiev, Ukraine. E-mail: office@paton.kiev.ua
}

\begin{abstract}
In automation of consumable electrode arc welding it is necessary to have a clear knowledge about the structure of system for a self-regulation of the electrode melting rate. In the given work a general structure of this system is constructed on the basis of analytical description of dynamic processes, proceeding in the welding circuit. A simple structure analysis allows easy obtaining the necessary characteristics of the self-regulation system, including accuracy in a steady mode and time of optimizing the effect of disturbances. Criteria are suggested, that allow selecting those parameters of welding processes from the admissible values, which provide the desirable quick-response of the self-regulation system. Results of comparison of quick-response estimates, obtained by using these criteria, with results of computer modeling, are given. 21 Ref., 5 Figures.
\end{abstract}

Ke y word s : robotic arc welding, consumable electrode, structure of self-regulation system, evaluation of accuracy and quick-response of system

A wide class of biosystems is known, realizing the self-regulation (homeostas) of processes in live organisms, the structures of which are «synthesized» by the nature itself in the course of a long evolution. A large factual material is accumulated, describing the different symptoms of homeostas [1, 2]. At the same time the problems, referring to the construction of structure itself of such systems, are poorly elucidated in literature. The main problem here consists in the fact that the distinguishing of separate substructures from the general structure, fulfilling the definite functions of the homeostas, and establishment of functional relations between these substructures occurred to be a rather difficult task.

The similar situation is formed in study of one of unique technical control systems, used wide-

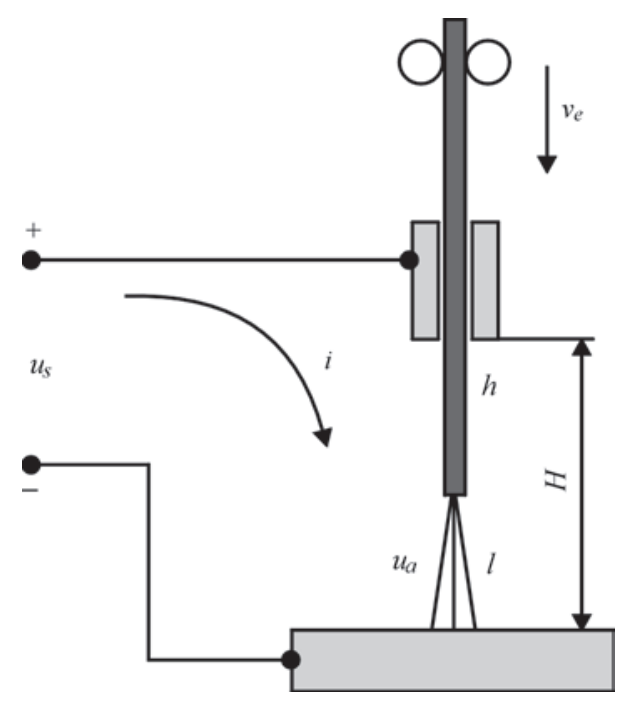

Figure 1. Scheme of welding circuit

(C) G.A. TSYBULKIN, 2017 ly in welding technology, namely the system of arc self-regulation [3-11], more precisely self-regulation of electrode melting rate (EMR). The same as in systems of homeostatic type, there is some uncertainty in EMR concerning its structure and separate elements, fulfilling either functions of the self-regulation. Nevertheless, in robotization of consumable electrode arc welding in shielding gas it is necessary to have a clear idea about the structure of EMR and its parameters.

It should be noted that problems connected with the construction of EMR structure were described earlier [7, 8], but the structural diagrams, given in the mentioned publications, were rather cumbersome, and, therefore, are hardly suitable for practical application. In the present work the task of synthesis of «curtail» easily visible structure of EMR on the basis of analytic description of well-observed dynamic processes, proceeding in welding circuit of the system, was put.

Construction of schematic diagram of EMR. Figure 1 shows a principal elementary diagram of welding circuit of EMR. At this diagram and in the further description $u_{s}=u_{s}(i, t)$ is the voltage, supplied to circuit input from the welding current source; $v_{e}=v_{e}(t)$ is the electrode feed speed relatively to current-carrying nozzle edge; $H=H(t)$ is the distance between the nozzle edge and workpiece welded; $h=h(t)$ is the electrode stickout; $l=l(t)$ is the arc length; $u_{a}=u_{a}(l, i)$ is the arc voltage; $i=i(t)$ is the welding current.

Let us denote by $R$ : the total electric resistance of supplying wires, a sliding contact in torch nozzle, electrode stickout and workpiece welded, included into welding circuit, and by $L$ : the inductance of weld- 
ing circuit. The differential equation of the circuit with account for $R$ and $L$ will be written in the form

$$
L \frac{d i}{d t}+R i=u_{s}(i, t)-u_{a}(l, i) .
$$

Functions $u_{s}(i, t)$ and $u_{a}=u_{a}(l, i)$ in the operating range of welding currents will be supposed as continuous and differentiable by their arguments and the arguments themselves as continuous and limited.

The electrode feed speed $v_{e}(t)$ and rate of its melting $v_{m}(t)$ are connected with actual value of electrode stickout $h(t)$ by the equation [6]

$$
h=h_{0}+\int_{0}^{t}\left(v_{e}-v_{m}\right) d t,
$$

in which $h_{0}$ is the initial value of stickout. Dependence of $v_{m}(t)$ on $i(t)$, according to works [9-11], will be written in the form

$$
v_{m}(t)=M i,
$$

where $M$ is the parameter, characterizing electrical, thermophysical and geometric properties of consumable electrode.

System of equations (1)-(3) will be added with equality

$$
h+l=H
$$

and differentiated (1), (2), and (4) by time $t$. Then, by excluding intermediate variables $u_{a}, i, h$ and $l$ from the formed equations, we shall come to one equation relative to variable $v_{m}$ :

$$
a \frac{d^{2} v_{m}}{d t^{2}}+b \frac{d v_{m}}{d t}+v_{m}=v_{e}+\frac{d g}{d t} .
$$

In this equation the following designations are introduced:

$$
a=\frac{L}{E M}, \quad b=\frac{R_{w}}{E M}, \quad g=\frac{u_{s}}{E}-H,
$$

where $E=\partial u_{d} / \partial l$ is the intensity of electric field in arc column; $R_{w}$ is the total resistance of welding circuit:

$$
R_{w}=R+S_{a}+R_{s} .
$$

Here $S_{a}=\partial u_{a} / \partial i, R_{s}=\partial u_{s} / \partial i$ are the tangents of angles of inclination of static volt-ampere characteristics of arc and welding current source in working point of welding.

Differential equation (5) represents a mathematical model, connecting the electrode melting rate $v_{m}(t)$ and its derivatives with feed speed $v_{e}(t)$ and disturbances $d u_{s} / d t$ and $d H / d t$. This equation will be written in operator form

$$
A(p) v_{m}(t)=v_{e}(t)+B(p) g(t),
$$

where

$$
A(p)=a p^{2}+b p+1 ; B(p)=p\left(p \equiv \frac{d}{d t}\right),
$$

and the equation of mismatching will be introduced for consideration

$$
\varepsilon(t)=v_{e}(t)+B(p) g(t)-v_{m}(t) .
$$

Let us compare the schematic diagram (Figure 2) with equations (7) and (8). In this diagram the function

$$
W(p)=\frac{K}{p(T p+1)}
$$

is a transfer function of opened part of system, and by $K$ and $T$ in expression (9) the following relations are designated

$$
K=\frac{1}{b}=\frac{E M}{R_{w}}, \quad T=\frac{a}{b}=\frac{L}{R_{w}} .
$$

Analysis of EMR structure. As is seen from Figure 2, the EMR represents a closed system with a rigid negative feed back by electrode melting rate $v_{m}(t)$. As input effects the $v_{e}(t)$ and $g(t)$ are used. Mismatching $\varepsilon(t)$ essentially controls the electrode melting rate $v_{m}(t)$ through the transfer function $W(p)$.

The standard appearance of schematic diagram of EMR allows using the results of theory of systems of automatic control in its analysis. In particular, only by the presence of multiplier $p$ in denominator of transfer function (9), according to works [12, 13], it is possible to state at once that EMR possesses a type 1 servo system with respect to effects of $v_{e}(t)$ and $g(t)$. It means that when $v_{m}(t)=v_{e 0}=$ const and $g(t)=g_{0}=$ const, the set error $\varepsilon_{\infty}=\lim _{t \rightarrow \infty} \varepsilon(t)$ is equal to zero. Consequently, in steady mode in accordance with expression (8), equality $v_{m}(\infty)$ is fulfilled, which denotes that EMR provides the stabilization of electrode melting rate $v_{m}(t)$ at the preset level $v_{e 0}$.

If $v_{e}(t) \neq$ const, and changed by some law, then $v_{m}(t)$ will be also changed by the same law, i.e. rate $v_{m}(t)$ will be as if «follow» the rate $v_{e}(t)$. In this case EMR, according to the terminology of work [14], represents a servo system. In particular, if $v_{e}=v_{e 0}+\Delta v_{e} \sin$ $\omega t$, where $\Delta v_{e}$ is the amplitude, and $\omega$ is the angular frequency, then after completion of transfer process the rate $v_{m}(t)$ will be changed as follows:

$$
v_{m}(t)=v_{e 0}+\Delta v_{m}(\omega) \sin [\omega t+\varphi(\omega)] .
$$

Here it is necessary to take into consideration that the amplitude $\Delta v_{m}(\omega)$ and phase shift $\varphi(\omega)$ depend on $\omega$ and, as shown in work [15], on $\Delta v_{m}(\omega) \rightarrow 0$ at $\omega \rightarrow$ $\rightarrow \infty$.Consequently, the frequency $\omega$, at which it is supposed to perform the oscillating movement $v_{e}(t)$, it is necessary to select from the condition $\omega<\omega_{c}$, where $\omega_{c}$ is the boundary frequency of EMR pass band. As

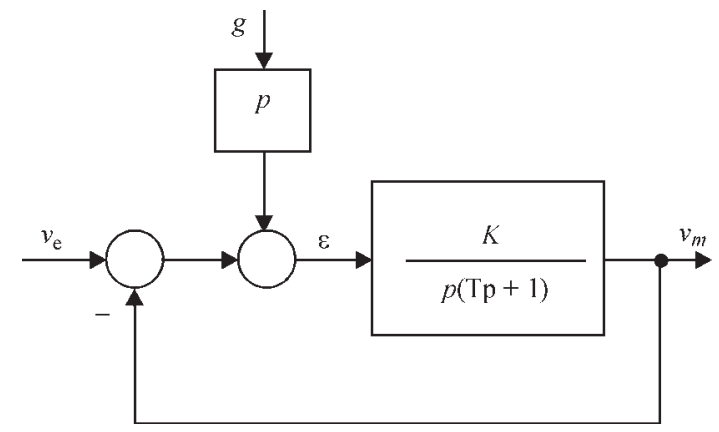

Figure 2. Schematic diagram of EMR 


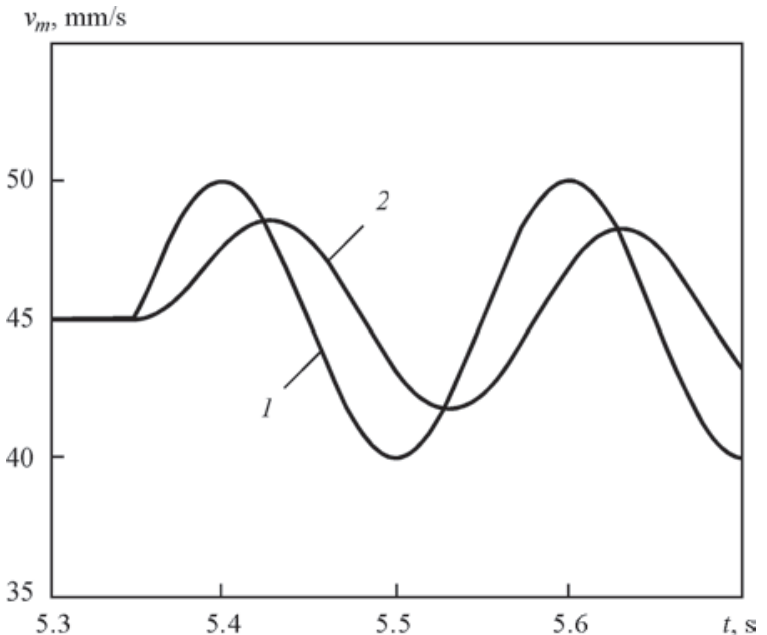

Figure 3. Reaction of electrode melting rate $v_{m}(t)$ on harmonic effect of $v_{e}(t)=45+5 \sin (31.4 t)$

to the case when $g(t) \neq$ const, then at $v_{e}(t)=v_{e 0}$ the rate $v_{m}(t)$, as is seen from schematic diagram of EMR, will «follow» the change of $d g / d t$. This is remarkable property, widely used in pulse-arc technologies of welding [16-19].

Let us now address the problem of EMR quick-response. We shall consider the case when the limitation is imposed on value $R_{w}$, as, for example, at the underwater arc welding [20]. But there is a feasibility to change in some limits the values of parameters $L, E$ and $M$. As a measure of quickness of proceeding the transient processes in this case, a generalized estimate of numerical value of coefficients of characteristic equation $T \lambda_{2}+\lambda+K=0$, corresponding to the differential equation, can serve (5):

$$
\Omega=\sqrt{\lambda_{1} \lambda_{2}}=\sqrt{\frac{K}{T}} .
$$

In this expression $\lambda_{1}, \lambda_{2}$ are the roots of equation $T \lambda_{2}+\lambda+K=0$. Estimation $\Omega$ in the theory of control is called as mean-square root [12]. Increase in $\Omega$ by $\beta$ times leads, according to work [12], to the decrease in the transient process decay time by $\beta$ times.

Taking into account the relations (10), the formula (11) will take the form

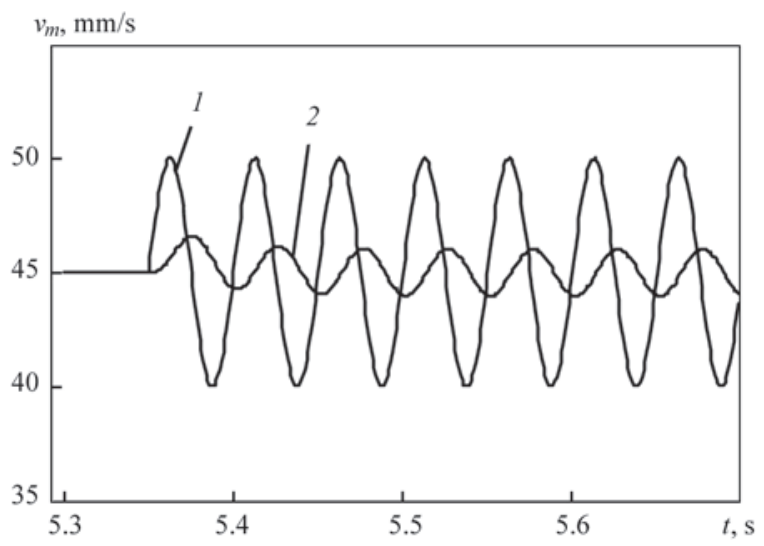

Figure 4. Reaction of electrode melting rate $v_{m}(t)$ on harmonic effect of $v_{e}(t)=45+5 \sin (125.6 t)$

$$
\Omega=\sqrt{\frac{E M}{L}} .
$$

From this formula it is seen at once, that to increase the EMR quick-response it is necessary to decrease $L$ and increase $E$ and $M$. The range of allowable values $L$, according to works [4, 5], is rather wide $\left(10^{-3}-10^{-4}\right) \mathrm{H}$. The values of parameter $E$ depend, as is known, on shielding gas composition, used in arc welding. From the data, given in work [4], in $\mathrm{CO}_{2}$ welding the parameter $E$ takes a values in the range from 1.7 up to $3.3 \mathrm{~V} / \mathrm{mm}$, and in argon welding it is from 0.6 up to $1.3 \mathrm{~V} / \mathrm{mm}$. As to parameter $M$, then its value depends greatly on electrode diameter $d$. This dependence, according to works [6, 21], has the following form: $M=$ $=\psi / d^{2}$, where $\psi$ is the coefficient, characterizing the thermophysical properties of electrode material (density, temperature of melting (and boiling), specific heat capacity and electron work function). Consequently, with decrease in $d$ the value of parameter $M$ is sharply increased. Thus, there is a principal possibility for providing the acceptable quick-response of EMR.

In Figures 3-5 the results of computer modeling of processes in EMR are given, obtained at the following values of parameters of welding circuit and mode of robotic arc welding: $u_{\mathrm{s}}=30 \mathrm{~V} ; H=17 \mathrm{~mm}$; $R_{1}=0.025 \mathrm{Ohm} ; R_{s}=0.01 \mathrm{~V} / \mathrm{A} ; S_{a}=0.005 \mathrm{~V} / \mathrm{A}$; $L_{1}=0.0001 \mathrm{H}, L_{2}=0.001 \mathrm{H}$.

The arc welding was modeled in argon $\left(E_{1}=1.7 \mathrm{~V} / \mathrm{mm}\right)$ and in $\mathrm{CO}_{2}\left(E_{2}=3 \mathrm{~V} / \mathrm{mm}\right)$ by electrodes of two different diameters: $d_{1}=1.2 \mathrm{~mm}\left(M_{1}=0.37 \mathrm{~mm} /(\mathrm{s} \cdot \mathrm{A})\right)$ and $d_{2}=$ $=0.8 \mathrm{~mm}\left(M_{2}=0.82 \mathrm{~mm} /(\mathrm{s} \cdot \mathrm{A})\right)$. As typical effects the functional relations, described by the following analytical expressions, were used:

$$
v_{e}(t)=\left\{\begin{array}{cc}
45, & t<t_{*}, \\
45+5 \sin \omega t, & t \geq t_{*},
\end{array}\right.
$$

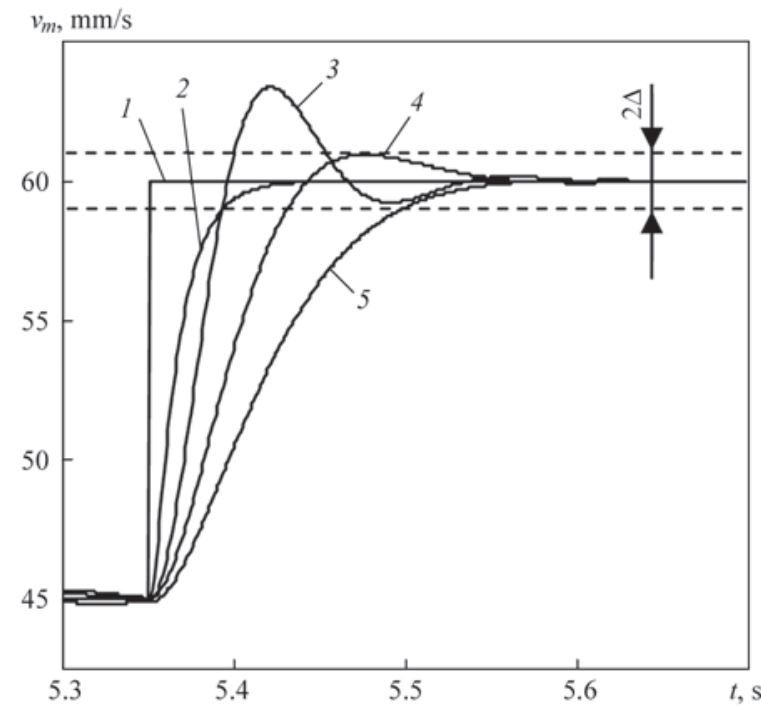

Figure 5. Reaction of electrode melting rate $v_{m}(t)$ on jump in its feed speed $v_{e}(t)$ at different combinations of parameters $L, E$ and M

ISSN 0957-798X THE PATON WELDING JOURNAL, No. 7, 2017 


$$
v_{e}(t)= \begin{cases}45, & t<t_{*}, \\ 60, & t \geq t_{*},\end{cases}
$$

where $t_{*}=5.35 \mathrm{~s}$.

In Figures 3, 4 the digit 1 marks the graphs of functions (13), and digit 2 marks the reaction $v_{m}(t)$ on effect $v_{e}(t)$, expressed by this function. Moreover, in Figure 3 the graph $v_{e}(t)$ is plotted at $\omega=31.4 \mathrm{~s}^{-1}$, and in Figure $4-$ at $\omega=125.6 \mathrm{~s}^{-1}$. It is seen from these Figures that, as was expected, the rate $v_{m}(t)$ in a steady mode is changed by the same law as the rate $v_{e}(t)$, and its amplitude is decreased with increase in frequency $\omega$.

In Figure 5 the digit 1 marks the graph of function (14), and digits (2-5) mark the reaction of $v_{m}(t)$ on effect of $v_{e}(t)$ at different combinations of parameters $L, E$ and $M$ : curve 2 was obtained at $L_{1}, E_{1}$ and $M_{2}$; curve 3 - at $L_{2}, E_{2}, M_{2}$; curve 4 - at $L_{2}, E_{1}, M_{1}$; curve 5 - at $L_{2}, M_{1}, E_{1}$.

It is seen from this Figure that the time of regulation $\tau_{c}$ (time, after the lapse of which, the difference $\left|v_{m}(t)-v_{e 0}\right|$ does not exceed some preset value $\Delta$ ) depends greatly on combination of parameters, given in formula (12). Parameters $\tau_{c}$ and $\Omega$ are related, according to work [12], by ratio

$$
\tau_{c}=\frac{4.8}{\Omega} \text {. }
$$

Consequently, by calculating the values by formula (12),

$$
\begin{aligned}
& \Omega_{2}=\sqrt{\frac{E_{2} M_{2}}{L_{1}}}=156.8 \mathrm{~s}^{-1}, \Omega_{3}=\sqrt{\frac{E_{2} M_{2}}{L_{2}}}=49.6 \mathrm{~s}^{-1}, \\
& \Omega_{4}=\sqrt{\frac{E_{2} M_{1}}{L_{2}}}=33.3 \mathrm{~s}^{-1}, \Omega_{5}=\sqrt{\frac{E_{1} M_{1}}{L_{2}}}=25.1 \mathrm{~s}^{-1}
\end{aligned}
$$

and by substituting them successively into formula (15) we shall obtain

$$
\begin{aligned}
\tau_{c 2} & =0.031 \mathrm{~s}, \quad \tau_{c 3}=0.097 \mathrm{~s}, \\
\tau_{c 4} & =0.144 \mathrm{~s}, \quad \tau_{c 5}=0.191 \mathrm{~s} .
\end{aligned}
$$

Comparison of calculated values (16) with the results of modeling, given in Figure 5, shows a good their correlation. Thus, the estimation of quick-response $\Omega$ or time of regulation $\tau_{c}$ can be easily obtained, not solving the differential equation (5), but using the simple relations (12) and (15).

\section{Conclusions}

1. On the basis of analytic description of well-observed dynamic processes, proceeding in welding circuit, the structure of EMR is constructed, the analysis of which allows quite simple obtaining of necessary idea about the main properties of EMR. In particular, it is seen from the schematic diagram of EMR, that it possesses a type 1 servo system and, depending on law of changing $v_{e}(t)$, can provide either stabilization of electrode melting rate $v_{m}(t)$ at the preset level $v_{e 0}$, or «follow» the changes $v_{e}(t)$ or $d g / d t$.
2. Criterion $\Omega$, used in this investigation, allows also a simple (without preliminary modeling or special experiments) selection of those parameters from allowable parameters $E, M$ and $L$, which provide the necessary quick-response of EMR.

1. Tsybulkin, V.N. (1978) Theory of control and biosystems. Analysis of conservation properties. Moscow: Nauka.

2. Albegov, E.V., Butenko, D.V., Butenko, L.N. (2014) Homeostatics: Concept modeling of structured stable systems: Monography. Moscow: Natural Sci. Acad.

3. Paton, B.E. (1952) Self-regulation in consumable electrode welding. Avtomatich. Svarka, 1, 38-45.

4. Lenivkin, V.A., Dyurgerov, N.G., Sagirov, Kh.N. (1989) Technological properties of welding arc in shielded gases. Moscow: Mashinostroenie.

5. Leskov, G.I. (1970) Electric welding arc. Moscow: Mashinostroenie.

6. Tsybulkin, G.A. (2014) Adaptive control in arc welding: Monography. Kiev: Stal.

7. Lebedev, A.V. (1978) Influence of heat evolution in electrode stickout on process of self-regulation. Avtomatich. Svarka, 7, $10-15$.

8. (1986) Automation of welding processes. Ed. by V.K. Lebedev. Kiev: Vyshcha Shkola.

9. Paton, B.E., Lebedev, V.K. (1966) Electric equipment for arc and slag welding. Moscow: Mashinostroenie.

10. Sudnik, V.A., Erofeev, V.A., Logvinov, R.V. (1999) Examination of stability of the consumable electrode shielded-gas arc welding. In: Computer technologies in joining of materials: Transact. Tula: TSU, 110-120.

11. Pan, J. (2003) Arc welding control. Wood head Publish. LTD and CRC LLC.

12. Makarov, I.M., Mensky, B.M. (1977) Linear automatic systems ( elements of theory, methods of calculation and reference document): Manual for inst. of higher education. Moscow: Mashinostroenie.

13. Dorf, R., Bishop, R. (2002) Modern control systems. Moscow: Laboratory of basic knowledges.

14. (1988) Theory of control. Terminology, Issue 107. Moscow: Nauka.

15. Tsybulkin, G.A. (2005) Influence of frequency properties of the welding circuit on current parameters in pulsed-arc welding processes. The Paton Welding J., 10, 9-13.

16. Voropaj, N.M., Ilyushenko, V.M., Lankin, Yu.N. (1999) Peculiarities of pulsed-arc welding with synergic control of mode parameters (Review). Avtomatich. Svarka, 6, 26-32.

17. Paton, B.E., Shejko, P.P., Zhernosekov, A.M. et al. (2003) Stabilization of the process of consumable electrode pulse-arc welding. The Paton Welding J., 8, 2-5.

18. Saraev, Yu.N. (2002) Adaptive pulsed-arc methods of mechanized welding in construction of main pipelines. Svarochn. Proizvodstvo, 1, 4-11.

19. Tsybulkin, G.A. (2016) Effect of parameters of welding circuit on formation of welding current pulses. The Paton Welding J., 9, 14-17.

20. Lebedev, V.K., Uzilevsky, Yu.A., Savich, I.M. et al. (1980) Analysis of possibility of adjustment by self-regulation system of typical disturbances on arc length in mechanized underwater welding: Underwater welding and cutting. Ed. by A.E. Asnis. Kiev: PWI, 10-23.

21. Korinets, I.F. (1995) Mathematical model of electrode wire melting in arc welding. Avtomatich. Svarka, 10, 39-43.

Received 11.05.2017 


\title{
STRUCTURE AND SERVICE PROPERTIES OF WELDED JOINTS OF HIGH-STRENGTH STEELS, ALUMINIUM AND TITANIUM ALLOYS
}

\author{
L.I. MARKASHOVA, V.D. POZNYAKOV, E.N. BERDNIKOVA, \\ T.A. ALEKSEENKO, O.S. KUSHNAREVA and E.V. POLOVETSKY \\ E.O. Paton Electric Welding Institute, NASU \\ 11 Kazimir Malevich Str., 03680, Kiev, Ukraine. E-mail: office@paton.kiev.ua
}

\begin{abstract}
A structural-analytical approach to evaluation of effect of structural-phase states on change of the most significant mechanical properties of examined materials was used in this work. A role of structural factors (alloying type, phase composition, size of grain and subgrain structure, distribution and density of dislocation, phase precipitations, their size and nature of distribution) was shown for ensuring optimum properties of welded joints and their operation reliability. Experimental-analytical evaluations have determined structural-phase parameters and factors providing the necessary complex of welded joint properties. 20 Ref., 2 Tables, 12 Figures.
\end{abstract}

Keywords : argon-arc welding, friction stir welding, electron beam welding, hybrid laser-arc welding, aluminium alloy, heat-resistant titanium alloy, high-strength steel, welded joints, structure, phase composition, mechanical properties, fracture toughness, crack resistance

Welded joints of complexly-alloyed aluminium and titanium alloys, high-strength and heat-resistant steels, produced by different welding methods (fusion, pressure) and widely used in aircraft and aerospace engineering, machine building and manufacture of critical designation structures require necessary mechanical properties. The latter are determined by structural-phase state of metal in a welding zone [1-5]. At that such welding methods (fusion, pressure) are selected, which could provide high process productivity as well as necessary complex of service properties of welded joints, namely indices of strength, ductility and crack resistance.

In this context it is very relevant to consider the issue of structure effect on properties of the welded joints of such materials as high-strength steels, complexly-alloyed aluminium as well as titanium alloys. The latter in course of technological processes of welding are characterized with dramatic change of phase composition, structure parameters, phase precipitations (PP) etc. At that there is a general understanding of the problem, however no clear vision, which structural-phase factors and parameters of the forming structures effect improvement of mechanical properties and crack resistance of welded joints that outline specific problems for investigation of these problems.

Solution of these problems requires, first of all, examination of structural state of metal of welded joints at all structural levels, including optical metallography, scanning and transmission electron microscopy. As for structural-phase states, then such a complex should include the most noticeable for service properties structural indices, i.e. phase composition, content of alloying elements, size of grain and subgrain structure, phase formations (their composition, size and distribution), and, what is very important, nature of dislocation density distribution. A complex analysis of structural-phase state allows carrying out analytical evaluation of specific input of all structural-phase parameters in main service properties of the welded joints, namely strength, ductility and crack resistance.

Therefore, aim of the present work from point of view of interconnection of welding modes $\rightarrow$ structure $\rightarrow$ joint properties lies in investigation of a role of structure and phase composition of the welded joints of specific materials (high-strength steels, complexly-alloyed aluminium and titanium alloys), produced by different welding methods (hybrid laser-arc welding, argon-arc welding, friction stir welding, electron beam welding) on change of service properties, i.e. strength, ductility and crack resistance of welded joints.

Materials and investigation procedures. The work was performed on the specimens of highstrength steel 14KhGN2MDAFB $\quad(0.183 \% \quad$ C, $1.19 \% \mathrm{Cr}, 0.98 \% \mathrm{Mn} ; 2.07 \% \mathrm{Ni} ; 0.22 \% \mathrm{Mo}$; $0.08 \% \mathrm{~V} ; 0.33 \% \mathrm{Si}$, not more than $0.018 \% \mathrm{P}$ and $0.005 \% \mathrm{~S}$ ) of up to $10 \mathrm{~mm}$ thickness using welding wire Sv-10KhN2GSMFTYu $(\leq 0.1 \% \mathrm{C} ; 0.7 \% \mathrm{Cr}$; $0.4 \% \mathrm{Mn} ; 0.22 \% \mathrm{Mo} ; 0.15 \% \mathrm{~V} ; 0.24 \% \mathrm{Si}$; not more than $0.007 \% \mathrm{~S}$ ) at the following modes of laser-arc welding, namely 1 st mode $-v_{\mathrm{w}}=72 \mathrm{~m} / \mathrm{h}, I \sim 125 \mathrm{~A}$, 
$U_{\mathrm{a}} \sim 23 \mathrm{~V} ; 2$ 2nd mode $-v_{\mathrm{w}}=90 \mathrm{~m} / \mathrm{h}, I \sim 150 \mathrm{~A}, U_{\mathrm{a}} \sim$ $\sim 25 \mathrm{~V}$; 3rd mode $-v_{\mathrm{w}}=110 \mathrm{~m} / \mathrm{h}, I \sim 200 \mathrm{~A}, U_{\mathrm{a}} \sim$ $\sim 26 \mathrm{~V}$. Indicated modes allow providing cooling of HAZ metal in $600-500{ }^{\circ} \mathrm{C}$ interval range with $w_{6 / 5} \approx$ $\approx 58-62{ }^{\circ} \mathrm{C} / \mathrm{s}$ rate. Laser radiation power source was Nd:YAG-laser DY 044 (Rofin Synar, Germany) of up to $4.4 \mathrm{~kW}$ radiation power and shielding gas (mixture of $\mathrm{Ar}+\mathrm{CO}_{2}$ with 15-20 l/min consumption) [6].

Welded joints of complexly-alloyed $\mathrm{Al}-\mathrm{Li}$ alloys 1460 (wt.\%): $0.1 \mathrm{Si}$; $0.15 \mathrm{Fe}$; $3.0 \mathrm{Cu}$; $0.1 \mathrm{Mn}$; $0.1 \mathrm{Mg} ; 0.05 \mathrm{Cr} ; 0.25 \mathrm{Zn} ; 0.04 \mathrm{Ti} ; 0.1 \mathrm{Zr} ; 2.3 \mathrm{Li}$; 0.09 Sc; $0.008-0.1$ Be were produced using argon-arc non-consumable electrode welding (AANEW) on MW-450 machine (Fronius, Austria) under the following conditions: rate $20 \mathrm{~m} / \mathrm{h}$ and current 140 A using filler materials Sv1201 and Sv1201 + 0.5 \% Sc. In parallel structural-phase states of the welded joints, made by friction stir welding (FSW) without filler material on laboratory unit designed at the E.O. Paton Electric Welding Institute, were investigated. In the latter case, butt joints were made using special tool with cone pin and shoulder $12 \mathrm{~mm}$ diameter, at that rotation rate of the tool made $1420 \mathrm{rpm}$ and linear rate of its movement along the joint was $14 \mathrm{~m} / \mathrm{h}$ [7].

Interconnection of composition $\rightarrow$ structure $\rightarrow$ properties was evaluated by investigation of the welded joints of two pilot heat-resistant multicomponent titanium alloys, made by electron beam welding (EBW) depending on silicon alloying. Both alloys contain silicon as an alloying element and refer to pseudo $\alpha$ - (alloy 1) and $\alpha+\beta$ (alloy 2) titanium alloys (Table 1) [8].

The structural-phase characteristics, i.e. size of grain and subgrain structure, distribution of phase precipitations, peculiarities of zones of brittle and tough fracture, nature of dislocation density distribution in weld metal and different areas of HAZ of welded joints were examined at all structural levels using a complex of experimental methods of modern physical metal science, including optical metallography (microscopes «Versamet-2» and «Neophot-32»), analytical scanning microscopy (SEM-515, Philips company) and transmission electron microscopy (JEM-200CX, JEOL Company). Hardness of examined metal was measured on M-400 microhardness tester of LECO Company.

Analytical evaluation of welded joint service properties. Complex investigations carried at all structural levels (from grain to dislocation) allowed evaluating differential input of various structural-phase constituents and their parameters (grain size $D_{\mathrm{g}}$, subgrain $d_{s}$, sizes of $\mathrm{d}_{\mathrm{pp}}$ and distribution of PP particles, dislocation density $\rho$, inter particle distance $\lambda$, volume fraction of forming structures) in change of mechanical properties $\sigma_{y}$, fracture toughness $K_{1 c}$ as well as local
Table 1. Composition of pilot heat-resistant titanium alloys, wt.\%

\begin{tabular}{|c|c|c|c|c|c|c|c|}
\hline Alloy & $\mathrm{Al}$ & $\mathrm{Sn}$ & $\mathrm{Zr}$ & $\mathrm{Mo}$ & $\mathrm{V}$ & $\mathrm{Nb}$ & $\mathrm{Si}$ \\
\hline 1 & 5.2 & 3.3 & 4.2 & 0.1 & 0.6 & 0.8 & 0.6 \\
\hline 2 & 4.3 & 4.4 & 6.0 & 1.6 & 0.7 & 4.3 & 0.4 \\
\hline
\end{tabular}

internal stresses $\left(\tau_{\text {l/in }}\right.$ - zones of nucleation and propagation of cracks) in different areas of the welded joints with used technological modes of welding [6-16].

Mechanical properties. Integral values of hardening $\left(\Sigma \sigma_{h}\right)$ were evaluated (according to equation including known dependencies of Hall-Petch, Orowan etc. [11-15]) as a sum value consisting of series of constituents: $\Sigma \sigma_{\mathrm{y}}=\Delta \sigma_{0}+\Delta \sigma_{\mathrm{s} . \mathrm{s}}+\Delta \sigma_{\mathrm{g}}+\Delta \sigma_{\mathrm{s}}+\Delta \sigma_{\mathrm{d}}+$ $+\Delta \sigma_{\text {disp.hard }}$, where $\Delta \sigma_{0}$ is the resistance of type of metal lattice to movement of free dislocations (stress of lattice friction or Peierls-Nabarro stress); $\Delta \sigma_{\text {s.s }}$ is the hardening of solid solution with alloying elements, according to Mott-Nabarro theory; $\Delta \sigma_{\mathrm{g}}$ and $\Delta \sigma_{\mathrm{s}}$ are hardening due to change of grain and subgrain in accordance with Hall-Petch dependence; $\Delta \sigma_{d}$ is the dislocation hardening, caused by interdislocation interaction on J. Taylor, A. Zeger, N. Mott and G. Hirsch theory as well as $\Delta \sigma_{\text {disp.hard }}$ is the dispersion hardening due to dispersion phases by Orowan.

Fracture toughness. Calculation values of fracture toughness indices $K_{1 c}$ are evaluated on dependence [17]: $K_{1 c}=\left(2 E \sigma_{\mathrm{y}} \delta_{c}\right)^{1 / 2}$, where $E$ is the Young's modulus; $\sigma_{\mathrm{v}}$ is the calculation value of hardening; $\delta_{\mathrm{c}}$ is the value of critical crack opening (according to data of substructure parameters).

Crack resistance (local and internal stresses). Analysis of different approaches to mechanisms of crack nucleation and fracture of materials was used for selection of an evaluation based on dislocation theory of crystalline solid bodies considering analysis of nature of dislocation structure and its distribution (dislocation accumulations or uniform dislocation distribution). This allows carrying detailed evaluation of a level of dislocation internal stresses depending on zones of dislocation accumulations, namely along sub- or intergranular boundaries, in PP zones and their accumulations etc, which promote formation of concentrators of local internal stresses, i.e. zones of nucleation and propagations of cracks. A field of internal stresses, developed by dislocation structure (dislocation density) is described by expression [18-20] $\tau_{\text {in }}=$ $=G b h \rho /[\pi(1-v)]$, where $G$ is the shear modulus; $b$ is the Burgers vector; $h$ is the foil thickness, $v$ is the Poisson's ratio; $\rho$ is the dislocation density.

Results of experiment. The welded joints of high-strength steel produced by hybrid laser-arc and arc welding [6] were investigated. Complex investigations at all structural levels determined changes of different phase constituents (upper bainite $B_{u}$ and lower $\mathrm{B}_{\mathrm{l}}$, martensite $\mathrm{M}$ ), their volume fraction $v_{\mathrm{f}}, \%$, 
Table 2. Change of volume fraction $\left(v_{\mathrm{f}}\right.$, \%) of phase constituents $\left(\mathrm{B}_{\mathrm{l}}, \mathrm{B}_{\mathrm{u}}, \mathrm{M}\right)$, grain value $\left(\mathrm{D}_{\mathrm{g}}\right)$ and integral microhardness $(H V)$ in welded joints at different rates of welding

\begin{tabular}{|c|c|c|c|c|c|c|}
\hline \multirow{2}{*}{ Indices/Area } & \multicolumn{2}{|c|}{$v_{\mathrm{w}}=72 \mathrm{~m} / \mathrm{h}$} & \multicolumn{2}{|c|}{$v_{\mathrm{w}}=90 \mathrm{~m} / \mathrm{h}$} & \multicolumn{2}{c|}{$v_{\mathrm{w}}=110 \mathrm{~m} / \mathrm{h}$} \\
\cline { 2 - 7 } & Weld & $\mathrm{HAZ}$ & Weld & HAZ & Weld & HAZ \\
\hline \multirow{2}{*}{$v_{\mathrm{f}}, \%$} & $\mathrm{~B}_{1} \sim 60 \%$ & $\mathrm{~B}_{1} \sim 80 \%$ & $\mathrm{~B}_{1} \sim 20 \%$ & $\mathrm{~B}_{1} \sim 30 \%$ & $\mathrm{~B}_{1} \sim 10 \%$ & $\mathrm{~B}_{1} \sim 20 \%$ \\
& $\mathrm{~B}_{\mathrm{u}} \sim 20 \%$ & $\mathrm{~B}_{\mathrm{u}} \sim 5 \%$ & $\mathrm{~B}_{\mathrm{u}} \sim 15 \%$ & $\mathrm{~B}_{\mathrm{u}} \sim 20 \%$ & $\mathrm{~B}_{\mathrm{u}} \sim 60 \%$ & $\mathrm{~B}_{\mathrm{u}} \sim 70 \%$ \\
Parameters & $\mathrm{M} \sim 20 \%$ & $\mathrm{M} \sim 15 \%$ & $\mathrm{M} \sim 65 \%$ & $\mathrm{M} \sim 50 \%$ & $\mathrm{M} \sim 30 \%$ & $\mathrm{M} \sim 10 \%$ \\
\hline$D_{\mathrm{g}}, \mu \mathrm{m}$ & $30-120 \times 170-350$ & $30-60$ & $30-80 \times 150-300$ & $25-50$ & $20-80 \times 150-250$ & $20-40$ \\
\hline$H V, \mathrm{MPa}$ & $3800-4010$ & $3540-3900$ & $4050-4420$ & $3830-4010$ & $3360-3940$ & $3360-4010$ \\
\hline
\end{tabular}

microhardness $(H V)$ as well as different structural parameters (values of grain and subgrain structures $\left.D_{g}, d_{s}\right)$, typical distributions and dislocation densities $(\rho)$ as well as peculiarities of fracture zone of welded joints (tough, brittle etc.) depending on used rates of laser-arc welding $\left(v_{\mathrm{w}}=72 ; 90 ; 110 \mathrm{~m} / \mathrm{h}\right)$.

It is shown that $v_{\mathrm{w}}=72 \mathrm{~m} / \mathrm{h}$ promotes formation of mainly $\mathrm{B}_{1}$ structure in weld metal and HAZ of welded joints, and at transfer from weld to HAZ metal the grain structure significantly refines (2-4 times) at uniform decrease (per $12 \%$ ) of microhardness, Table 2. Increase of welding rate $\left(v_{\mathrm{w}}\right)$ from 72 to $90 \mathrm{~m} / \mathrm{h}$ provides variation of phase composition of weld metal and HAZ of the welded joints from bainite-martensite (B-M) to martensite (M) type as well as relationship of structural constituents in HAZ metal of the welded joints: volume fraction of $B_{1}$ decreases $2-3$ times at 3 times rise of fraction of $\mathrm{M}_{\text {temp }}$. This, as a result, provides the maximum indices of strength, however, leads to substantial decrease of ductility $\psi$ in the weld. In the case of increase of welding rate to $v_{\mathrm{w}}=110 \mathrm{~m} / \mathrm{h}$, regardless the fact that phase composition of weld metal and HAZ overheating area are the same as at $v_{\mathrm{w}}=72 \mathrm{~m} / \mathrm{h}$ modes, i.e. bainite-martensite, the maximum $v_{w}$ provokes significant volume fraction of $\mathrm{B}$ to $10-20 \%$ and formation of mainly $B_{u}$ structure (60$70 \%$ ). Such structural changes can result in non-uniform level of mechanical properties along the welding zone and decrease of crack resistance of welded joints.

Detailed electron microscopy transmission investigations of structures of the welded joints, made at $v_{\mathrm{w}}=72$ and $110 \mathrm{~m} / \mathrm{h}$, determined the following.

Formation of inner substructure with uniform distribution of volume dislocation density $(\rho)$ up to (4-
6) $\cdot 10^{10} \mathrm{~cm}^{-2}$ is observed in $B_{1}$ grains of weld metal, at $v_{\mathrm{w}}=72 \mathrm{~m} / \mathrm{h}$ and in $\mathrm{M}_{\text {temp }}$ structures dislocation density makes $8 \cdot 10^{10}-10^{11} \mathrm{~cm}^{-2}$. Fragmentation of $B_{1}$ grains is typical for HAZ metal of the joints, i.e. 10-20 \% refinement of lath structure of $\mathrm{B}_{1}$ and $\mathrm{M}_{\text {temp }}$ is observed. It is accompanied by somewhat increase of dislocation density (Figure 1, a).

The following is typical for fine metal structure of welded joint in the case of $v_{\mathrm{w}}=110 \mathrm{~m} / \mathrm{h}$, i.e. integral value of dislocation density in weld metal and HAZ rises, mainly upper bainite $B_{u}$ structure is formed at maximum increase of dislocation density $\rho$ to $1.5 \cdot 10^{11} \mathrm{~cm}^{-2}$ (see Figure $1, b$ ).

Thus, it is shown that the most uniform distribution of dislocation density in formation of lower bainite structure $\mathrm{B}_{1}$ is provided at hybrid laser-arc welding mode with $v_{\mathrm{w}}=72 \mathrm{~m} / \mathrm{h}$ rate.

The following was determined as a result of carried evaluations on changes along the welding zone of such strength characteristic as $\sigma_{y^{\prime}}$ Calculation value $\Sigma \sigma_{\mathrm{y}}$ makes 917 and $1077 \mathrm{MPa}$, respectively, in weld metal and HAZ under conditions of $v_{\mathrm{w}}=72 \mathrm{~m} / \mathrm{h}$, and the maximum input in yield strength has substructural $\left(\Delta \sigma_{\mathrm{s}} \sim 318-356 \mathrm{MPa}\right)$, dispersion $\left(\Delta \sigma_{\text {disp.hard }} \sim\right.$ 253-295 MPa) and dislocation $\left(\Delta \sigma_{d} \sim 157-180 \mathrm{MPa}\right)$ hardening (Figure 2,a). At that input of such type of structural constituent as lower bainite $\left(\mathrm{B}_{1}\right)$ is the maximum one (Figure 2, $b$ ).

In the case of welding modes at $v_{\mathrm{w}}=110 \mathrm{~m} / \mathrm{h}$ the total value of yield strength rises (in comparison with $v_{\mathrm{w}}=72 \mathrm{~m} / \mathrm{h}$ mode) by $10-15 \%$ (Figure 3 ) that is caused by somewhat refinement of grain structure and
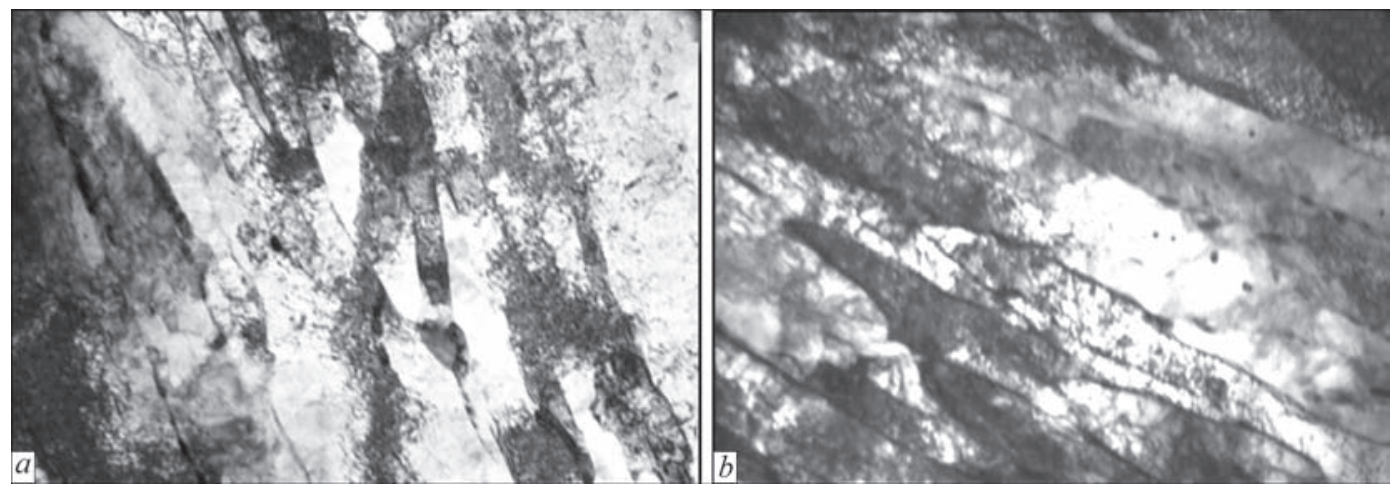

Figure 1. Fine structure of HAZ metal: $a$ - lower bainite at $v_{\mathrm{w}}=72 \mathrm{~m} / \mathrm{h}(\times 20000) ; b$ - upper bainite $(\times 30000)$ at $v_{\mathrm{w}}=110 \mathrm{~m} / \mathrm{h}$ 


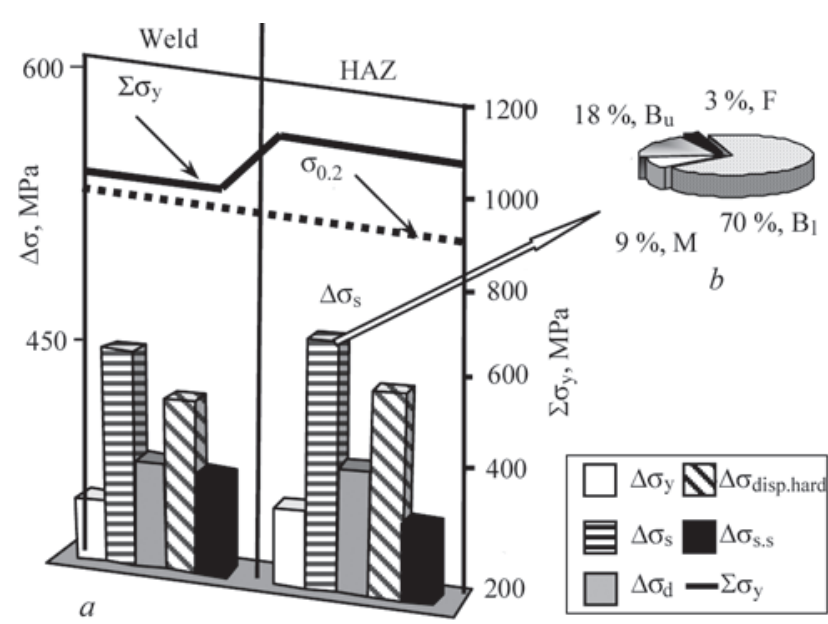

Figure 2. Input of different constituents $\Delta \sigma$ of structural hardening in calculation value of yield limit $\Delta \sigma_{y}$ of weld metal $(a)$ and input of structural constituents $\left(\mathrm{B}_{\mathrm{u}}, \mathrm{B}_{1}, \mathrm{M}_{\text {temp }}, \mathrm{F}\right)$ in change of substructural hardening $\Delta \sigma_{\mathrm{s}}$ at welding rate $72 \mathrm{~m} / \mathrm{h}(b)$

increase (1.3 times) of integral value of dislocation density $(\rho)$.

The following is shown by the calculation values of fracture toughness indices $K_{1 c}$ as well as comparison of $K_{1 c}$ and $\sigma_{\mathrm{y}}$ (see Figure 3). If with $v_{\mathrm{w}}=72 \mathrm{~m} / \mathrm{h}$ the substructure, which is mainly lower bainite $\left(B_{1}\right)$ substructure, makes the largest input in metal hardening $\left(\Sigma \sigma_{\mathrm{y}}\right)$ and increase of fracture toughness $\left(K_{1 c}\right)$, then in the case of increased welding rate $v_{\mathrm{w}}=110 \mathrm{~m} / \mathrm{h} K_{1 c}$ index significantly decreases $(30 \%)$. The latter is caused by dominating formation of another type of structure, namely upper bainite $\left(\mathrm{B}_{\mathrm{u}}\right)$ with corresponding further nonuniform distribution of dislocation density $(\rho)$.

Further comparative analysis of calculation indices of strength properties $\left(\sigma_{\mathrm{y}}\right)$ and fracture toughness $\left(K_{1 c}\right)$ for the investigated welded joints of highstrength steel 14KhGN2MDAFB, produced using different modes of welding (arc welding and hybrid laser-arc one), showed that the best indices combining

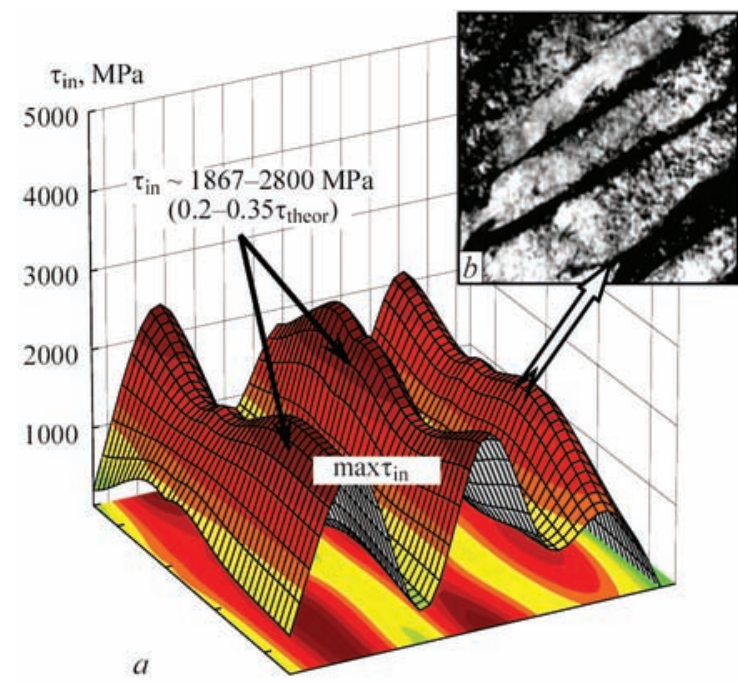

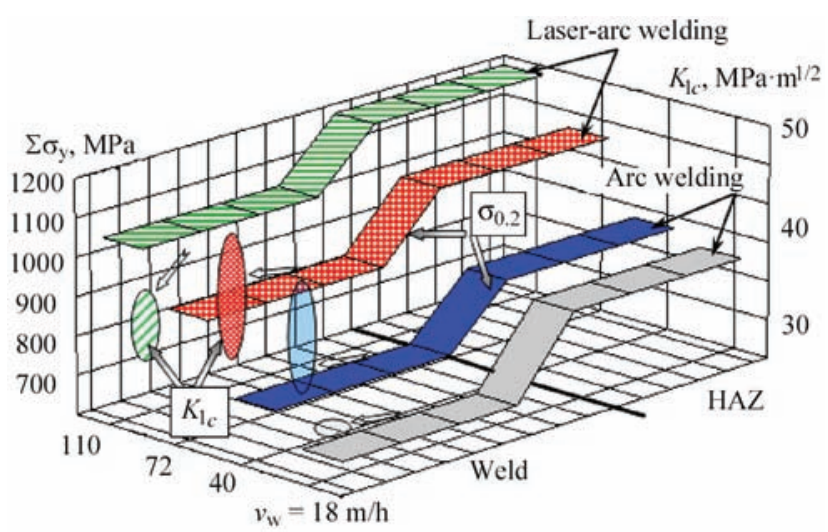

Figure 3. Change of average calculation value of yield limit $\left(\Sigma \sigma_{y}\right)$ and fracture toughness $\left(K_{1 c}\right)$ along welding zone (weld, HAZ) of steel 14KhGN2MDAFB at different rates of hybrid laser-arc $\left(v_{\mathrm{w}}=\right.$ $=72 \mathrm{~m} / \mathrm{h}$ and $110 \mathrm{~m} / \mathrm{h})$ and $\operatorname{arc}\left(v_{\mathrm{w}}=18 \mathrm{~m} / \mathrm{h}\right.$ and $\left.40 \mathrm{~m} / \mathrm{h}\right)$ welding properties of strength and toughness are provided by modes of hybrid welding (see Figure 3).

The results of evaluation of change in the level of local internal stresses showed that the maximum values of $\tau_{\text {l/in }} \sim 1900-2800 \mathrm{MPa}\left((0.2-0.35) \tau_{\text {theor }}\right.$ from theoretical strength) are formed at $v_{\mathrm{w}}=110 \mathrm{~m} / \mathrm{h}$ in the places of extended dislocation accumulations $\left(\rho=1.5 \cdot 10^{11} \mathrm{~cm}^{-2}\right)$ along $B_{u}$ boundary. This results in nucleation of microcracks in these zones and decrease of crack resistance of welded joints (Figure 4, $a, b$ ). And the lowest values of $\tau_{\text {in }}$ (around 1500-1800 MPa) are typical for welded joints received at $v_{\mathrm{w}}=72 \mathrm{~m} / \mathrm{h}$. It is promoted by formation in the welding zone of fine grain and fragmented $\mathrm{B}_{1}$ structures in combination with uniform distribution of dislocations (Figure 4, $c, d$ ).

It is determined as a result that the optimum properties of strength, ductility and crack resistance of high-strength steel welded joints are provided under conditions of $v_{\mathrm{w}}=72 \mathrm{~m} / \mathrm{h}$ welding rates. It is caused by formation of the most dispersed structures, namely lower bainite, fine grain martensite tempered in ab-

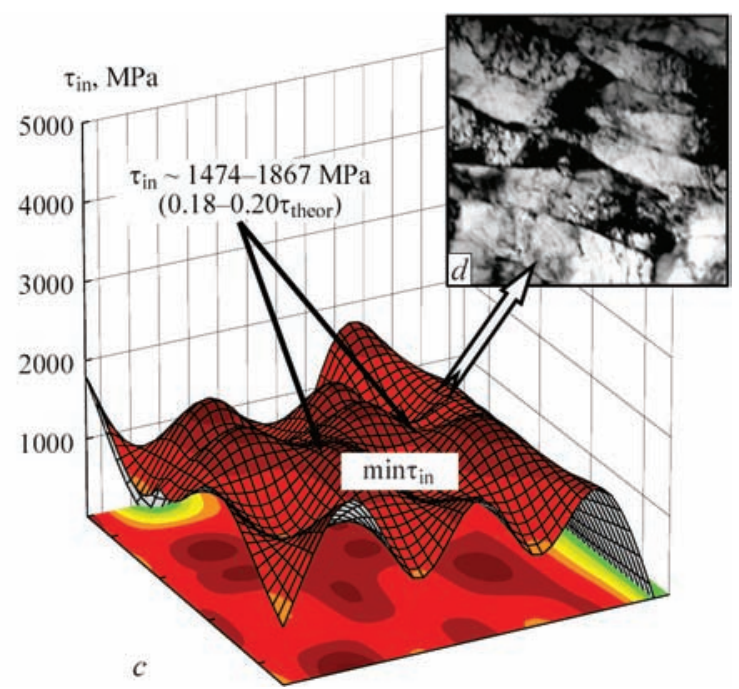

Figure 4. Distribution of local internal stresses $\left(\tau_{\mathrm{in}}\right)$ in weld metal in structural zones of upper bainite at $v_{\mathrm{w}}=110 \mathrm{~m} / \mathrm{h}(a, b, \times 20000)$ and lower bainite at $v_{\mathrm{w}}=72 \mathrm{~m} / \mathrm{h}(c, d, \times 30000)$ 

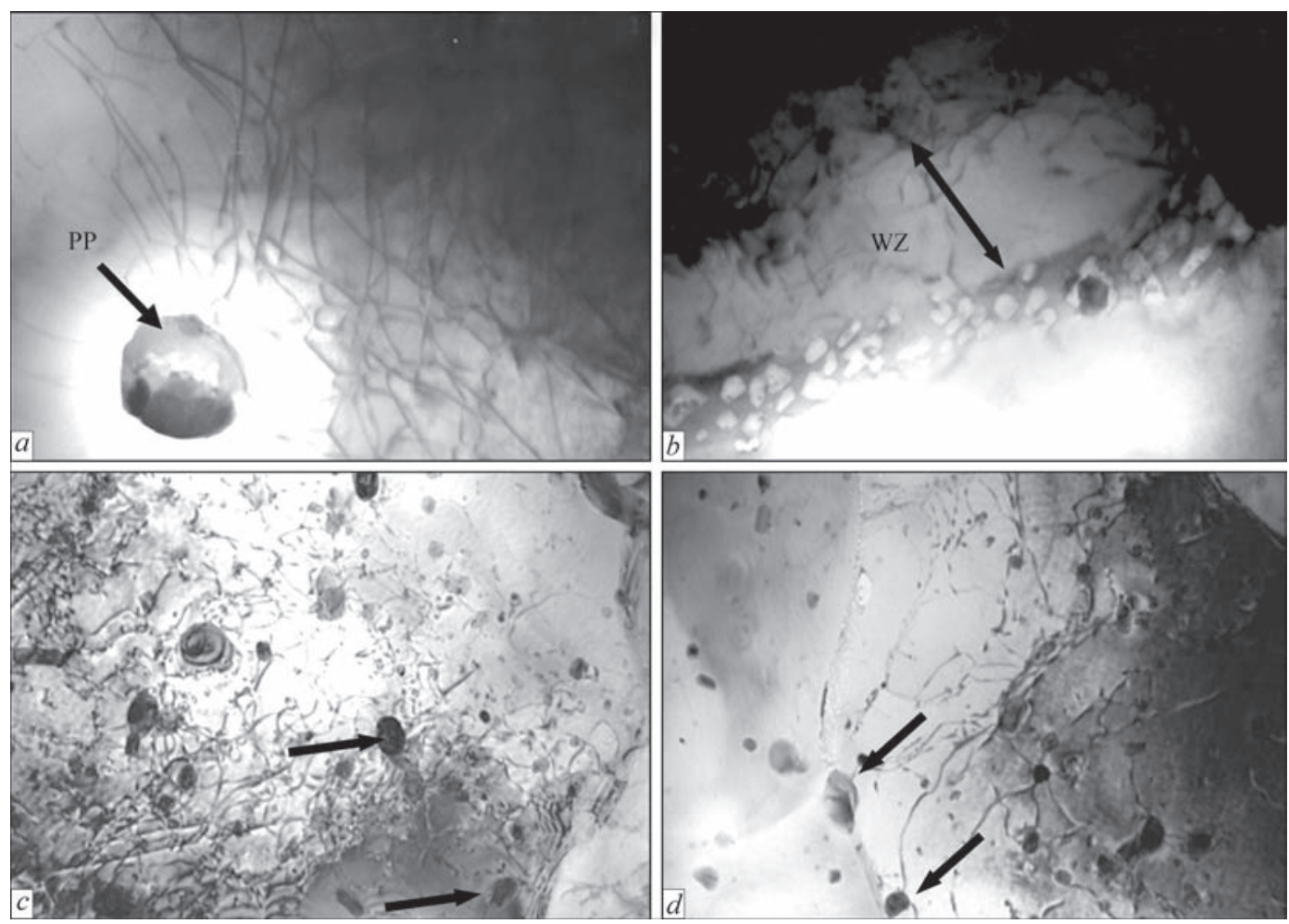

Figure 5. Distribution of phases in grain volumes of weld metal of aluminium alloy 1460 produced by AANEW: $a$ - phase precipitations in internal grain volumes; $b$ - near-boundary zones free from precipitations and FSW: $c$ - phase precipitations in grain volumes; $d$ - phase precipitations in grain boundary zones of weld metal $(\times 30000)$

sence of extended dislocation accumulations - concentrators of local internal stresses $\left(\tau_{\text {lin }}\right)$.

Welded joints of complexly-alloyed aluminium-lithium alloys (argon-arc welding and FSW) [7]. The following is determined as a result of investigation of welded joints of aluminium alloys, produced by AANEW without and with scandium alloying. Weld metal of the welded joints of Al-Li alloy 1460 using filler material Sv1201 (without scandium alloying) after AANEW is characterized with coarse grain structures; formation of large globular intergranular phase precipitations ( $d_{\mathrm{pp}}$ size up to $3.5 \mu \mathrm{m}$, Figure 5, $a$ ), extended massive intergranular eutectics (thickness $h_{\text {eut }}$ to $5 \mu \mathrm{m}$ and zones free from precipitations (ZFP) (Figure 5, $b$ ).

At that, non-uniformity of dislocation distribution is noted, in particular along the extended near-boundary zones, where dislocation density $\rho$ drops virtually by order in comparison with intergranular dislocation density from $\rho \sim(2-6) \cdot 10^{9} \mathrm{~cm}^{-2}$ (Figure 5, $a, b$ ).

Scandium alloying of weld metal (up to $0.5 \%$ ) promotes the following changes in structure of welding zone metal, i.e. refinement of grain structure, grain boundary eutectics, dispersion of phase precipitations in grain volumes in combination with somewhat increase of dislocation density to $\rho \sim(4-9) \cdot 10^{9} \mathrm{~cm}^{-2}$.

Investigations of peculiarities of structural changes in FSW determined significant structure refinement; increase of total dislocation density to $\rho \sim$
(3-6) $\cdot 10^{10} \mathrm{~cm}^{-2}$ (that is an order higher than the dislocation density of weld metal in fusion welding, Figure $5, a, b)$ accompanied by active redistribution of dislocations and formation of substructure (blocks, fragments, etc.); substantial refinement (2.5-5.0 times) of PP at increase of their volume fraction and uniform distribution along intergranular as well as grain boundary volumes (Figure 5, $c, d$ ).

The results of the analytical evaluations of mechanical properties $\left(\Sigma \sigma_{\mathrm{y}}\right)$ of investigated joints after AANEW with scandium and without it showed the highest indices in scandium alloyed joints (Figure 6).

At that, the largest input in total (integral) value of hardening of weld metal with scandium has grain $\left(\Delta \sigma_{\mathrm{g}} \sim 29 \%\right)$ and solid solution $\left(\Delta_{\mathrm{s} . \mathrm{s}} \sim 25 \%\right)$ hardening. Under FSW conditions the evaluations of total (integral) values of $\Sigma \sigma_{y}$ showed the total increase of values of strength indices by $40 \%$ in comparison with such for AANEW welding conditions without scandium. It is provided mainly by refinement of grain (to $27 \%$ ) and subgrain (to $21 \%$ ) structures and PP dispersion (to $23 \%$ ).

Comparison of properties of fracture toughness $\left(K_{1 c}\right)$ of the investigated joints showed the following. After AANEW without scandium toughness index is $K_{1 c} \sim 26-47 \mathrm{MPa} \cdot \mathrm{m}^{-1 / 2}$ (Figure 7, $a, b$ ). As a result of FSW application $K_{1 c}$ is preserved at the level of $K_{1 c} \sim 31-57 \mathrm{MPa} \cdot \mathrm{m}^{-1 / 2}$ (Figure 7, $a, c$ ) that indicates increase (by $20 \%$ ) of ductility properties of welded 


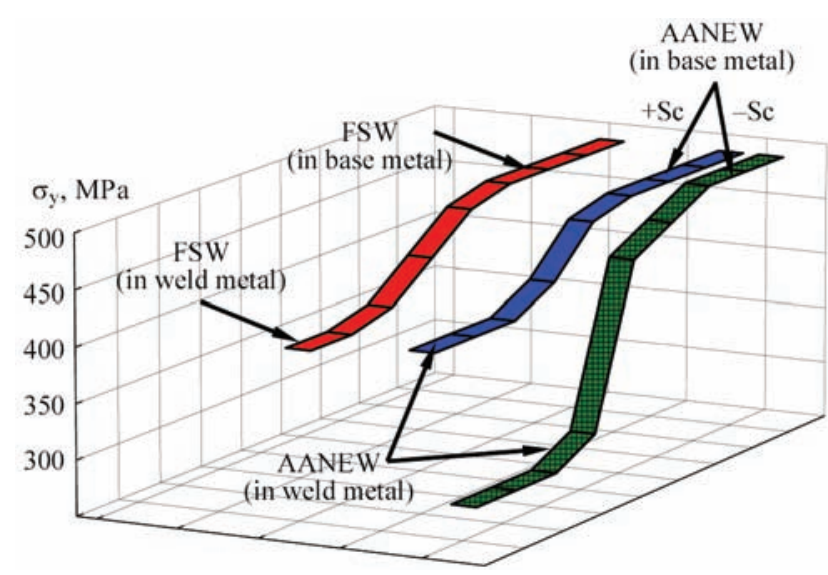

Figure 6. Change of integral value of hardening $\Sigma \sigma_{y}$ of welded joints of aluminium alloy 1460 at transfer from base metal to weld metal produced by AANEW using filler materials Sv1201 and Sv1202 + $0.5 \%$ Sc, and FSW

joint in comparison with conditions of AANEW without scandium.

Specific results of the investigations and, first of all, nature of dislocation structure distribution in the investigated specimens allowed evaluating local internal stresses $\left(\tau_{1 / i n}\right)$, determine their level and extension as well as determine structural factors provoking processes of crack nucleation and propagation.

The analytical evaluations determined, as a result, that the extended concentrators of local internal stresses with $\tau_{\text {l/in }}$ level to $1500 \mathrm{MPa}$ (from 0.34 to $0.85 \tau_{\text {theor }}$ ) are formed under AANEW conditions in metal without scandium. These are the zones of crack nucleation and propagation. The boundaries of strong shear bands (SB) (Figure $8, a, b$ ) refer to such zones. In contrast to this, values of $\tau_{\text {lin }}$ rapidly decrease (virtually two orders) to value approximately $5-15 \mathrm{MPa}\left(0.0016-0.0055 \tau_{\text {theor }}\right)$ in the internal volumes of SB. This, as a result, develops a strong gradient $\left(\Delta \tau_{\nu / i n}\right)$ of local internal stresses along SB boundaries (Figure $8, b$ ).

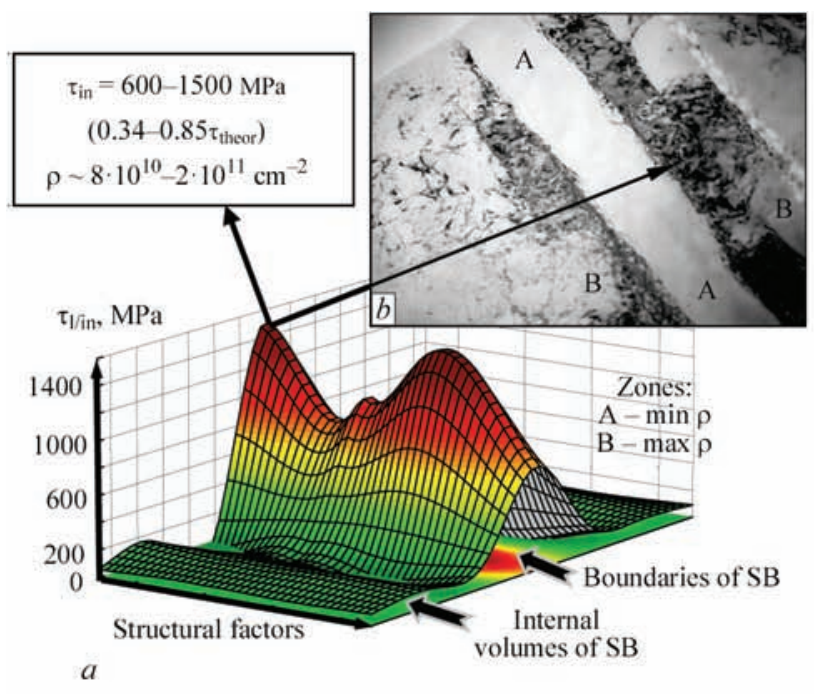

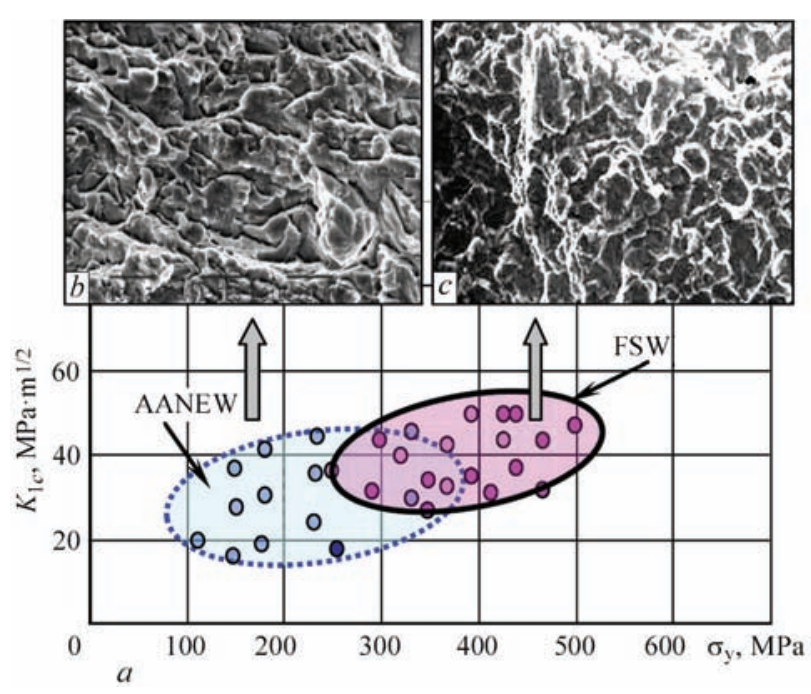

Figure 7. Change of calculation values of strength $\Sigma \sigma_{\mathrm{y}}$ and fracture toughness $K_{1 c}$ of weld metal $(a)$ and fractograms $(\times 2020)$ : $b$ - brittle fracture of aluminium alloy 1460 produced by AANEW using filler material Sv1201; c - tough fracture at FSW

Microstructure of the weld metal under FSW conditions represents general significant decrease $(3.5$ times) of the level of local internal stresses (to 221$447 \mathrm{MPa}$ ) at uniform (without gradients) distribution of such type of local stresses along the whole volume of weld metal (Figure 8, $c, d$ ) that provides rise of welded joint crack resistance.

Thus, improvement of strength characteristics and crack resistance of the welded joints of complexly-alloyed aluminium alloys requires aiming at formation of the optimum structure that is provided by FSW as shown by investigations of structure and properties interconnection.

Welded joint of titanium alloys (electron beam welding) [8]. Metallographic examinations of structure of the most problematic zone of welded joints, namely heat-affected zone (HAZ), determined that

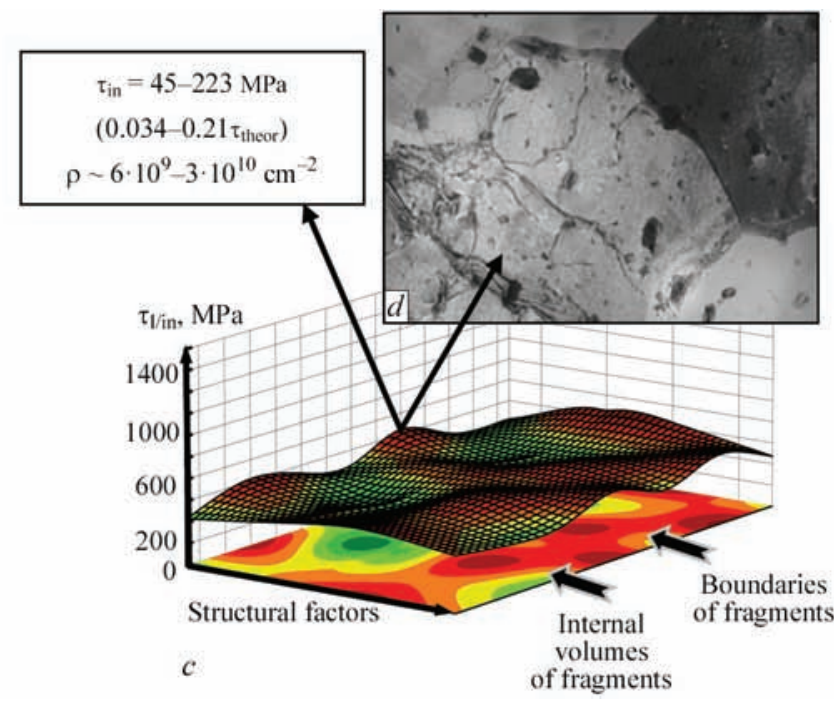

Figure 8. Distribution of local internal stresses $\tau_{\text {l/in }}$ in weld metal of alloy 1460 after different welding methods: $a, b$ - AANEW (weld metal without scandium); $c, d-$ FSW 
formation of cold cracks of $100-300 \mu \mathrm{m}$ length is observed after welding in a near-weld zone (NWZ). Moreover, volume fraction of cracks is significantly higher in the welded joints of pilot alloy 1 , than in the welded joints of alloy 2. At that, the NWZ of welded joint of pilot alloy 1 in cooling contains the coarse equiaxial polyhedral primary $\beta$-grains of up to $500 \mu \mathrm{m}$ size. The NWZ of welded joints of alloy 2 has a nonuniform primary structure. Together with the vast areas of polyhedral grains of $200 \mu \mathrm{m}$ size there are areas of fine equiaxial grains of $20-60 \mu \mathrm{m}$ size in the coarse grain surrounding. Intergranular structure in the NWZ of alloy 1 and NWZ of alloy 2 is martensite $\alpha^{\prime}$-phase characterized with fine acicular structure. Residual $\beta$-phase can be present in the NWZ of both alloys in addition to martensite phase. Its amount in alloy 1 following from composition is very small, and it is more in alloy 2 , than in alloy 1 . More detailed structural-phase investigations of HAZ of welded joints of titanium alloys were carried out using scanning microdiffraction electron microscopy for determination of composition of the forming phases as well as their size, morphology and structural zones of their localizing.

The results of examination of dislocation structure and processes of phase formation showed essential difference in the structural-phase state of $\alpha^{\prime}$ - and $\beta$ lamellar structures in the welded joints of pilot alloy 1. Parallel formation of dramatically different on structural-phase composition lamellar structures takes place, namely virtually dislocation-free $(\rho$ $10^{9} \cdot \mathrm{cm}^{-2}$ ) and containing no phase precipitations of the lamellas of extended shape (with cross-section $h_{\mathrm{lam}} \sim 0.3-1.6 \mu \mathrm{m}$, Figure 9, a) together with the lamellas characterized with high dislocation density (to $\rho$ $(7-8) \cdot 10^{10} \mathrm{~cm}^{-2}$ ) and saturation of inner lamella volumes with chaotically distributed precipitations, mainly $\mathrm{Ti}_{5} \mathrm{Si}_{3}$ of sufficiently coarse size $\left(d_{\mathrm{pp}} \sim 0.1-0.2 \mu \mathrm{m}\right.$, Figure $9, b)$ and dispersed $\mathrm{PP}\left(\mathrm{Ti}_{2} \mathrm{ZrSi}_{3} ; \mathrm{Ti}_{3} \mathrm{Al}\right)$ fringing the interlamellar structure. Formation of the strong gradient (on phase precipitations and dislocation density) lamellas is caused, apparently, by type of crystalline lattice, corresponding to $\beta$ - and $\alpha$-formations in titanium alloys. Thus, for $\beta$-phase having BCC-lattice (this is up to 48 slip systems) there is virtually unlimited possibility of nucleation, slip and redistribution of the dislocations, which, as it is well known, are active channels for transporting alloying elements and, respectively, activation of phase formation processes. The $\alpha$-structure, having HCP-lattice, is characterized with very limited amount of the slip systems. Mainly, it is one base (0001) plane and deformation in a metal with such type of lattice is mostly realized due to twinning, when nucleation and dislocation slip is virtually complicated, so that as phase formation.

Apparently, different peculiarities of processes of deformation realizing (dislocation slip or twinning) and as a result different possibilities of phase formation for main phase constituents ( $\alpha$ - and $\beta$-phases) are the explanation of formation of strong gradient on dislocation density and saturation by phase precipitations of the extended lamellar structures in the welded joint of pilot alloy 1 .

Thus, it is determined that presence of gradient structural-phase formations, significantly different on amount and dispersion of silicide phases, including on dislocation density, is apparently the basis for formation in metal of such type of corresponding strong gradient mechanical characteristics, namely, gradients on strength properties $\left(\sigma_{0.2}, \sigma_{t}\right)$ in the adjacent lamellar structures.

The NWZ structure of welded joint of pilot alloy 2 , as in alloy 1 , is characterized with formation of the extended lamellar type phases $\left(\alpha^{\prime}\right.$-martensite and $\beta$-phase), but significantly different (approximately 2-3 times) in sizes, namely width of lamellar structures $\left(h_{\mathrm{lam}} \sim 0.2-0.5 \mu \mathrm{m}\right)$, more disperse acicular $\alpha^{\prime}$-martensite structure and interlamellar substructure as well as more uniform distribution of dislocations $\left(\rho \sim(8-9) \cdot 10^{10} \mathrm{~cm}^{-2}\right)$ in all volume of the NWZ metal (Figure 10). There are differences in process of forma-
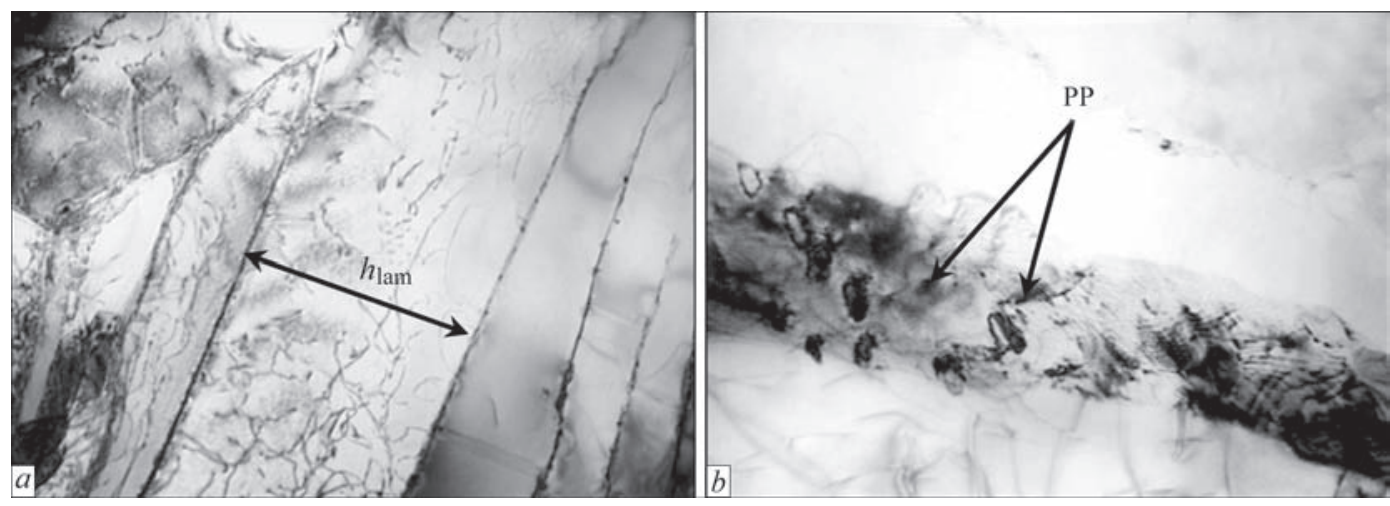

Figure 9. Microstructure $(\times 20000)$ of pilot titanium alloy 1, NWZ: $a-$ strictly oriented lamellas of mainly $\alpha$-containing structure at comparatively low density and uniform dislocation distribution; $b$ - phase formation in internal volumes of $\beta$-lamellar structures, $\times 37000$ 

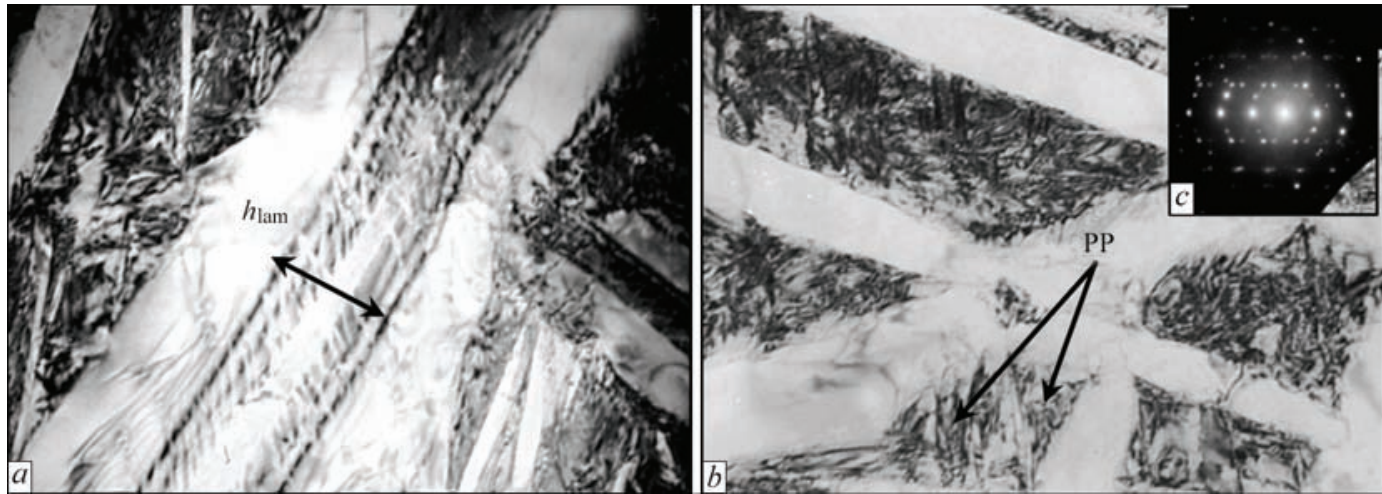

Figure 10. Microstructure of pilot titanium alloy 2, NWZ; $a, b-$ fine structure of lamellar phases of martensite type $(a-\mathrm{x} 50000$; $b-\times 37000) ; c-$ microdiffraction reflections of PP, registered in combined images

tion of silicide intermetallic phases. At the same (as in the case of alloy 1) stoichiometric compostion $\left(\mathrm{Ti}_{5} \mathrm{Si}_{3}\right.$; $\mathrm{Ti}_{2} \mathrm{ZrSi}_{3} ; \mathrm{Ti}_{3} \mathrm{Al}$ ) phase sizes are more fine disperse $\left(d_{\mathrm{pp}}^{2} \sim 0.01-0.02 \times 0.02-0.06 \mu \mathrm{m}\right)$ and their distribution is uniform along the whole volume with localizing mainly on substructure boundaries (Figure 10, $b$ ).

The analytical evaluations of mechanical properties showed that HAZ metal of welded joints of pilot alloy 1 is characterized with strong gradient (approximately 1.8 times) change of yield strength $\left(\Delta \sigma_{0.2} \sim\right.$ 570-1010 MPa), depending on structural-phase state of the lamellar structures (Figure 11). The rapid increase of $\Delta \sigma_{0.2}$, typical for the lamellar structures with high dislocation density $\left(\rho \sim(7-8) \cdot 10^{10} \mathrm{~cm}^{-2}\right)$ and the most saturated phase precipitations, results in rise of dislocation $\left(\Delta \sigma_{\mathrm{d}} \sim 250 \mathrm{MPa}\right)$ and dispersion $\left(\Delta \sigma_{\text {disp }} \sim\right.$ 375-500 MPa) hardening. The NWZ of alloy 2 has high level and more uniform distribution of strength characteristics $\left(\Delta \sigma_{\mathrm{y}} \sim 910-1040 \mathrm{MPa}\right)$ in forming martensite phases of lamellar type that is related with their more fine disperse structure. At that somewhat increase of hardening is caused by substructure dispersion $\left(\Delta \sigma_{\mathrm{s}} \sim 530 \mathrm{MPa}\right)$ and comparatively uniform rise of total dislocation density on metal volume results in hardening of around $\Delta \sigma_{\mathrm{d}} \sim 360 \mathrm{MPa}$.

Thus, the analytical evaluations of differential input of different structural-phase factors and parameters, forming in the welded joints of investigated alloys, in change of mechanical characteristics $\left(\sigma_{0.2}\right)$, showed that the NWZ of alloy 1 welded joints has significant change of $\sigma_{\mathrm{y}}$ in the adjacent lamellar structures from $570 \mathrm{MPa}$ for lamellar $\alpha^{\prime}$-phase to low dislocation density to $1010 \mathrm{MPa}$ for lamellas with high dislocation density and silicide precipitations. Alloy 2 NWZ has higher level and more uniform distribution of strength characteristics $\left(\sigma_{0.2}\right.$ varies from 910 to $1040 \mathrm{MPa}$ in all volume of the NWZ metal).

Local internal stresses in HAZ of pilot alloys welded joints were determined as a result of examination of the dislocation structure. It is shown that (Figure 12, a) HAZ metal of alloy 1 has strong gra- dient, directed along the lamellas, distribution of internal stresses (from 10-100 to 700-1100 MPa). It is related with change of dislocation density in the lamellas of different type: low $\left(\rho \sim\left(10^{9}-10^{10} \mathrm{~cm}^{-2}\right)\right.$ and high $\left(\rho \sim(7-8) \cdot 10^{10} \mathrm{~cm}^{-2}\right)$. However, there are areas with the higher local dislocation density $(\rho \sim$ $2 \cdot 10^{11} \mathrm{~cm}^{-2}$ ), where local internal stresses $\tau_{1 / \text { in }}$ reach $2000 \mathrm{MPa}$ order. Alloy $2 \mathrm{HAZ}$ is characterized with relatively uniform distribution of internal stresses $\left(\tau_{\text {1/in }} \sim 860-970 \mathrm{MPa}\right)$ that corresponds to uniform dislocation density $\left(\rho \sim(8-9) \cdot 10^{10} \mathrm{~cm}^{-2}\right)$ on interlamellar structures (Figure 12, b).

Thus, evaluations of changes of internal stresses $\tau_{\text {in }}$ in the NWZ of welded joints of investigated alloys, performed on the basis of examination of dislocation structures, showed that the NWZ of alloy 1 welded joints has a very nonuniform distribution of internal stresses (approximately 10 times gradient), and directed along the lamellar structures in the lamellas with low and high dislocation density. The NWZ of alloy 2 welded joints has a more uniform distribution of internal stresses, however, connection of direction of the distribution of local internal stresses and lamellar structures can be a reason for directed crack propagation. Therefore, in order to eliminate gradient on strength

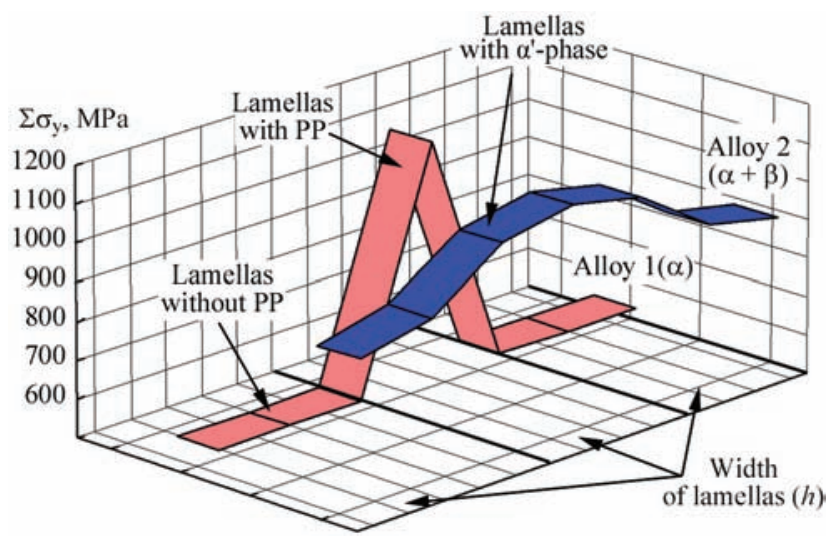

Figure 11. Input of different constituents of structural hardening (grain, subgrain, dislocation, dispersion) of pilot alloys in calculation value of hardening $\left(\Sigma \sigma_{\mathrm{y}}\right)$ 


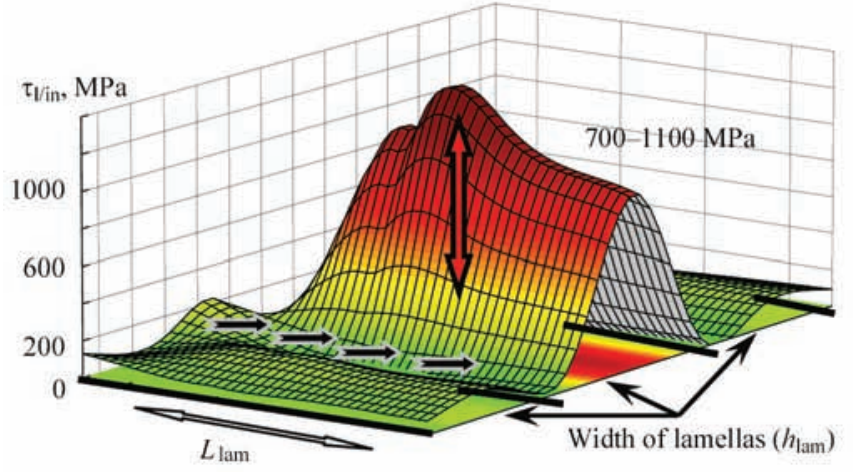

$a$

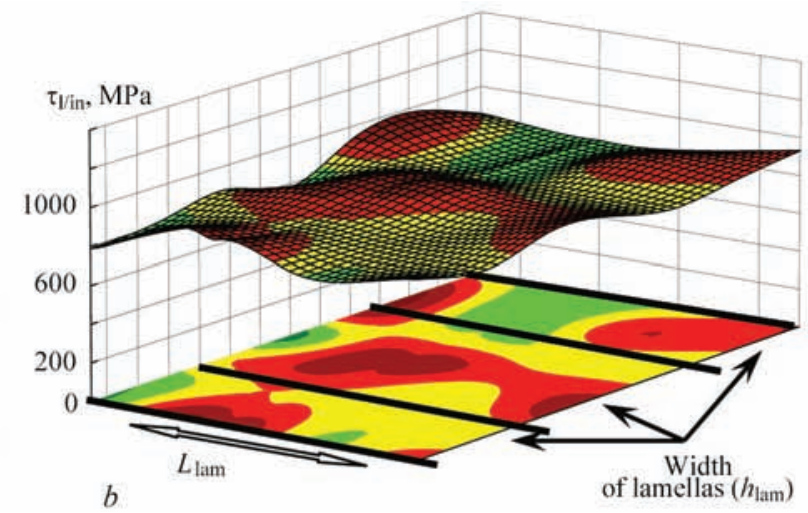

Figure 12. Level of local internal stresses forming in lamellar structures of NWZ of welded joints: $a$ — in lamellar structures, gradient on distribution of dislocation density and intravolume PP (pilot alloy 1); $b$ - in martensite lamellar structures (pilot alloy 2)

and internal stresses it is necessary to achieve formation of homogeneous uniform dispersed structure.

\section{Conclusions}

1. Complex investigations were carried out at all structural levels (from grain to dislocation ) for study of structural-phase changes in metal of welded joints of highstrength steels, complexly-alloyed aluminium-lithium and titanium alloys, produced by different methods of welding (hybrid laser-arc welding, argon-arc welding, friction stir welding, electron beam welding).

2. Combination of examinations at different structural levels with analytical evaluations of mechanical properties in the produced welded joints determined interconnection of structural changes with variation of the most important for service conditions mechanical characteristics of the welded joints, namely indices of strength $\left(\sigma_{y}\right)$, fracture toughness $\left(K_{1 c}\right)$ and crack resistance $\left(\tau_{1 / \mathrm{in}}\right)$.

3. It is determined that the most optimum structural factors providing necessary complex of the welded joint properties under service conditions, namely properties of strength $\left(\sigma_{\mathrm{y}}\right)$, fracture toughness $\left(K_{1 c}\right)$ and crack resistance $\left(\tau_{1 / \text { in }}\right)$, are fine of grain and subgrain structures; dispersion of phase precipitations at their uniform distribution; absence of extended dislocation accumulations, i.e. potential concentrators of internal stress (zones of nucleation and propagation of cracks).

1. (1965) High-strength steel: Coll. Ed. by L.K. Gordienko. Moscow: Metallurgy.

2. Houdremont, E. (1959) Special steels. Moscow: Metallurgizdat.

3. Fridlyander, I.N. (2000) Aluminium alloys in aircrafts during 1970-1999 and 2000-2015. In: Proc. of Sci. Council on New Materials of IAAS: Problems of Modern Materials Sciences. Kiev: Naukova Dumka, 15-19.
4. Solonin, O.P., Glazunov, S.G. (1976) Heat-resistant titanium alloys. Moscow: Metallurgiya.

5. Chechulin, B.B., Ushkov, S.S., Razuvaeva, I.N. et al. (1977) Titanium alloys in machine-building. Moscow: Mashinostroenie.

6. Markashova, L.I., Poznyakov, V.D., Berdnikova, E.N. et al. (2016) Structure and service properties of hybrid laser-arc welded joints of 14KhGN2MDAFB steel. The Paton Welding J., 5/6, 104-113.

7. Markashova, L.I., Poklyatsky, A.G., Kushnaryova, O.S. (2016) Effect of structure and properties of aluminium-lithium alloy welded joints produced by argon-arc and friction stir welding methods. Ibid., 81-85.

8. Markashova, L.I., Akhonin, S.V., Grigorenko, G.M. et al. (2012) Structure and properties of welded joints on titanium alloys containing silicon additions. Ibid., 11, 6-15.

9. Markashova, L.I., Poznyakov, V.D., Berdnikova, E.N. et al. (2014) Effect of structural factors on mechanical properties and crack resistance of welded joints of metals, alloys and composite materials. Ibid., 6/7, 22-28.

10. Markashova, L., Kushnareva, O. (2014) Effect of structure on the mechanical properties of the metal of welded joints of aluminium alloys of the Al-Cu-Li system. Mater. Sci., 49(5), 681-687.

11. Goldshtejn, M.I., Litvinov, V.S., Bronfin, B.M. (1986) Physics of metals of high-strength alloys. Moscow: Metallurgiya.

12. Conrad, H. (1973) Model of strain hardening for explanation of grain size effect on flow stress of metals. In: Superfine grain in metals. Ed. by L.K. Gordienko. Moscow: Metallurgiya.

13. Armstrong, R.V. (1973) Strength properties of superfine grain metals. Ibid., 11-40.

14. Petch, N.J. (1953) The cleavage strength of polycrystalline. J. Iron and Steel Inst., 173, 25-28.

15. Orowan, E. (1954) Dislocation in metals. New York: AIME.

16. Ashby, M.F. (1983) Mechanisms of deformation and fracture. Adv. Appl. Mech., 23, 117-177.

17. Romaniv, O.N. (1979) Fracture toughness of structural steels. Moscow: Metallurgiya.

18. Stroh, A.N. (1954) The formation of cracks as a recoil of plastic flow. Proc. of the Roy. Soc. A, 223(1154), 404-415.

19. Panin, V.E.,Likhachev, V.A., Grinyaeva, Yu.V. (1985) Structure levels of deformation of solids. Siber. Depart.: Nauka.

20. Conrad, H. (1963) Effect of grain size on the lower yield and flow stress of iron and steel. Acta Metallurgica, 11, 75-77. 


\title{
STRUCTURAL CHANGES IN METAL OF WELDED JOINTS OF STEAM PIPELINES
}

\author{
V.V. DMITRIK ${ }^{1}$, A.V. GLUSHKO ${ }^{1}$ and T.O. SIRENKO ${ }^{2}$ \\ ${ }^{1}$ National Technical University «Kharkiv Polytechnic Institute» \\ 2 Kirpichova Str., 61002, Kharkiv, Ukraine. E-mail: svarka126@ukr.net \\ ${ }^{2}$ Kharkiv Machine-Building College \\ 79 Plekhanivska Str., 61068, Kharkiv, Ukraine
}

\begin{abstract}
The structural changes in metal of welded joints of steam pipelines, operated for a long time under the creep conditions, predetermine the need in study of dislocation displacements, occurring in their structure. The paper deals with peculiarities of dislocation displacements, which cause the deformation of metal in regions of heat-affected zone of welded joints, and also with the dependence of deformational changes on the duration of their operating time. It was found that dislocation displacements and deformation of welded joints depend to a definite extent on their initial structure. 8 Ref., 8 Figures.
\end{abstract}

Ke ywords : welded joints of steam pipelines, structural changes, dislocation, carbides, heat-affected zone, deformation, diffusion, polygonization

During the long-time service of welded joints of steam pipelines under the creep conditions, the structural changes take place in their metal, the intensity of which is much higher as compared with similar changes in the base metal. The structural changes can be considered as an initial stage of metal degradation. These changes cause the decrease in adhesive forces between the atoms both in crystals of $\alpha$-phase, and also at the interface of phases (to a greater extent). For example, they take place at the interface of grains of $\alpha$-phase and coagulating carbides $\mathrm{M}_{23} \mathrm{C}_{6}$ [1], thus leading to initiation and further development of creep pores.

The aim of the work is the clarification of peculiar features of physical and chemical processes, occurring in metal of welded joints of steam pipelines, which operate for a long time under creep conditions, to decrease the rate of structural transformations. The revealing of these peculiarities gives opportunity to increase the reliability and life of welded joints by producing their preset initial structure.

The intensity of physical and chemical processes in metal of welded joints, which provide the appropriate structural changes, is higher than that in base metal of steam pipelines, which is predetermined by their higher initial structural heterogeneity. During the process of long-time service (more than 250000 hours) the structural heterogeneity is noticeably increased, thus leading to deterioration of service characteristics of welded joints.

In the process of long-time service of steam pipelines of heat-resistant pearlitic steels (12Kh1MF and $15 \mathrm{Kh} 1 \mathrm{M} 1 \mathrm{~F}$ ) under creep conditions (temperature is $545-585{ }^{\circ} \mathrm{C}$, pressure is $20-25 \mathrm{MPa}$ ) the polygoniza-

(c) V.V. DMITRIK, A.V. GLUSHKO and T.O. SIRENKO, 2017 tion effect is manifested in grains of $\alpha$-phase. To reveal the polygonal structure, the sections were subjected to electrolytic polishing in $150 \mathrm{ml}$ solution of perchloric acid, $600 \mathrm{ml}$ of ethyl alcohol and $100 \mathrm{ml}$ of glycerine, and then to twice etching: firstly in $2 \%$ solution of nitric acid with a washing in alcohol, and then in $2 \%$ solution of picric acid, using the improved procedure [2]. To study the dislocation structure the methods of electron microscopy of thin foils were used.

At the beginning stage of polygonization structure formation the sharp reduction of mechanical properties is not observed, which can be explained by the effect of decreasing the length of sliding lines by the boundaries of subgrains. The presence of diffusion transfer of chromium and molybdenum from the central zones of $\alpha$-phase grains to their near-boundary zones contributes to the appearance of new vacancies and thresholds on dislocations, thus leading to increase in the polygonization intensity. The highest degree of polygonization in structure of welded joints is typical for the region of a partial recrystallization of the heat-affected zone (HAZ), Figure 1. It was as-

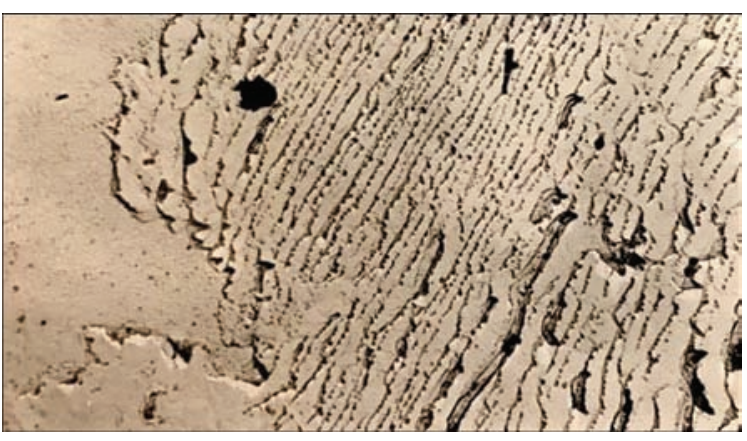

Figure 1. Polygonal structure $(\times 12000)$ of metal of region of HAZ partial recrystallization. Welded joint of steel 12Kh1MF, $\varepsilon=8 \%$ 


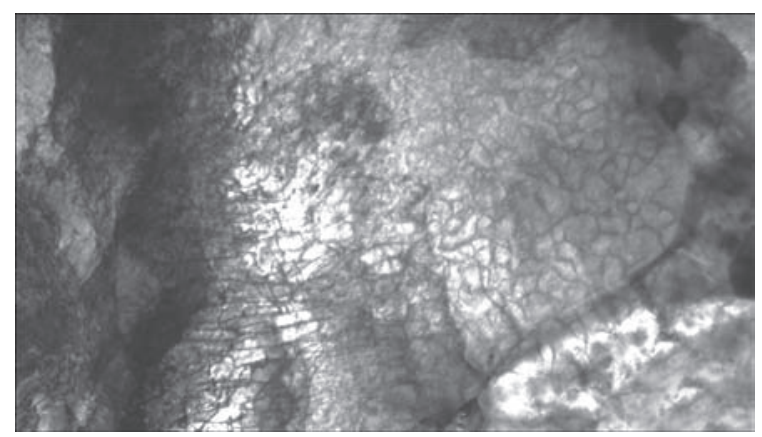

Figure 2. Substructure $(\times 50000)$ of creep in region of a partial recrystallization of HAZ metal of welded joints of steel $15 \mathrm{Kh} 1 \mathrm{M} 1 \mathrm{~F}$, $\varepsilon=5 \%$ (operating time is 280000 hours)

sumed that the effect of formation of the polygonal structure, as a level of development of substructure of $\alpha$-phase grains, is a function of stress and temperature. During operation of steam pipelines in the condition of starts-stops and overheating (emergency steam ejection), which is typical for creep conditions and fatigue, as a function constituent: the rate of deformation of their metal was taken into account.

At a long operating time the dislocations are originated and multiplied in steam pipeline metal, which is connected with their motion. The presence of defects, precipitations of other phases, as well as diffusion processes, represent the origination of dislocations as a heterogeneous process.

Under the action of stresses and temperature the displacement of dislocations in sliding plane, as well as ascending displacement of dislocations, have a discontinuous nature, which was caused by their certain braking. At the first stage of creep the dislocations are displaced at a low rate and the formation of subgrains is slightly noticeable. At the second stage of creep the rate of motion of dislocations is increased, the substructure with a well-developed network of dislocations is formed, that is noticeable at a high magnification (Figure 2). In deformed ( $\varepsilon=2-3 \%$ ) polygonal grains of $\alpha$-phase the boundaries of subgrains lead to decrease in length of the sliding lines (Figure 3).

The intensity of formation of polygonal structure at HAZ regions of welded joints is remarkably different. The intensity is the highest in the region of a partial

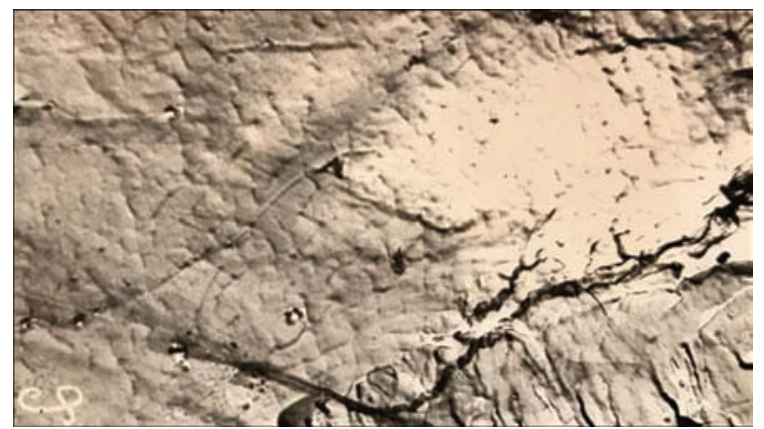

Figure 3. Polygonal structure $(\times 12000)$ of deformed grain of $\alpha$-phase. Overheating region of HAZ. Welded joint of steel $15 \mathrm{Kh} 1 \mathrm{M} 1 \mathrm{~F}, \varepsilon=3 \%$

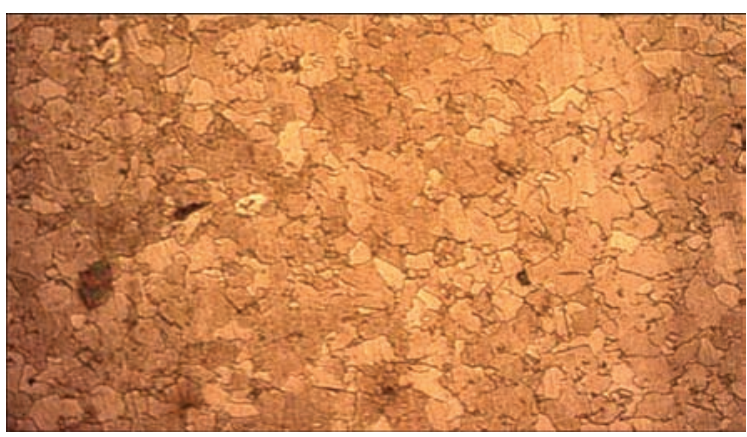

Figure 4. Initial stage of primary recrystallization. Structure $(\times 200)$ of weld metal of steel 10KhMF (operating time of welded joints is 276000 hours)

recrystallization of HAZ, and it is the least in the base and weld metal. At operating time of welded joints above 270000 hours the appearance of subgrains in the body of $\alpha$-phase grains is observed, however, the grains themselves are not increased in sizes, and the new grains are not formed. Precisely, their increase is at the initial stage, which is confirmed by a local liquidation of the grain boundaries (Figure 4). Dislocations, which are located at the grain boundaries, are braked by precipitations of other phases, released from these precipitations, and then replaced by other dislocations, which are displaced similarly to the previous ones (Figure 5). The removal of grain boundaries from coagulating precipitations of other phases is observed, which was firstly noted by T.G. Berezina [3]. The initial process of recrystallization takes place in structure of welded joints at their operating time of more than 250000 hours. Locally the regions of grain boundaries disappear in those places where the level of their free energy is increased, including the places of contact with coagulating precipitations $\mathrm{M}_{23} \mathrm{C}_{6}$ [4].

It was revealed, that the sizes of subgrains in the volume of grains are characteristic for each region of HAZ, and also for weld metal and base metal. Their sizes, in comparison with appropriate structures of regions, have remarkable differences. The largest size of subgrains is noted in the structure of region of a partial recrystallization and overheating. Number of subboundaries is increased to a greater extent at the first unsteady stage of creep and to a less extent at the steady

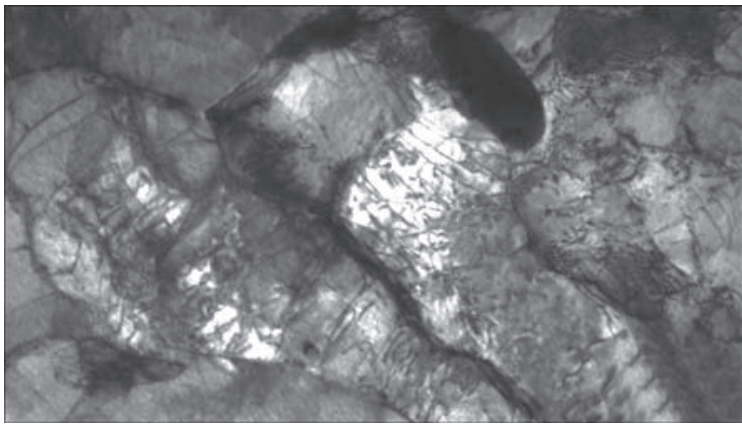

Figure 5. Interaction of dislocations with precipitations of other phases. Structure $(\times 50000)$ in region of overheating of steel $15 \mathrm{Kh} 1 \mathrm{M} 1 \mathrm{~F}, \varepsilon=3 \%$ (operating time is 280000 hours) 
one. However, the thickness of lines of subboundaries is increased at the steady stage of creep and to the least degree in the region of a partial recrystallization.

The maneuverable condition of service (starts-stops) promotes the appearance of fatigue features in metal of steam pipelines and their welded joints. Increase in number of vacancies also promotes the accelerated descending of dislocations and formation of a subgrained structure. Etching of grain boundaries (operating time of steam pipelines is more than 270000 hours) becomes more clear, and direct etching of grains is decreased. The linear dislocations are lined up along the boundaries of blocks in the form of vertical walls with small angles of inclination (see Figure 1). A large part of dislocations is annihilated [5].

During long-time service of steam pipelines under the creep conditions (more than 270000 hours) the total deformation of steam pipelines is approximately $0.5-0.7 \%$, and the deformation of HAZ regions is $0.7-8 \%[1,6]$. It is rational to consider the mechanism of plastic deformation of welded joint metal by using the theory of dislocations $[7,8]$.

Dislocation in passing under the action of tangential stresses through a crystal of $\alpha$-phase performs the work $\tau$. Effective force, which provides the motion of dislocations, is $F=\tau \bar{b}$, where $\bar{b}$ is the Burgers vector. Applied stress $\sigma$, parallel to $\bar{b}$, under the action of force $F_{\text {cr.o }}$ causes the creep over of dislocations, $F_{\text {cr.o }}=\sigma \bar{b}$. The creep over of dislocations is occurred by separation or joining the half-plane of atoms of chromium and molybdenum, and also by formation of vacancies. Taking $\alpha$-phases in crystal as a full-value, initial concentration of atoms of chromium and molybdenum $C_{0}$, similar to concentration of vacancies, and their real concentration $C_{1}$ (after definite operating time), we shall write the change in free energy $k \ln \left(C_{1} /\right.$ $C_{0}$ ), where $k$ is the Boltzmann's constant, $T$ is the absolute temperature. Creeping over of dislocations under the action of force $F_{\text {cr.o }}$ takes place at the presence of gradient of chromium and molybdenum concentration:

$$
F_{\text {cr.o }}=\frac{k T}{b^{2}} \ln \frac{C_{1}}{C_{0}} \text {. }
$$

It was found by using the surface microprobe analysis that after operating time of welded joints of more than 276000 hours the chromium concentration (segregation) in near-boundary zones of $\alpha$-phase grains can amount to 3.0-4.0\%, and in the central zones it can be $0.2-0.4 \%$ [1]. It was revealed, that the segregation of molybdenum begins to increase remarkably after operating time of welded joints of more than 260000 hours, which leads to increase in pore formation. It should be noted that the level of segregation is noticeably different in specimens, subjected to creep-rupture tests and cut from real steam pipelines, as to their similar operating time.
In crystals of $\alpha$-phase the displacement of dislocations is realized by two combined mechanisms: creep over and sliding. During creep over of dislocations of joining and separation of atoms (mostly chromium and molybdenum) the displacement of vacancies takes place on steps of a half-plane. Simultaneously, the thresholds are formed on the half-plane, which are capable to displacement without change in their shape. Motion of dislocations, which cross the potential barriers, is controlled by Peierls forces. The set concentration of dislocations in welded joint metal was considered as a density of dislocations, i.e. as the total length of all the dislocations per a unit of volume. It was found that the density of dislocations in the HAZ regions, as well as in weld metal and base metal noticeably differ (see Figures 2, 3, 6). For example, the average density of dislocations in the region of a partial recrystallization of HAZ was approximately $10^{9} \mathrm{~cm}^{-2}$, and in the weld metal it is close to $10^{8} \mathrm{~cm}^{-2}$. In formation of density the important role is played by the rate of creep over of dislocations, which depends on volume diffusion (self-diffusion of chromium and molybdenum), as well as on annihilation of dislocations. Local removal of grain boundaries (see Figure 4) depends greatly on grain-boundary diffusion, the intensity of which is much higher under the creep conditions than that of volume one [1].

In study of plastic deformation of welded joints metal the following was taken into consideration: peculiarities of structural state of HAZ regions, weld metal and base metal; number of mobile dislocations in crystal of $\alpha$-phase; average motion of dislocations; dependence of change in density of dislocations and rate of their motion on stress, time, temperature and diffusion displacement of alloying elements.

Level of plastic deformation $(\gamma)$ in crystal of $\alpha$-phase was considered as a shear deformation $\gamma=b N \bar{x}$, where $b$ is the displacement caused by motion of dislocations over all the crystal volume, $N$ is the density of dislocations which pass through single cross-section of crystal, $\bar{x}$ is the average displacement of dislocations.

Under the conditions of creep the rate of deformation of metal of HAZ regions, as well as weld metal

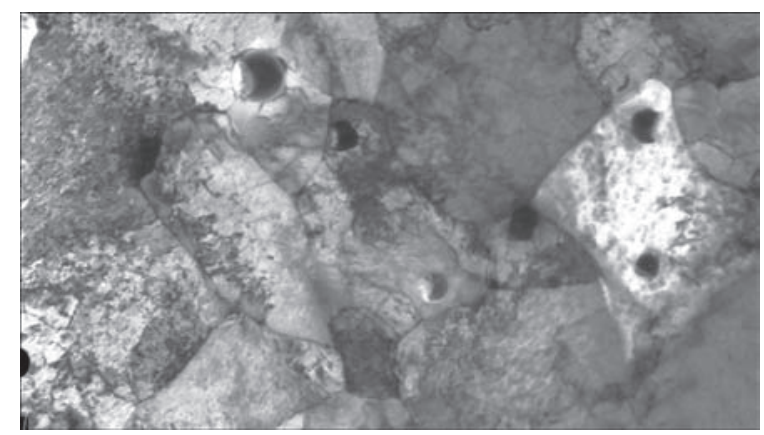

Figure 6. Dislocation structure $(\times 20000)$ of weld metal. Network is seen on separate fragments of subgrains of $\alpha$-phase (on steel $10 \mathrm{KhMF}$ ), $\varepsilon=0.7 \%$ 


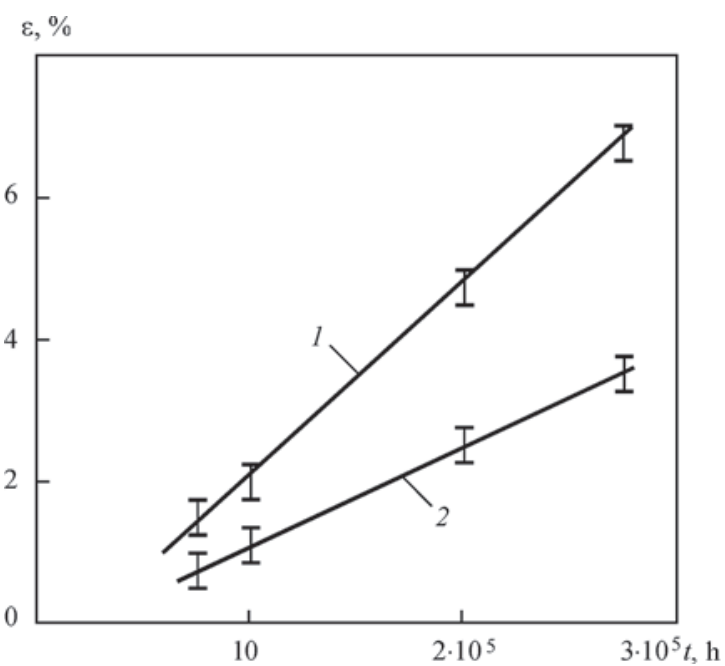

Figure 7. Dependence of deformation $\varepsilon$ on service time of welded joints of steel 12Kh1MF: 1 - metal of region of a partial recrystallization of HAZ; 2 - region of overheating

and base metal, which depends on long-time service of welded joints, is greatly differ (Figure 7). The rate of deformation depends also on their structural state (Figure 8). Determination of deformation rate should be made for the development of methods of its decrease:

$$
\frac{\partial \gamma}{\partial t}=b N V
$$

where $V$ is the rate of deformation.

It is rational that the welding heating and subsequent tempering provided the formation of such a dislocation constitution that could guarantee higher physical and mechanical properties of welded joints. These properties can be obtained by formation of initial structure, the composition of which is as follows: 75-90 \% of bainite, ferrite - the rest, at a uniform distribution of precipitation of other phases in body of grains of $\alpha$-phase, and also along their boundaries. It is not admissible to have the locally grouped and enlarged ferrite grains in weld metal. At the fusion regions of HAZ the welding heating should provide a smooth transition between the structures of weld metal and base metal, as well as an absence of enlarged ferrite grains. At the overheating region the number of austenite grain should not be less than 5 (GOST 5639-82). At the region of a partial recrystallization the new products of austenite decay in the form of chains of globularized pearlite are not admitted. The mentioned constituents of initial structure promote the increase in intensity of physical and chemical processes and, respectively, the structure transformations and, therefore, they should be considered as rejected.

To define the residual life of welded joints more precisely, it is rational to study integrally the main regularities of effect of a dislocation structure on their service characteristics. It is rational to determine the effect of the following factors on dislocation constitution: hardening by $\alpha$-phase alloying; dispersion hardening; elastic interaction of dislocation with spot

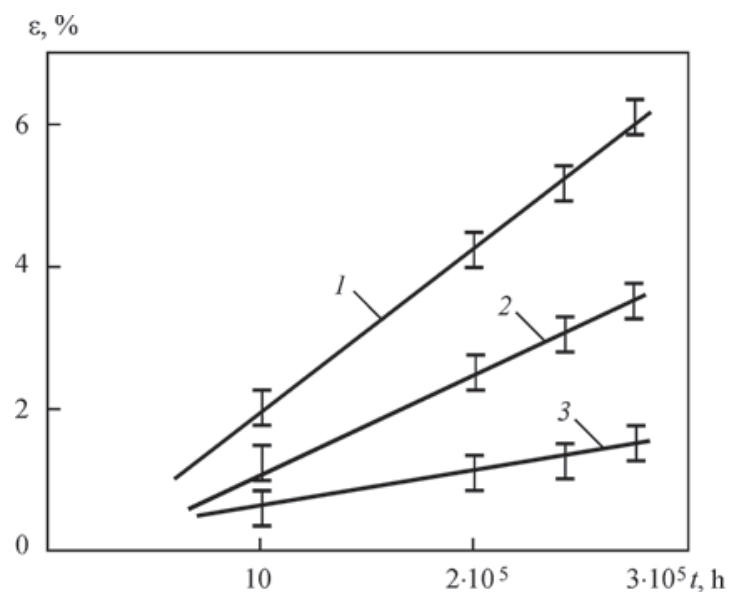

Figure 8. Dependence of deformation of metal of region of a HAZ partial recrystallization of welded joints of steel $15 \mathrm{Kh} 1 \mathrm{M} 1 \mathrm{~F}$ on service time: 1 - globularized pearlite; 2 - sorbite; 3 - troostite defects and Cottrell clouds; chemical interaction of dislocations with dissolved atoms and Suzuki clouds; hardening as a result of ordering of interstitial elements in the field of stresses.

\section{Conclusions}

1. It was found that increase in stability of structure of welded joints of steam pipelines, which are long-time operated under the creep conditions, can be provided by hardening effect of dislocations and precipitations of other phases.

2. It was established that the producing of initial structure of welded joints with improved quality characteristics provides the sufficient decrease in intensity of dislocation displacements in $\alpha$-phase crystals.

3. It was established that the metal deformation at the region of a partial recrystallization of HAZ in structure of welded joints is the highest and depends on type of new products of austenite decay.

1. Dmitrik, V.V., Sobol, O.V., Pogrebnoj, M.A. et al. (2015) Peculiarities of degradation of metal in welded joints of steam pipelines. The Paton Welding J., 7, 10-15.

2. Ivanova, V.S., Gordienko, L.K., Geminov, V.N. et al. (1965) Role of dislocations in hardening and fracture of metals. Moscow: Nauka.

3. Berezina, T.G., Shklyarov, M.I., Shtrom, Yu.Yu. (1992) Assessment of service life of electric equipment parts, operating under creep conditions considering structure factor. Teploenergetika, 2, 2-5.

4. Dmitrik, V.V., Tsaryuk, A.K., Konyk, A.I. (2008) Carbide phases and damageability of welded joints of steam pipelines under creep conditions. The Paton Welding J., 3, 28-32.

5. Glushko, A. (2016) Researching of welded steam pipe joints operated for a long time. Eastern-Europ. J. of Enterprise Technologies, (6), 84(1), 14-20.

6. Khromchenko, F.A. (2002) Resource of welded joints of steam pipelines. Moscow: Mashinostroenie.

7. Mirkin, L. I. (1968) Physical principles of strength and plasticity. Moscow: MGU.

8. Suzuki, T., Esinaga, H., Tekeuti, S. (1989) Dynamics of dislocations and plasticity. Moscow: Mir. 


\title{
INVESTIGATION OF MICROPLASTIC DEFORMATION OF METAL DEPOSITED BY ELECTRIC RESISTANCE METHOD
}

\author{
E.V. BEREZHNAYA ${ }^{1}$, V.D. KUZNETSOV ${ }^{1}$, V.D. KASSOV ${ }^{2}$ and P.A. GAVRISH ${ }^{2}$ \\ ${ }^{1}$ NTTU Igor Sikorsky Kyiv Polytechnic Institute \\ 37 Pobedy Ave., 03056, Kiev, Ukaine. E-mail: elena.kassova07@gmail.com \\ ${ }^{2}$ Donbass State Machine-Building Academy \\ 72 Akademicheskaya Str., 84313, Donetsk region, Kramatorsk, Ukraine
}

\begin{abstract}
The search for optimization of structure and properties of the deposited metal of parts is an urgent task, the solution of which allows increasing their service properties and extending the service life. The data of investigations in this direction using the electric resistance surfacing are very limited. It was found in the work that the tendency of the deposited surface layer of a part (deposited metal and HAZ) to microplastic deformation is an important factor in determination of metal sensitivity to stress concentration. A structure of the deposited metal was obtained, which is characterized by a low sensitivity to stress concentration. It was shown that increase in the content of cementite in the structure of deposited layer leads to growth in tendency of accumulating dislocations during microdeformations, and the presence of a large volume of free ferrite allows decreasing the intensity of accumulating dislocations, reducing sensitivity of the deposited metal to stress concentration. 11 Ref., 2 Tables, 5 Figures.
\end{abstract}

Ke yw ord s : electric resistance surfacing, surface layer structure, microdeformation, stress concentration

The process of electric resistance surfacing applying compact materials (wires, strips) is realized by joint deformation of the material welded-on and the surface layer of a part heated in the deformation zone by short current pulses [1-3]. The overlapping of welding spots between each other is achieved by rotating a part at the speed proportional to the frequency of current pulses [4]. Therefore, the electric resistance surfacing should be understood as a totality of operations of heating, deformation and cooling by water (if necessary), as a result of which the deposited layer is characterized by heterogeneity of structure and mechanical properties, as well as different sensitivity to stress concentration [5].

The presence of heterogeneous structure in the deposited layer, which is predetermined by the specifics of the surfacing process, leads to decrease in the service life of parts operating under the cyclic loads [6]. Taking into account that the tendency of the deposited layer metal to microplastic deformation is an important factor of sensitivity to stress concentration [7], the determination of the optimal structure from the point of view of physical state of the surface layers (deposited layer and HAZ) will allow a correct selection of technology for restoration of worn-out parts. The regulation of the complex of values of physical and mechanical character (mechanical properties of the surface layers metal, microstructure, residual stresses with the creation of their favorable distribution in the surface layer) is a significant reserve for providing reliability of the restored parts.
The aim of the work is the carrying out of investigations, directed to revealing the microstructure, characterized by a low resistance of microplastic deformation and a low sensitivity to stress concentration applied to the selected group of restoring and surfacing materials.

The investigation of the microplasticity of the deposited metal was carried out on the specimens under tensile deformation. The object of the investigation was the specimens of steels of 25,40 and $40 \mathrm{X}$ grades, on which the electric resistance surfacing was performed applying the strip of $0.5 \mathrm{~mm}$ thick at the following conditions: $I_{\mathrm{s}}=6.0-6.5 \mathrm{kA}, P=1.25-1.5 \mathrm{kN}$, $t_{\mathrm{p}}=0.04-0.06 \mathrm{~s}$. The material of strips was selected being identical to the steel grades of the specimens: 25 (GOST 3560-73), 40 (GOST 3560-73), 40X (GOST 21996-76). The deposited specimens were subjected to heat treatment at different conditions to change the structure of the surface layer (Table 1), as a result of which the five groups of deposited specimens were produced to investigate the microplasticity and its homogeneity deep into the deposited metal and HAZ.

To investigate the influence of structure on microplasticity of the surface layers along the longitudinal axis of the specimen, a number of reference points were made by pyramid under the load of $20 \mathrm{~g}$ using the microdurometer PMT-3 [6]. The prints were applied every $0.04-0.05 \mathrm{~mm}$, i.e. through the distances, commensurate with the grain size of the deposited metal of the specimens investigated. The distance between the prints served as the basis for calculating the 


\section{$\sigma, \mathrm{MPa}$}

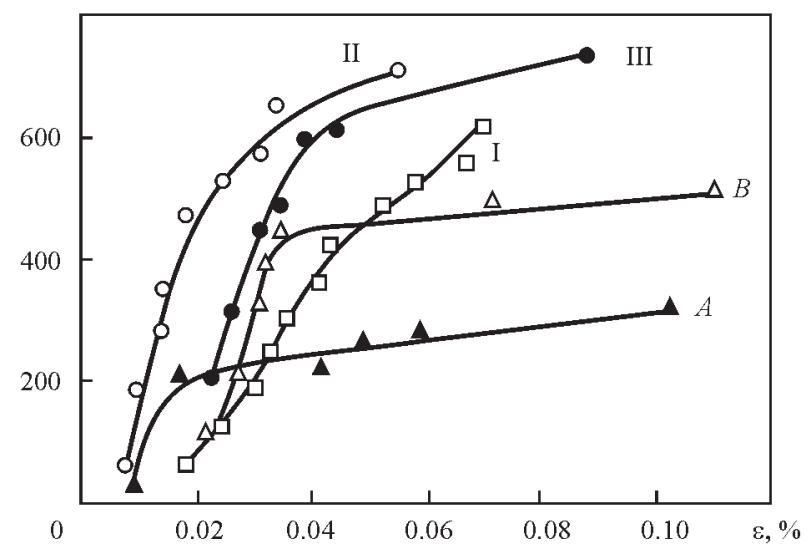

Figure 1. Experimental data on the changes in the value of microplastic deformation $\varepsilon$ in the deposited specimens after heat treatment (see Table 1 ) at the increase of tensile stress $\sigma$

relative deformations under the action of the applied loads.

The analysis of the microstructure was carried out using the metallographic microscope MIM 8 with a digital photographic attachment, which provided determination of minimum loads and, correspondingly, the stresses causing a visible plastic deformation. After each next loading, the measurements of 150-160 basic distances were carried out (distances between the prints of the reference points). According to the data of measurements of the distances between the prints, the change in this distance was determined at stress increase as a result of the applied current load.

The experimental results of the investigation of the microplastic deformation of deposited specimens in a different structural state are shown in Figure 1.

The large microplastic deformation of group A deposited specimens as compared to the deposited specimens, which passed heat treatment according to the modes II, III and normalization (Figure 1), indicates a structural condition which causes an increase in fracture toughness. The low stress values indicate a higher motion of dislocations. In spite of the fact that during investigation of microplastic deformation the residual microdeformations occurred already at the lowest
Table 1. Modes of heat treatment of deposited specimens for investigation of microplasticity (holding time $1 \mathrm{~h}$ )

\begin{tabular}{|c|c|c|c|c|c|}
\hline \multirow{2}{*}{$\begin{array}{c}\text { Grade of } \\
\text { substrate } \\
\text { steel }\end{array}$} & \multirow{2}{*}{ Group } & \multicolumn{2}{|c|}{$\begin{array}{r}\text { Initial heat treatment } \\
\text { mode }\end{array}$} & \multicolumn{2}{c|}{ Tempering mode* } \\
\cline { 3 - 6 } & & $T,{ }^{\circ} \mathrm{C}$ & $\begin{array}{c}\text { Cooling } \\
\text { medium }\end{array}$ & $T,{ }^{\circ} \mathrm{C}$ & $\begin{array}{c}\text { Holding } \\
\text { time, } \mathrm{h}\end{array}$ \\
\hline 25 & $\mathrm{~A}$ & $880-900$ & Air & 620 & 2.5 \\
\hline 40 & $\mathrm{~B}$ & $860-880$ & In furnace & 620 & 1.5 \\
\hline $40 \mathrm{X}$ & $\mathrm{I}$ & $850-870$ & Same & $640-660$ & 1.5 \\
\hline $40 \mathrm{X}$ & $\mathrm{II}$ & $850-870$ & Oil & $640-660$ & 1.5 \\
\hline $40 \mathrm{X}$ & III & $850-870$ & Same & $540-560$ & 1.5 \\
\hline Furnace cooling. & & & \\
\hline
\end{tabular}

stresses, under the microscope the sliding lines were detected at sufficiently high stresses (Figure 2).

It is characteristic that this stress grows with increase in the volume content of pearlite and together with decrease in the tempering temperature during heat treatment according to the mode III. In deposited specimens of the group A, the forming sliding lines are parallel. With appearance of a large amount of pearlite, the shape of sliding lines also changes, they aquire a curved nature. This phenomenon is the more distinct, the higher the volume content of perlite.

The sliding lines in sorbite-like structures (deposited specimens of the group II) are curved, they appear gradually in a wide range of stresses. At high stresses, the number of volumes with a high density of lines also increases. Thus, the shape of sliding lines depends on the obstacles for free propagation of plastic shears (near-boundary volumes, intergranular structural violations). If a deposited specimen contains a relatively large volume of grains of excessive ferrite, then there are fewer obstacles for shears, and the sliding lines are rectilinear. In sorbite structures with a developed intergranular surface, there are far more obstacles for sliding, which namely predetermines the curvature of lines.

The plastic deformation is associated with the motion of dislocations. The experimentally established values of stresses, causing the first acts of microplastic

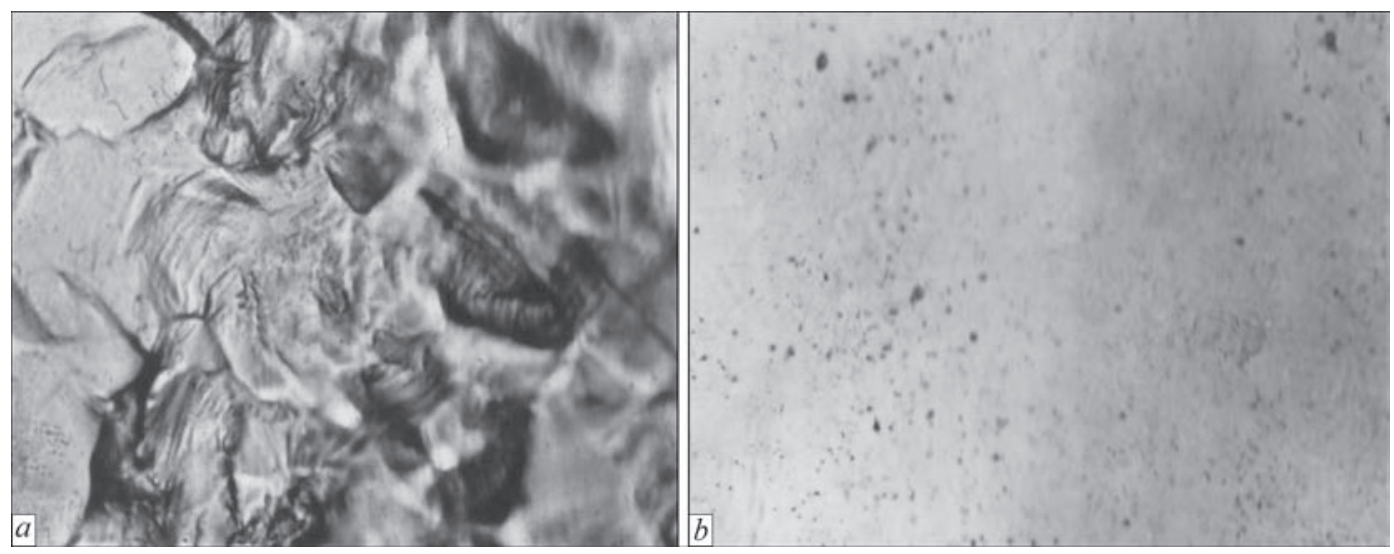

Figure 2. Microstructure $(\times 500)$ of the surface of deposited specimens of steel $40 \mathrm{X}$ after annealing (group I) at the maximum stress of $602 \mathrm{MPa}(a)$ and after heat treatment according to the mode II (group II) at the minimum stress of $59.804 \mathrm{MPa}(b)$ 
deformation, determine the average necessary value of stresses for the start of dislocations, causing microplastic deformation. In the deposited specimens with a low sensitivity to stress concentration, the required average value of stresses for the start of dislocations turns to be small. Consequently, the lower is the value of stresses, necessary for start of dislocation motion, the less sensitive is the specimen to stress concentration. The highest tendency to microplastic deformation is peculiar to deposited specimens of the group A, the basic structural component of which is ferrite. This is predetermined by the highest tendency to motion of dislocations under the influence of applied stresses. In the specimens mentioned above, the deformation occurs most easily, the relatively low stresses are required both for start as well as for motion of dislocations in the microvolumes. With increase in content of cementite component (pearlite), the resistance of specimens to microplastic deformation grows.

For specimens deposited of steel 25, for appearance of microplastic deformation the least stresses are required - 30.5 MPa (see Figure 1). In deposited specimens with a high content of cementite in the structure, these stresses are higher. Especially they are high for specimens, which were subjected to heat treatment after surfacing with obtaining of sorbite and troostite of tempering. For example, for deposited specimens of steel $40 \mathrm{X}$ with tempering sorbite (group II), the minimum stresses for appearance of microplastic deformation are 59.804 MPa (see Figure 2, b), and for the same specimens with tempering troostite (group III) they are 201.16 MPa (see Figure 1).

The morphology of the deposited layer surface, depending on the applied load, is conveniently observed using the method of layer-by-layer microscopy, which allows obtaining the topographic relieves of volumetric objects. The 3D-surface profile (Figure 3) shows that already at the minimum stresses, a significant uneven distribution of microdeformations over

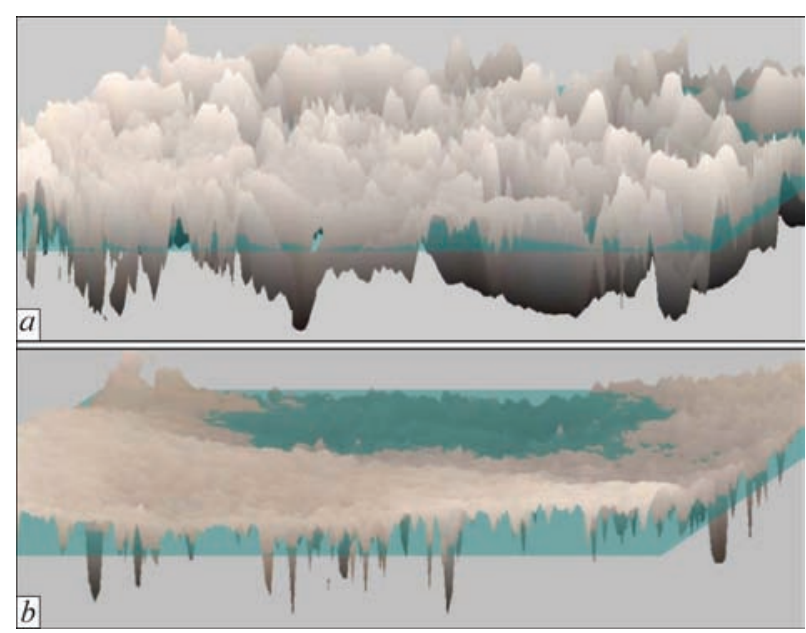

Figure 3. 3D-profiles of the deposited specimens surface of steel $40 \mathrm{X}$ after annealing (group I) at the maximum stress of $602 \mathrm{MPa}$ (a) and after heat treatment according to the mode II (group II) at the minimum stress of $59.804 \mathrm{MPa}(b)$

the surface of the investigated deposited specimen, subjected to heat treatment, is noticeable, which indicates an increased tendency to stress concentration.

The difficulty in the motion of dislocations in the surface layer of the deposited metal leads to formation of single peaks of different value, chaotically distributed along the surface, i.e. to the formation of stress concentrators throughout the entire surface (Figure 3). At the maximum stresses, the morphology of the surface indicates an increase in the dimensions of the surface irregularities with a significant increase in separate peaks and the frequency of irregularities (see Figure 3, a). The growth of height of irregularities can be the result of a high resistance to dislocations motion.

There is a relation between the behavior of dislocations (their motion, accumulation of obstacles) and the modulus of plasticity. In particular, the higher the modulus of plasticity, the faster is accumulation of dislocations and the higher is the sensitivity of material to stress concentration $[8,9]$. The modulus of plasticity (hardening coefficient) was determined using

Table 2. Equations, approximating the dependence of experimental data of the hardening coefficient on the degree of relative deformation

\begin{tabular}{|c|c|c|c|c|}
\hline $\begin{array}{c}\text { Metal of surfacing } \\
\text { on steels }\end{array}$ & Heat treatment & Group & Structure & Form of equation \\
\hline 25 & Normalization & A & Ferrite + pearlite & $D=4.6226-27.1629 \varepsilon_{i}+\frac{0.0068}{\varepsilon_{i}}$ \\
\hline 40 & Same & B & Pearlite + ferrite & $D=4.7773-42.8378 \varepsilon_{i}+\frac{0.0121}{\varepsilon_{i}}$ \\
\hline $40 \mathrm{X}$ & Annealing & I & Same & $D=6.643-45.5734 \varepsilon_{i}+\frac{0.0068}{\varepsilon_{i}}$ \\
\hline $40 \mathrm{X}$ & Heat treatment by the mode II & II & Sorbite & $D=6,7291-48,2929 \varepsilon_{i}+\frac{0,0023}{\varepsilon_{i}}$ \\
\hline $40 \mathrm{X}$ & Heat treatment by the mode III & III & Troostite & $D=5.2241-6.10107 \varepsilon_{i}+\frac{0.0074}{\varepsilon_{i}}$ \\
\hline
\end{tabular}




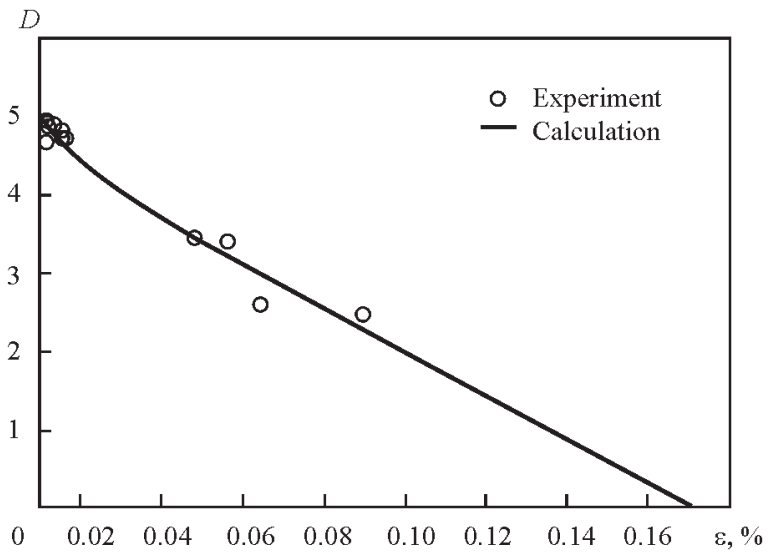

Figure 4. Changes in the coefficient of hardening $D$, depending on average total microplastic deformation $\varepsilon$ of the deposited specimens of steel 25 in the normalized state (group A)

the modeling methods in the software environment of StatSoftStatisticaV6.0 (Table 2, Figure 4, 5).

Therefore, the values of hardening coefficient at microplastic deformation are not the same for different structural states and the degree of deformation, which correlates with the data of the works [10, 11]. Among the investigated specimens, the specimens of the group A are characterized by the lowest hardening coefficient (see Figure 4), and the highest hardening coefficient is peculiar to the specimens deposited in the state after heat treatment according to the mode III (see Figure 5). With increase in the degree of deformation, the hardening coefficient decreases in all the investigated structural states, which indicates the dependence of plastic flow process on the degree of microdeformation.

The carried out investigations of tendency of deposited metal in different structural states to microplastic deformation allowed revealing the structure of the deposited metal, which is the least sensitive to stress concentration. Thus, with the increase in the structure of cementite component, the sensitivity of the metal to stress concentration increases, and the presence of deposited layer of free ferrite in the structure reduces the intensity of accumulation of dislocations during microdeformations and, as a consequence, the sensitivity of deposited metal to stress concentration decreases. The results of investigations in this work were used during selection of the rational technology for restoration of parts.

\section{Conclusions}

1. The effect of the structure on the microplasticity of specimens, deposited by electric resistance surfacing, was investigated. It was shown that the deposited metal, in which in the process of microdeformation the conditions preventing the motion of dislocations are not so intensively accumulated, is less prone to stress concentration.

2. The effect of hardening coefficient on sensitivity to stress concentration as-applied to specimens depos-

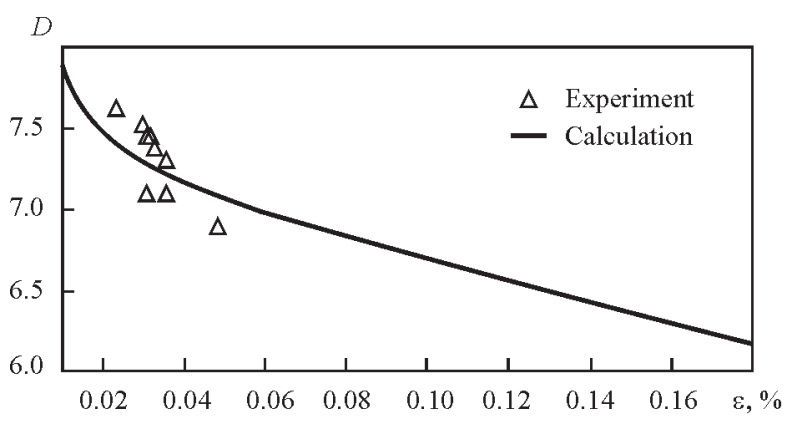

Figure 5. Changes in the coefficient of hardening $D$, depending on the average total microplastic deformation $\varepsilon$ of deposited specimens of steel $40 \mathrm{X}$ after heat treatment according to the mode III (group III)

ited by strips of structural carbon steels with the subsequent heat treatment was experimentally confirmed. It was established that the highest resistance to microplastic deformation is observed in the deposited specimens after their heat treatment with obtaining of sorbite and troostite, which is associated with a more developed uneven distribution of microdeformations over the specimen surface and increase in the number of obstacles for motion of dislocations.

1. Burak, P.I. (2007) Driving forces of cohesion and formation of surface bonding process in electric resistance welding-on. Int. Techn. and Economic J., 4(4), 33-37.

2. Sajfullin, R.N. (2008) Restoration of machine parts by electric resistance welding-on of metal-powder compositions. Tekhnika $v$ Selskom Khozyajstve, 2, 26-28.

3. Sajfullin, R.N. (2009) Restoration of parts by electric resistance welding-on with flux-cored wire. Mekhanizatsiya i Elektrifikatsiya Selskogo Khozyajstva, 1, 27-28.

4. Pontileenko, F.I., Lyalyakin, V.P., Ivanov, V.P. et al. (2003) Restoration of machine parts: Refer. Book. Moscow: Mashinostroenie.

5. Chernoivanov, V.I., Lyalyakin, V.P. (2003) Organizing and technology of restoration of parts. Moscow: GOSNITI.

6. Golovin, S.A., Pushkar, A. (1980) Microplasticity and fatigue of metals. Moscow: Metallurgiya.

7. Madyanov, S.A., Kalinin, V.R., Kraev, A.P. et al. (1990) Examination of microplastic deformation as a method of evaluation of metal embrittlement. In: Mechanics and physics of fracture of brittle materials: Transact. Kiev, 33-38.

8. Isaev, N.V. Shumilin, S.E., Zabrodin, P.A. et al. (2013) Strain hardening and stepwise deformation of ultrafine-grained polycrystals of solid solution $\mathrm{Al}-\mathrm{Li}$ at temperature of $0.5 \mathrm{~K}$. Fizika Nizkikh Temperatur, 39(7), 818-826.

9. Markashova, L.I., Alekseenko, T.A., Zhdanov, S.L. et al. (2013) Influence of external static loading on change of metal structure parameters of over-heat area in HAZ of highstrength steel welded joints. Visnyk Chernigiv. Derzh. Tekhnol. Un-tu, 63(1), 87-92.

10. Terentiev, V.F. (2006) Fatigue of high-strength steels. Part 1: Correlation with ultimate strength, types of curves and crack initiation. Deformatsiya i Razrusheniya Materialov, 8, 2-11.

11. Chapetti, M.D., Tagawa, T., Miyata T. (2003) Ultra-long cycle fatigue of high-strength carbon steels. Part 1: Revive and analysis of the mechanism of failure. Mater. Sci. \& Engin. A, 356(1/2), 227-235. 


\title{
HYBRID PLASMA-ARC WELDING OF THIN-WALLED PANELS FROM ALUMINIUM ALLOY
}

\author{
V.N. KORZHIK \\ E.O. Paton Electric Welding Institute, NASU \\ 11 Kazimir Malevich Str., 03680, Kiev, Ukraine. E-mail: office@paton.kiev.ua
}

\begin{abstract}
The urgency of this work is associated with the need to develop accessible highly efficient technology of welding thin-walled ship panels from $\mathrm{Al}-\mathrm{Mg}$ system alloys, which will allow minimizing the effect of deterioration of strength characteristics of the produced joints, characteristic for traditional arc welding methods, as well as reducing weld width and welding heat input without any essential increase of welding equipment cost. Research performed by the author was the base to propose the technology of hybrid plasma-MIG welding with axial feed of wire through hollow circular electrode, allowing production of joints of thin-walled (5-8 mm) ship panels from aluminium alloys of Al-Mg system, with strength higher than $80 \%$ of that of base metal and by 3-6 \% higher than strength provided by consumable electrode pulsed-arc welding. Developed technology allows improvement of the efficiency of manufacturing ship panels 5-8 mm thick, compared to currently applied consumable electrode pulsed-arc welding due to improvement of welding speed by $25-40 \%$ and elimination of the need for edge preparation. It is shown that application of hybrid plasma-arc welding, compared to traditional consumable electrode arc welding allows reducing weld width by approximately $20 \%$ and decreasing by $10-15 \%$ the quantity of wire used for weld formation of the same process speed. Here, welding heat input is reduced by $20-30 \%$ that promotes an improvement of strength characteristics and reduction of the width of base metal softening zone under the impact of welding arc heat. 10 Ref., 3 Tables, 5 Figures.
\end{abstract}

Ke y word s: aluminium alloys, direct action plasma, consumable electrode arc, hybrid welding, welding mode, weld hardness, joint strength

Aluminium and its alloys are widely applied in modern shipbuilding. They are used to manufacture ship hulls, deck superstructures, communication systems and all kinds of ship equipment [1]. The main advantage achieved here is up to $50-60 \%$ reduction of ship weight, compared to application of steel. This enables increasing ship tonnage or improving its tactical and technical characteristics (maneuverability, speed, etc.).

Alloys of Al-Mg system (for instance, 1530 (AMg3), 1550 (AMg5), 1560 (AMg6) and 1561 (AMg61) are becoming the most widely accepted of aluminium alloys for fabrication of structures of river and sea fleet. These alloys are characterized by good weldability. With increase of magnesium content, the coefficient of cracking in welding decreases. However, welded joints of these alloys, produced by traditional arc welding processes, are weaker compared to base material [2]. This, primarily, concerns strength and ductility characteristics that may lead to negative consequences in sea ship manufacture. It is rational to develop accessible highly efficient welding technology, which allows minimizing the effect of deterioration of strength properties of the produced joints of Al-Mg system alloys, as well as reducing weld width and welding heat input without any essential increase of welding equipment cost.

(c) V.N. KORZHIK, 2017
One of the welding processes allowing the defined task to be solved is hybrid plasma-MIG welding [3]. This process was presented for the first time in 1972 by Willhelm Essers and others at Philips Research Center (The Netherlands) [4]. With such a welding process a hybrid heat source is formed, consisting of a direct action constricted arc, enclosing the consumable electrode arc. Further constriction of the latter provides a high rate of wire melting and considerable reduction of spattering. Application of such a process for manufacturing aluminium alloy structures can provide formation of fine-grained weld structures, as well as high quality and efficiency of welding [5].

In early designs of heads for hybrid plasma-MIG welding regular pin nonconsumable electrode was applied. In modern designs it was replaced by hollow, namely tubular or annular one to increase welding process stability [6]. Modern modified process of hybrid plasma-arc welding still has not become sufficiently widely accepted, being, however, actively pursued by researchers [7]. Technologies of welding diverse materials by this process are also at the development stage.

The objective of this work was development of such a technology of manufacturing thin-walled (5-8 mm) ship panels from aluminium alloys of AlMg system based on hybrid plasma-MIG welding with axial wire feed, which will allow eliminating the 
Table 1. Chemical composition of welded samples $(\delta=5$ and $8 \mathrm{~mm})$

\begin{tabular}{|c|c|c|c|c|c|c|c|c|c|c|c|}
\hline Alloy & Normative document & $\mathrm{Mg}$ & $\mathrm{Mn}$ & $\mathrm{Cu}$ & $\mathrm{Fe}$ & $\mathrm{Si}$ & $\mathrm{Cr}$ & $\mathrm{Zn}$ & $\mathrm{Ti}$ & $\mathrm{Zr}$ & $\mathrm{Be}$ \\
\hline 5083 & EN 573-3 & $4.0-4.9$ & $0.4-1.0$ & 0.1 & 0.4 & 0.4 & $0.05-0.25$ & 0.25 & $0.10-0.15$ & - & 0.005 \\
\hline 1561 (AMg61) & OST 1 92014-90 & $5.5-6.5$ & $0.7-1.1$ & 0.1 & 0.4 & 0.4 & - & 0.2 & - & $0.02-0.12$ & $0.0001-0.003$ \\
\hline
\end{tabular}

Table 2. Chemical composition of electrode wire (1.2 and $1.6 \mathrm{~mm}$ diameter)

\begin{tabular}{|c|c|c|c|c|c|c|c|c|c|c|}
\hline Grade & $\mathrm{Mg}$ & $\mathrm{Mn}$ & $\mathrm{Cu}$ & $\mathrm{Fe}$ & $\mathrm{Si}$ & $\mathrm{Cr}$ & $\mathrm{Zn}$ & $\mathrm{Ti}$ & $\mathrm{Zr}$ & $\mathrm{Be}$ \\
\hline ER5356 & $4.5-5.5$ & $0.08-0.2$ & 0.1 & 0.4 & 0.4 & $0.05-0.25$ & 0.1 & $0.06-0.20$ & - & 0.0005 \\
\hline Sv-AMg61 & $5.8-6.8$ & $0.5-0.8$ & 0.1 & 0.4 & 0.25 & - & 0.2 & $0.02-0.10$ & - & $0.0002-0.005$ \\
\hline Ok. Autrod 18.22 & $5.5-6.2$ & $0.8-0.9$ & 0.05 & 0.2 & 0.4 & - & 0.2 & $0.02-0.20$ & $0.02-0.10$ & 0.005 \\
\hline
\end{tabular}

softening of welded joint metal, characteristic for arc processes.

A number of technological studies of the processes of hybrid plasma-arc welding (Plasma-MIG) and consumable electrode reverse polarity pulsed-arc welding (MIG) were performed to achieve the defined objective, using aluminium-magnesium alloys of 5083 and 1561 grades 5 and $8 \mathrm{~mm}$ thick with up to 370 MPa strength. Used as electrode wires were those from alloys of 5356 grade (for 5083 alloy), as well as Sv-AMg61, or its European analog Ok. Autrod 18.22 (manufactured by ESAB Company) (for welding 1561 alloy). Chemical composition of the above alloys is given in Tables 1, 2 .

Modes were selected on samples of $400 \times 200 x \delta$ $\mathrm{mm}$ size made from alloys specified in Table 1 . Modes of welding butt joints of sheets of thickness $\delta=5$ and $8 \mathrm{~mm}$ were optimized. Weld deposits were made for preliminary selection of the modes, and after selection of mode parameters butt welding was performed. No edge preparation was made for $5 \mathrm{~mm}$ thickness. For $8 \mathrm{~mm}$ thickness Y-shaped edge preparation with angle of opening of $60^{\circ}$ and $2 \mathrm{~mm}$ toe was performed only in the case of pulsed-MIG welding, as the hybrid process provided sound square edge welding in this case also. Removable substrates from nonmagnetic austenitic steel were used to produce the reverse reinforcement bead in this case - for welding samples with $\delta=5 \mathrm{~mm}$ the groove size in the substrate was equal to $6.0 \times 2.0 \mathrm{~mm}$, and for welding samples with $\delta=8 \mathrm{~mm}$ it was $8.0 \times 3.0 \mathrm{~mm}$.

Experiments were performed with application of specialized complex of equipment developed at PWI, which included [8]: inverter welding power source for nonconsumable electrode argon-arc welding TIG ACDC EVO 450/T Robot, plasma module FPM, EVO Speed Star 520 TS Robot, autonomous cooling unit, plasmatron for machine hybrid plasma-MIG welding with axial wire feed, multiposition laboratory manipulator based on welding column and rotator, and common control system of hybrid welding complex. Welding was performed according to technological schematic given in Figure 1, $a$. Here, the effect of additional compression of consumable electrode arc by constricted arc from hollow nonconsumable electrode was achieved, Figure 1, $b$ [9].
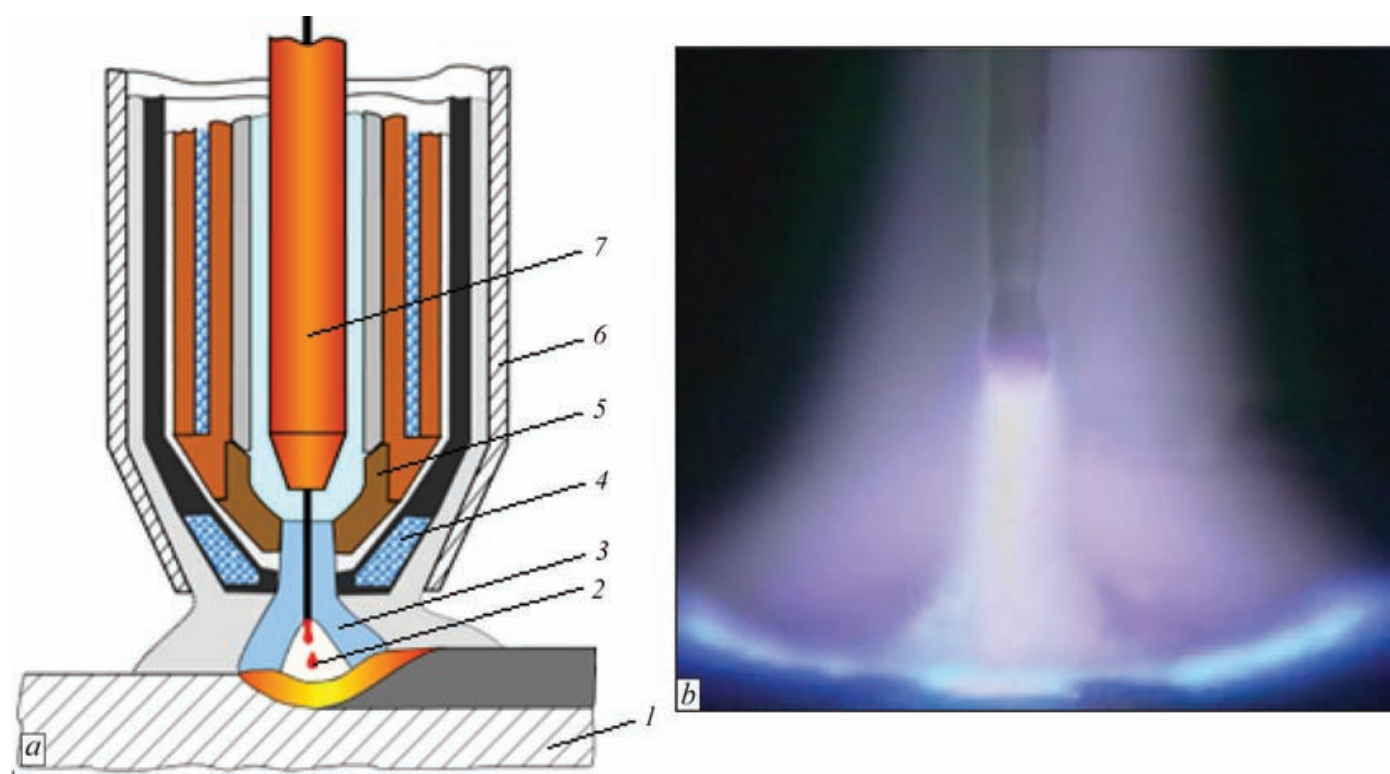

Figure 1. Flow diagram of the process of (a) hybrid plasma-arc welding: 1 - welded sample, 2 - consumable electrode arc; 3 direct action constricted arc; 4 — plasmaforming nozzle; 5 - plasmatron tubular electrode (anode); 6 - protective nozzle; 7 - consumable electrode feeding nozzle; photo of joint action of constricted arc and consumable electrode arc $(b)$ 
Table 3. Parameters of modes of consumable electrode (MIG) welding and hybrid plasma-arc (plasma-MIG) welding of 5083 and 1561 alloys

\begin{tabular}{|c|c|c|c|c|c|c|c|c|c|c|}
\hline $\begin{array}{l}\text { Welding } \\
\text { speed, } \\
\mathrm{m} / \mathrm{min}\end{array}$ & $\begin{array}{c}\text { Constricted } \\
\text { arc current, } \\
\text { A }\end{array}$ & $\begin{array}{c}\text { Constricted } \\
\text { arc voltage, } \\
\text { V }\end{array}$ & $\begin{array}{c}\text { Plasma gas } \\
\text { flow rate, } \\
\text { l/min }\end{array}$ & $\begin{array}{c}\text { Consumable } \\
\text { electrode arc } \\
\text { current, A }\end{array}$ & $\begin{array}{c}\text { Consumable } \\
\text { electrode arc } \\
\text { voltage, V }\end{array}$ & $\begin{array}{c}\text { Electrode } \\
\text { wire feed } \\
\text { rate, } \mathrm{m} / \mathrm{min}\end{array}$ & $\begin{array}{c}\text { Central gas } \\
\text { flow rate, } \\
\text { l/min }\end{array}$ & $\begin{array}{c}\text { Sample } \\
\text { thickness } \delta \text {, } \\
\text { mm }\end{array}$ & $\begin{array}{c}\text { Heat } \\
\text { input (Plas- } \\
\text { ma-MIG) + } \\
\text { MIG, kJ/m }\end{array}$ & $\begin{array}{c}\text { Electrode } \\
\text { wire diame- } \\
\text { ter, mm }\end{array}$ \\
\hline \multicolumn{11}{|c|}{5083 alloy } \\
\hline 0.6 & - & - & - & 280 & 26.5 & 8.4 & - & 5.0 & $0+740$ & \multirow{4}{*}{1.6} \\
\hline 0.6 & 115 & 26 & 5.0 & 165 & 18 & 7.6 & 7.0 & 5.0 & $300+297$ & \\
\hline 0.3 & - & - & - & 251 & 27.0 & 9.5 & - & 8.0 & $0+1350$ & \\
\hline 0.4 & 168 & 22.8 & 5.0 & 213 & 23.0 & 7.0 & 7.0 & 8.0 & $570+730$ & \\
\hline \multicolumn{11}{|c|}{1561 alloy } \\
\hline 0.6 & - & - & - & 253 & 25.8 & 8.0 & - & 5.0 & $0+650$ & 1.6 \\
\hline 0.6 & 100 & 25.4 & 5.0 & 155 & 17.4 & 12.5 & 7.0 & 5.0 & $255+270$ & 1.2 \\
\hline 0.6 & 100 & 24.6 & 5.0 & 165 & 17.4 & 7.4 & 7.0 & 5.0 & $246+287$ & \multirow{4}{*}{1.6} \\
\hline 1.0 & 178 & 29.2 & 3.5 & 154 & 18.2 & 7.5 & 6.5 & 4.5 & $311+170$ & \\
\hline 0.3 & -- & -- & -- & 251 & 27.0 & 9.5 & -- & 8.0 & $0+1350$ & \\
\hline 0.4 & 155 & 21.8 & 5.0 & 213 & 23.0 & 7.0 & 7.0 & 8.0 & $505+730$ & \\
\hline
\end{tabular}

Plasma forming nozzle diameter was varied in the range of 6-10 mm. Anode design was composite, consisting of a copper case with an insert from tungsten of $6.0 \mathrm{~mm}$ diameter. A hole of $4.0 \mathrm{~mm}$ diameter was made in the tungsten for electrode wire feeding. In all the experiments the distance between the plasmaforming nozzle and sample was $6.0 \mathrm{~mm}$. This distance was selected from the condition of ensuring electrode extension (distance from current-conducting tip to

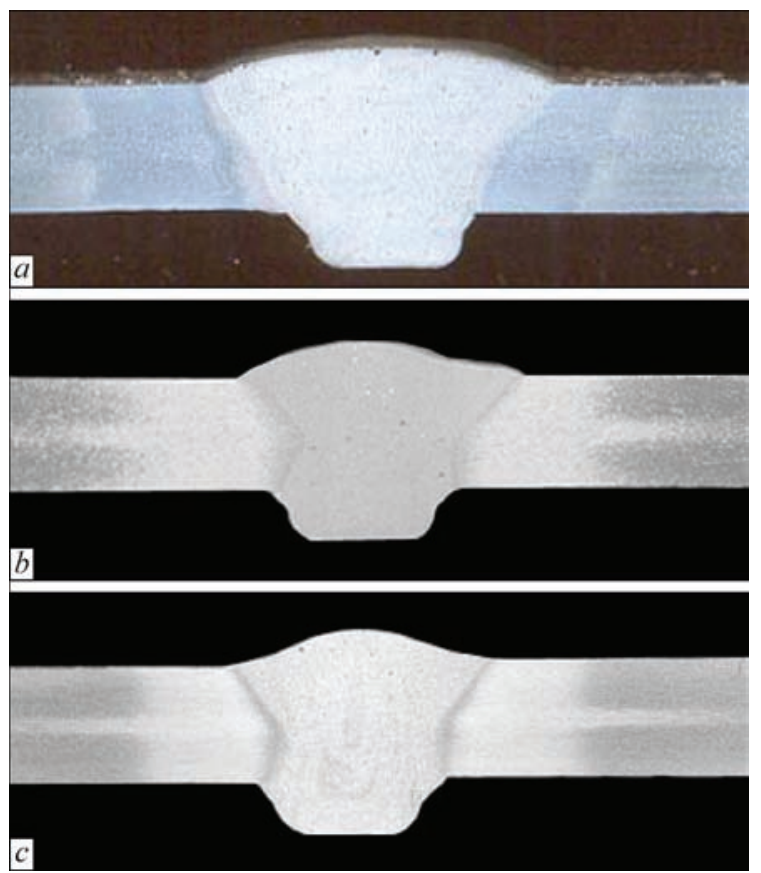

Figure 2. Transverse sections of welded joints of sheets from 1561 alloy $(\delta=5.0 \mathrm{~mm})$ made by pulsed-MIG welding $(a)$ and hybrid plasma-arc welding with electrode wire of $1.2(b)$ and $1.6 \mathrm{~mm}(c)$ diameter electrode wire) in the range of 16-18 mm. Here minimum spatter deposition on plasmaforming and protective nozzles of the plasmatron is achieved.

The criterion of weld suitability for subsequent mechanical testing was correspondence to requirements to admissible surface defects, according to the results of external inspection and measurements, in keeping with the requirements of [10] and GOST 14806-80.

After making weld deposits, modes of hybrid plasma-arc welding were selected, which were then used to conduct butt welding of samples for mechanical testing. Similar samples were made by traditional pulsed-MIG welding with consumable electrode arc (Table 3). Welding was performed in the downhand position in shielding atmosphere of argon with flow rate of $25-30 \mathrm{l} / \mathrm{min}$ at velocities of $0.3-0.6 \mathrm{~m} / \mathrm{min}$. Results of application of both the methods were compared (Figures 2, 3).

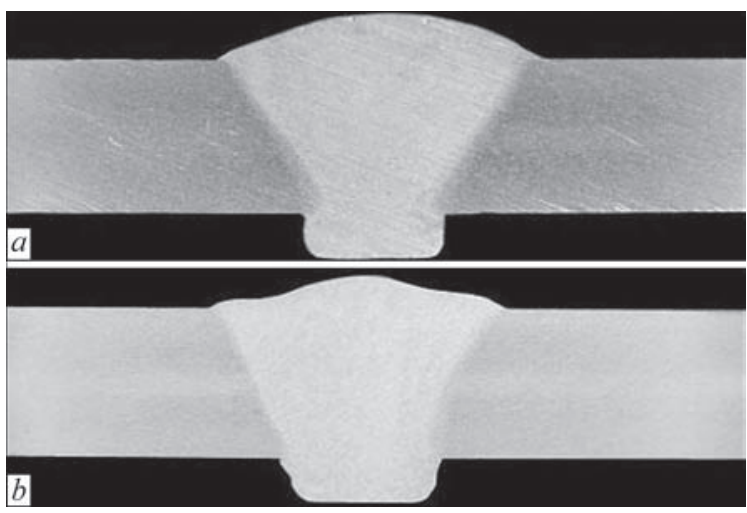

Figure 3. Transverse sections of welded joints of sheets of 1561 alloy $(\delta=8.0 \mathrm{~mm}$ ) made by pulsed-arc MIG $(a)$ and hybrid plasma-MIG welding $(b)$ 

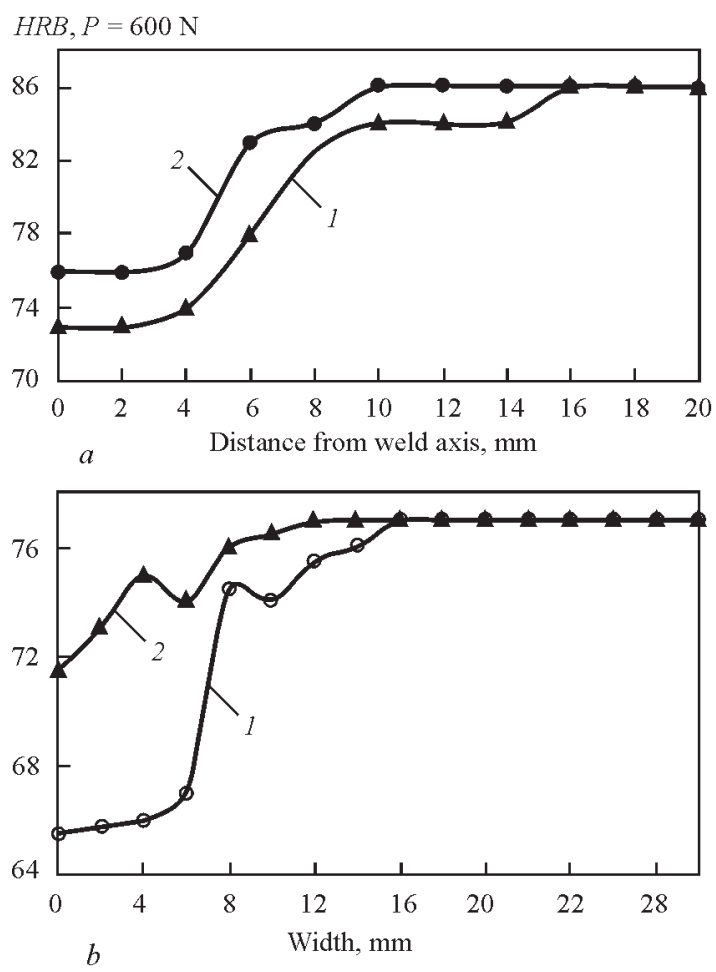

Figure 4. Hardness distribution in the cross-section of welded joint produced by MIG (1) and plasma-MIG (2) welding on samples of: $a-1561$ alloy $(\delta=5.0 \mathrm{~mm})$ at welding speed of $0.6 \mathrm{~m} /$ min; $b-5083$ alloy $(\delta=8.0 \mathrm{~mm})$ at welding speeds of 0.3 and $0 / 4 \mathrm{~m} / \mathrm{min}$, respectively

Comparison of heat inputs of consumable electrode and hybrid plasma-arc welding of $5 \mathrm{~mm}$ thick aluminium alloys performed at the same speed, shows lowering of this parameter in the second case by approximately 20-30 \% (Table 3). Welding of 1561 alloy $(\delta=5.0 \mathrm{~mm})$ by hybrid process without edge preparation allowed process speed to be increased up to $1.0 \mathrm{~m} / \mathrm{min}$, that is by $40 \%$ higher than that of traditional pulsed-MIG welding (Table 3). In the case of welding $8 \mathrm{~mm}$ thick samples, the approximate matching of heat inputs in both the cases makes comparison of these process results valid, despite the different welding speeds (Table 3).

Welds, produced by consumable electrode welding of samples from 5083 alloy $(\delta=8.0 \mathrm{~mm})$, had pores in weld upper part, weld width being $18.0 \mathrm{~mm}$ at reinforcement height of $3.0 \mathrm{~mm}$. Reduction of geometrical dimensions of welds at selected preparation of edges to be welded was impossible, as in order to achieve the respective penetrability of the arc, welding current of about 250 A was required, which was directly related to electrode wire feed rate and certain quantity of metal added to the weld pool, respectively.

In hybrid plasma-MIG welding it is possible to dose wire feed rate by selecting the ratio of heat inputs of each of the components so, as to ensure for-

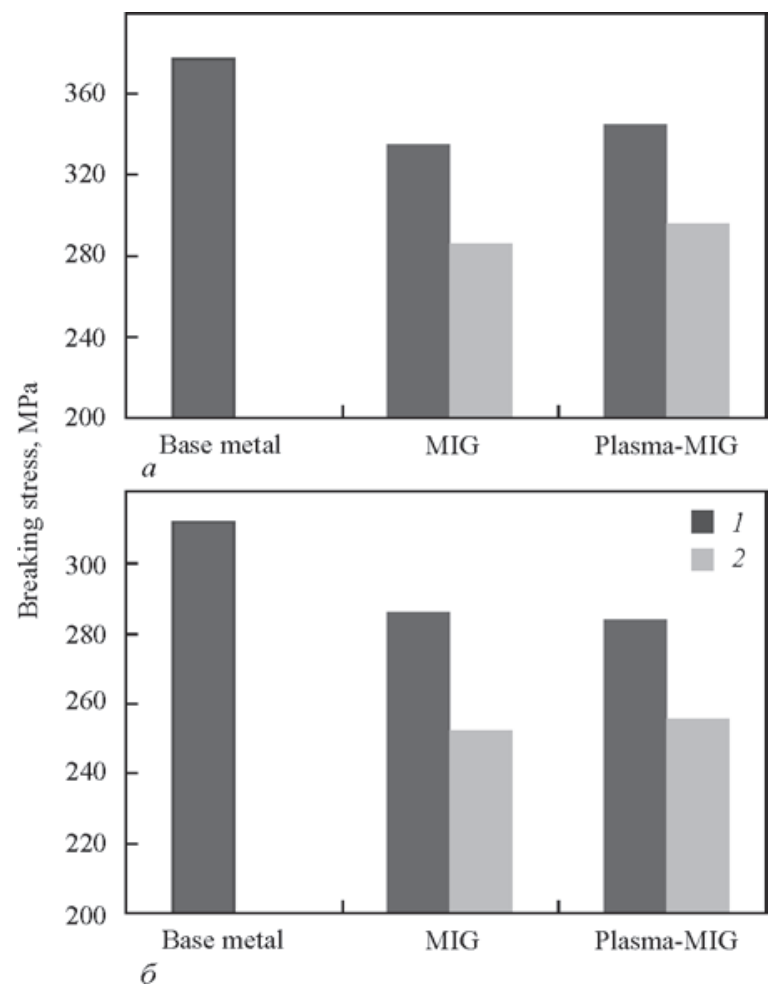

Figure 5. Strength values at static tension of welded joints produced by MIG (1) and Plasma-MIG (2) welding on samples of: $a-1561$ alloy $(\delta=5.0 \mathrm{~mm})$ at welding speed of $0.6 \mathrm{~m} / \mathrm{min}$; $b-5083$ alloy $(\delta=8.0 \mathrm{~mm})$ at speeds of 0.3 and $0.4 \mathrm{~m} / \mathrm{min}$, respectively $(1$ - welded joint; 2 - weld metal

mation of upper and lower beads. Heat input required for complete penetration of the sheets being joined is ensured by the action of nonconsumable electrode constricted arc. This allowed in hybrid plasma-MIG welding of sheets of 5083 alloy $(\delta=8.0 \mathrm{~mm}$ ) reaching weld width of $15.0 \mathrm{~mm}$ at weld reinforcement height of $1.7 \mathrm{~mm}$, i.e. reducing these parameters by approximately 20 and $45 \%$, respectively.

Templates for conducting microdurametric analysis were cut out of butt welded joints produced by the compared processes, as well as samples of type XIIIa for static strength testing according to GOST 6996-66. Comparison of hardness distributions in the cross-sections of welded joints produced by the traditional pulsed-MIG welding in argon atmosphere and hybrid-MIG welding is given in Figure 4. It follows from the Figure that hybrid welding leads to certain (up to $4 \%$ for 1561 alloy and up to $8 \%$ for 5083 alloy) increase of the joint hardness.

Comparison of strength of welded samples at static loading with removed lower reinforcement of the weld (reverse bead), as well as those with removed lower and upper weld reinforcements for pulsed-MIG welding and hybrid plasma-MIG welding, is given in Figure 5. This comparison shows that the studied welding process, compared to the traditional one, al- 
lows increasing strength of 1561 alloy joints up to $3 \%$, and of those of 5083 alloy - up to $6 \%$.

\section{Conclusions}

1. Performed research was the base for development of the technology of hybrid plasma-MIG welding with axial wire feed through hollow annular electrode, which allows producing joints of thin-walled (5-8 mm) ship panels from aluminium alloys of $\mathrm{Al}-$ Mg system with the strength of more than $80 \%$ of that of base metal and by 3-6\% higher than the strength provided by pulsed-MIG welding.

2. Developed technology allows increasing the efficiency of manufacturing ship panels of 5-8 mm thickness, compared to currently applied pulsed-MIG welding through increasing welding speed by 25 $40 \%$ and elimination of the need for edge preparation.

3. Application of hybrid plasma-MIG welding, compared to traditional consumable electrode arc welding at the same process speed allows reducing weld width by approximately $20 \%$ and lowering by $10-15 \%$ the quantity of wire used for weld formation. The value of welding heat input decreases by $20-30 \%$ that promotes improvement of strength characteristics and reduction of the width of the zone of base metal softening under the impact of welding arc heat.

The work was performed with the support of Chinese Program of Foreign Experts No.
WQ20124400119, Guangdong Innovative Research Team Program No. 201101C0104901263, China, Project of Guangdong Provincial Key Laboratory No. 2012A061400011, China.

1. Zusin, V.Ya., Serenko, V.A. (2004) Welding and surfacing of aluminium and its alloys. Mariupol: Renata.

2. Rabkin, D.M. (1986) Metallurgy of fusion welding of aluminium and its alloys. Kiev: Naukova Dumka.

3. Essers, W.G., Jelmorini, G. (1975) Method of plasma-MIG-welding. U.S. Philips Corp. Pat. US3891824.

4. Essers, W.G., Liefkens, A.C. (1972) Plasma-MIG welding developed by Philips. Machinery and Production Engineering, 12, 632-633.

5. Essers, W.G., Willemes, G.A. (1984) Plasma-MIG-Schweissen von Aluminium Auftragschweissen und Zweielektrodenschweissen. DVS-Berichte, 90, 9-14.

6. Dedyukh, R.I. (2014) Peculiarities of consumable electrode plasma welding (Review). Svarochn. Proizvodstvo, 5, 34-39.

7. Yang Tao, Gao Hongming, Zhang Shenghu et al. (2013) The study on plasma-mig hybrid arc behaviour and droplet transfer for mild steel welding. Rev. on Advanced Materials, 33, 459-464.

8. Grinyuk, A.A., Korzhik, V.N., Shevchenko, V.E. et al. (2016) Hybrid technologies of welding aluminium alloys based on consumable electrode arc and constricted arc. The Paton Welding J., 5/6, 98-103.

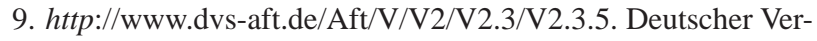
band fuer Schweissen und verwandte Verfahren e.V. Ausshuss fuer Technik. Arbeitsgruppe V 2.3.5 Plasma-MIG-Schweissen.

10. ND 2-020101-040 (2013): Rules of technical supervision in construction of ships and manufacture of materials and products for ships. Vol. 2. St.-Petersburg: Russian Maritime Register of Shipping.

Received 06.04.2017 


\title{
DEVELOPMENT OF TECHNOLOGY OF MICROPLASMA SPRAYING FOR RESTORATION OF LOCAL DAMAGES OF ENAMEL COATING
}

\author{
Yu.S. BORISOV, S.G. VOJNAROVICH, A.N. KISLITSA, \\ Ie.K. KUZMYCH-IANCHUK, O.P. MASYUCHOK and S.N. KALYUZHNY \\ E.O. Paton Electric Welding Institute, NASU \\ 11 Kazimir Malevich Str., 03680, Kiev, Ukraine. E-mail: borisov@paton.kiev.ua
}

\begin{abstract}
Fundamentals of microplasma spraying technology for restoration of local damages in enamel coatings of tank equipment were developed. A double-layer repair coating consisting of a layer of zirconium oxide and tantalum sublayer was proposed. The optimum parameters of microplasma spaying mode were determined in order to obtain a layer of zirconium oxide with dense microstructure (porosity 1.2-1.9\%). It is shown that application of tantalum-based sublayer increases adhesion strength of zirconium oxide coating by $25 \%$ (up to $8.14 \pm 2.16 \mathrm{MPa}$ ). Evaluation of coating through porosity was carried out. A method was proposed for increase of coating uniformity using epoxy-resin treatment. The technology was approved under real production conditions at CJSC «Kharkovreakhim». 15 Ref., 1 Table, 6 Figures.
\end{abstract}

Keywords : microplasma spraying, enamel coatings, restoration, adhesion strength, zirconium oxide, tantalum, coating permeability

Local damages of the enamel coatings appear under effect of a complex of service conditions and, mostly, at the presence of initial production defect. In chemical industry appearance of the defects of enamel coatings is related with effect of aggressive chemical media (acids, alkalies, salts), high temperatures (as well as rapid changes of temperatures) and mechanical damages due to movement of equipment parts. Thus, the main defects of enameled chemical devices and reservoirs are chips, cracks and defects of corrosion nature [1].

The traditional methods of restoration of such local damages, described in work [2], include additional enameling, putting special seals of gold or tantalum, using of polymer fillings as well as reenameling. However, mentioned methods have a series of disadvantages such as need in reannealing of the whole product or its part, expensive materials, accelerated aging of polymers in the aggressive media and necessity in complete removal of a present enamel coating for new layer deposition.

In recent times, repair of damaged areas of the enamel coatings is mostly carried out using thermal spraying methods (TS), which can provide local repair with high process efficiency in restoration of complex shape surfaces [3-13]. It is noted that combination of electric arc, flame and plasma coatings with enamel surface layers allows 5 times extension of service life of enameled equipment.

However, application of traditional methods of plasma and flame spraying imposes a series of limita- tions, which do not allow sound, and effective repair of the enameled equipment under production conditions. Thus, for example, repair of inner surfaces of the reservoirs using traditional plasma spraying units is impossible due to their large dimensions.

In this connection it is proposed to use a technology of microplasma spraying (MPS), developed at the E.O. Paton Electric Welding Institute of the NAS of Ukraine for repair of the enamel coatings on equipment of chemical enterprises. It has a series of significant advantages in comparison with traditional plasma spraying [14] for solving set tasks:

- low plasmatron power (to $2 \mathrm{~kW}$ ) eliminates the possibility of product overheating and damage of enamel coating around area being repaired;

- small size of spraying spot (1-5 mm) provides the possibility of precision repair of small defects with minimum losses of material being sprayed;

- mode of plasma jet outflow from microplasmatron provides a low noise level (less than $50 \mathrm{~dB}$ ) that allows spraying without special chambers with minimum protective means for operator;

- small dimensions of equipment for microsplasma spraying allow local repair of the enamel coatings on the products without their disassembly as well as inside reservoirs of large dimensions.

Convenience of equipment and geometry accuracy of coating deposition provide a prompt repair of the enamel coatings at early stages of defect formation that is, apparently, a preferable approach. 
Determination of requirements to repair microplasma coatings and materials selection. The analysis of existing experience to repair of local defects using TS methods determined the main requirements to repair of the microplasma coatings:

- material of the coating should provide resistance to effect of environment at the level equal to strength of working enamel coating;

- coating should have a layer density which does not allow contact of environment with a base metal surface (product, structure);

- coating strength should be sufficient for adhesion with the base and its keeping on the surface under operation of product or structure.

The following materials, suitable for repair coatings, namely oxide $\left(\mathrm{ZrO}_{2}, \mathrm{Al}_{2} \mathrm{O}_{3}, \mathrm{TiO}_{2}\right)$ and metallic (Zr, Ta, Ti) were selected based on considered requirements taking into account available experience of MPS of different materials.

Analysis of the works, dedicated to deposition of repair thermal coatings, allows assuming that the most effective approach for repair of local damages of the enamel coatings will be application of the double-layer metal-ceramic coatings.

The aims of work were generated based on mentioned above:

- determination of parameters for powder microplasma spraying of $\mathrm{ZrO}_{2}$ coating with minimum porosity for restoration of local damages of the enamel coatings;

- determination of effect of tantalum sublayer on adhesion strength of ceramic coating with the base;

- evaluation of through porosity (evaluation of uniformity) of coatings.

Procedure of experiment and investigations. Materials. Zirconium oxide powder $\left(\mathrm{ZrO}_{2}+\right.$ $7 \% \mathrm{Y}_{2} \mathrm{O}_{3}$ ) of $40 \mu \mathrm{m}$ granulation was used as a material being sprayed. Figure 1 shows appearance of zirconium oxide powder. The coatings were deposited on the specimens of steel 40 of $10 \times 20 \times 3 \mathrm{~mm}$ size subjected to gas-abrasive treatment (corundum).

Equipment. The coatings were produced on microplasma spraying unit MPN-004 with MP-04 plasmatron in powder spraying mode [14].

Procedure of experiment planning. The method of multifactor experiment with half-replication $2^{4-1}$ was selected in planning. Current (I, A), consumption of plasma-forming gas $\left(V_{\mathrm{pg}}, \mathrm{l} / \mathrm{h}\right)$, spraying distance $(h$, $\mathrm{mm})$ and powder consumption $\left(G_{\mathrm{p}}, \mathrm{g} / \mathrm{min}\right)$ were selected as independent variables (factors). A response function was a value of coating porosity in \%.

The values of mode parameters (Table) were taken based on the results of preliminary experiments and accumulated practical experience of plasma spraying of zirconium oxide on MPN-004 unit.

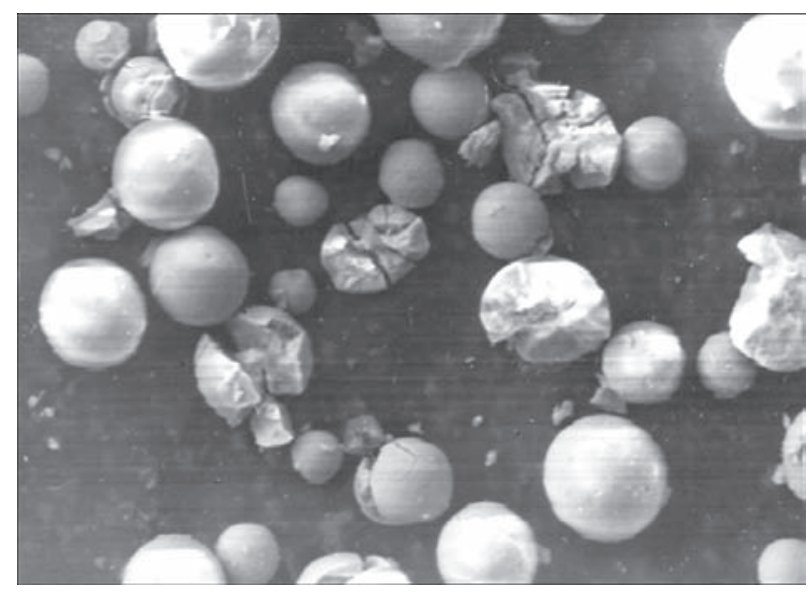

Figure 1. Appearance of zirconium oxide powder $\left(\mathrm{ZrO}_{2}+7 \%\right.$ $\mathrm{Y}_{2} \mathrm{O}_{3}$, size $\approx 40 \mu \mathrm{m}$ )

Investigation procedures. Preparation of the specimens for metallographic investigations was carried out in accordance with the standard procedures used in metallography. The sections were firstly made on waterproof polish paper SiC with P800, P1200 grain size, after that on the flexible disks containing diamond inclusions of different dispersion (A28/14, A14/10 and A5/3). The final polishing of the sections was carried out on woolen cloth adding diamond suspension with DiaDuo lubricant having diamond particles of $3 \mu \mathrm{m}$ size. Coating microstructure was examined on «Neophot-32» microscope equipped with add-on device for digital photo. A system of image registration was carried out with a computer program QuickPhoto.

Determination of porosity. Optical methods of porosity determination (method of image analysis) have found the widest distribution for qualitative and quantitative analysis of porosity geometry. They lie in determination of an area covered with found pores relative to whole area of coating section.

Analysis of the sections was carried out using «Neophot-32» and Jenavert devices. A digital image was processed with Atlas program, which allows measuring porosity (outlining inclusions different on color and brightness) on standard ASTM B-276, determine

Parameters of mode of microplasma spraying of zirconium oxide powder

\begin{tabular}{|c|c|c|c|c|}
\hline $\begin{array}{c}\text { Number } \\
\text { of mode }\end{array}$ & $I, \mathrm{~A}$ & $V_{\mathrm{pg}}, \mathrm{l} / \mathrm{min}$ & $h, \mathrm{~mm}$ & $G_{\mathrm{p}}, \mathrm{g} / \mathrm{min}$ \\
\hline 1 & 45 & 2.0 & 160 & 2.0 \\
\hline 2 & 45 & 2.0 & 80 & 1.0 \\
\hline 3 & 45 & 1.0 & 160 & 1.0 \\
\hline 4 & 45 & 1.0 & 80 & 2.0 \\
\hline 5 & 35 & 2.0 & 160 & 1.0 \\
\hline 6 & 35 & 2.0 & 80 & 2.0 \\
\hline 7 & 35 & 1.0 & 160 & 2.0 \\
\hline 8 & 35 & 1.0 & 80 & 1.0 \\
\hline 9 & 40 & 1.5 & 120 & 0 \\
\hline
\end{tabular}


dimensions of maximum and minimum pores, number and percent relationship of pores over the area.

Measurement of adhesion strength of coatings with base at tear was carried out on a glue procedure according to GOST-14760-69 and ASTM C 633-76 using versatile servohydraulic machine MTS-318.25 (USA production) with maximum force $250 \mathrm{kN}$ under normal conditions $\left(t=20^{\circ} \mathrm{C}\right)$. A grip movement rate was $0.17 \mathrm{~mm} / \mathrm{s}$. The coating was deposited on edge surface of cylinder specimens of $25 \mathrm{~mm}$ diameter and $24 \mathrm{~mm}$ height, the specimen with coating was glued to a check specimen and pressed with $0.5 \mathrm{~kg} / \mathrm{cm}^{2}$ force. Epoxypolyurethane glue EPU-TEKhKO with $65 \%$ of epoxy resin and $35 \%$ of hardener was used for gluing.

Evaluation of through porosity(uniformity evaluation) was carried out by means of evaluation of their permeability in a model medium (tap water). The segments of enameled pipes of low-carbon steel with two inches inner diameter were cut for specimens manufacture. A through defect of enamel coating of $10 \mathrm{~mm}$ diameter was formed at a face side by the gas-abrasive treatment method. Then the defect was removed using microplasma spraying of zirconium oxide coating of $150 \mu \mathrm{m}$ thickness. The edges and backsides of the specimen were isolated with multiple application of lacquer. Visual monitoring of appearance of spot exits of corrosion material via through pore channels was performed in course of the experiments.

Results and discussion. Figure 2 shows the microstructures of $\mathrm{ZrO}_{2}$-coatings produced under MPS conditions. The results of measurement of $\mathrm{ZrO}_{2}$-coating porosity are given in Figure 3.

The coatings with the densest microstructure and tight contact with the base are formed at $I=40-45$ A (experiments $1,3,4$ ) values. Reduction of current to $35 \mathrm{~A}$ value results in decrease of coating thickness and porosity growth.

Porosity in the experiment rises in the following way, i.e. experiment 3-4-1-9-8-2-6.

Thus, the results of carried analysis of coating structures determined that $\mathrm{ZrO}_{2}$-coatings with minimum porosity are produced using the mode No.3 (Table), namely $I=45 \mathrm{~A}, V_{\mathrm{pg}}=1 \mathrm{l} / \mathrm{min}, h=160 \mathrm{~mm}, G_{\mathrm{p}}=1 \mathrm{~g} / \mathrm{min}$.

Coating to base adhesion strength. The investigations of adhesion strength of coatings with base showed that deposition of zirconium oxide coating directly on specimens of steel 40 subjected to gas-abrasive treatment promotes an average adhesion strength $6.11 \pm 1.32 \mathrm{MPa}$ during tear testing at coating thickness $150-200 \mu \mathrm{m}$. Adhesion strength rises to
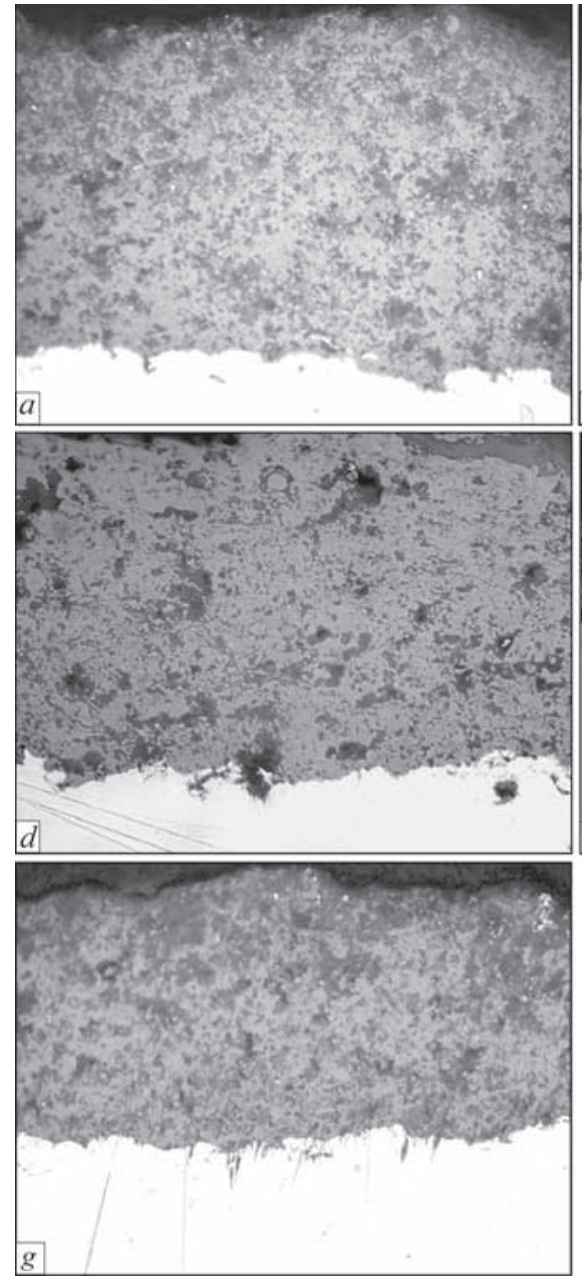
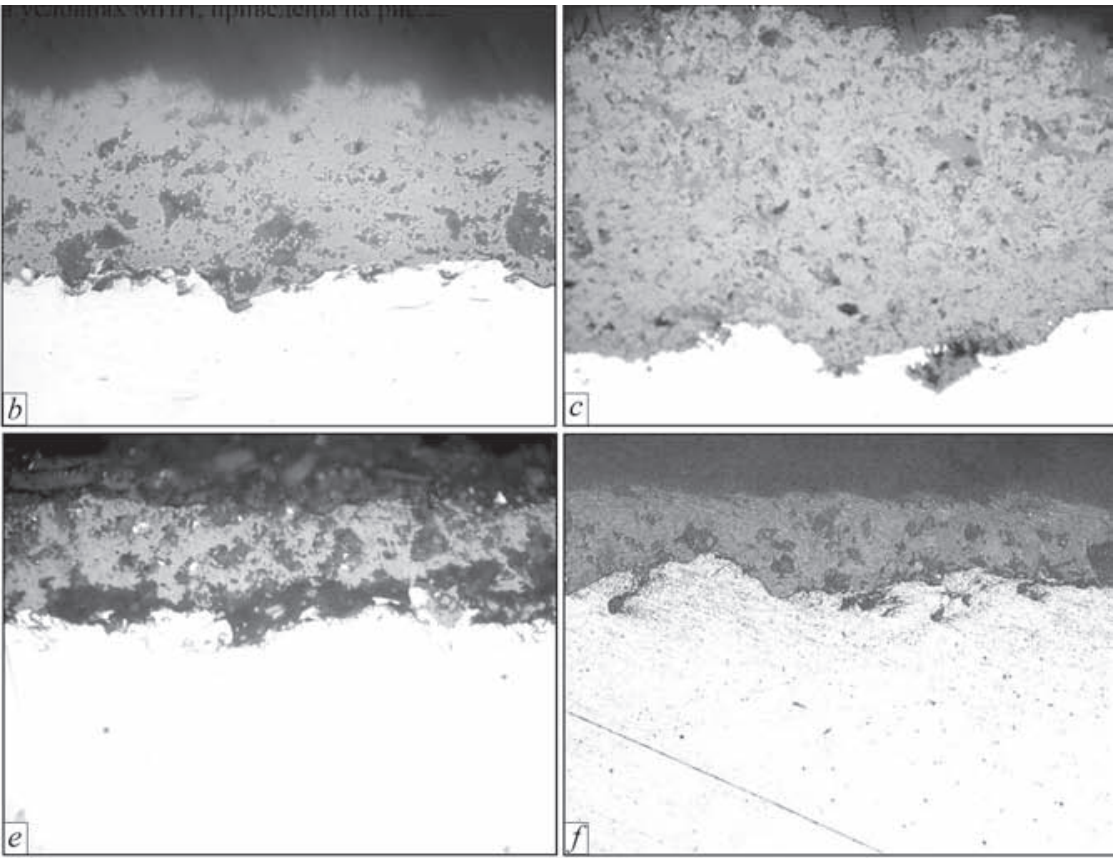

Figure 2. Microstructure $(\times 150)$ of $\mathrm{ZrO}_{2}$-coatings produced using different MPS modes: $a-g$ - experiments with mode 1-9 (Table) 


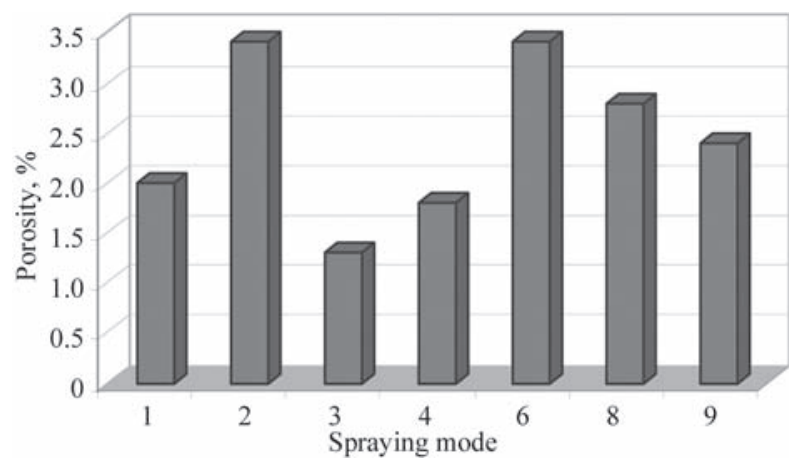

Figure 3. Porosity of microplasma coatings of $\mathrm{ZrO}_{2}$

8.14 $\pm 2.16 \mathrm{MPa}$, i.e. increment of adhesion strength makes $25 \%$, in deposition of $\mathrm{ZrO}_{2}$-coating on tantalum sublayer (Figure 4).

Conditions for decrease of surface ripples. In process of coating deposition on the area, which is certainly more than a spraying spot, there is linear movement of the plasmatron in combination with part rotation or transverse displasement of part or plasmatron. At unmovable position of plasmatron and part the material being sprayed forms a bead shape coating on the surface, cross-section of which is described by Gaussian curve:

$$
y=y_{0} e^{-\left(r^{2} / r_{0}^{2}\right)} \text {, }
$$

where $y_{0}$ is the thickness of the coating on bead axis; $r_{0}$ is the scattering radius; $r$ is the distance from bead axis.

It follows from equation (1) that the best uniformity of coating thickness in microplasma spraying is achieved under condition of transverse displacement $s$ of the plasmatron under the next conditions:

$$
s=1.2 r_{0} \text {. }
$$

Spraying of the specimen for measurement of the spraying spot was carried out using the optimum mode for deposition of repair $\mathrm{ZrO}_{2}$-coating (mode No.3). A scattering radius for given specimen made $2.75 \mathrm{~mm}$ on big axis and $2.15 \mathrm{~mm}$ on small axis.

It was determined based on the results of analysis of calculation data and conditions of coating uniformity $\left(s / r_{0}=1.2\right)$ that transverse displacement of the plasmatron during movement along large diagonal in $\mathrm{ZrO}_{2}$-coating deposition should not exceed $4 \mathrm{~mm}$ and in displacement along smaller diagonal it makes $3 \mathrm{~mm}$. Less than $1 \%$ of ripples is reached under these dimensions of step of plasmatron transverse movement.

Evaluation of coating permeability for outdoor environments. Impregnation of coatings for sealing. Carried metallographic examinations of the specimen showed that the coating is tight with the base, including enamel coating (Figure 4).

Appearance of spot exits of rust was noted in the investigated specimens with $\mathrm{ZrO}_{2}$-coating. In this connection the coating was impregnated with special compound for sealing the coating microdefects. Dichtol (Germany) is a one-component fluid material based on

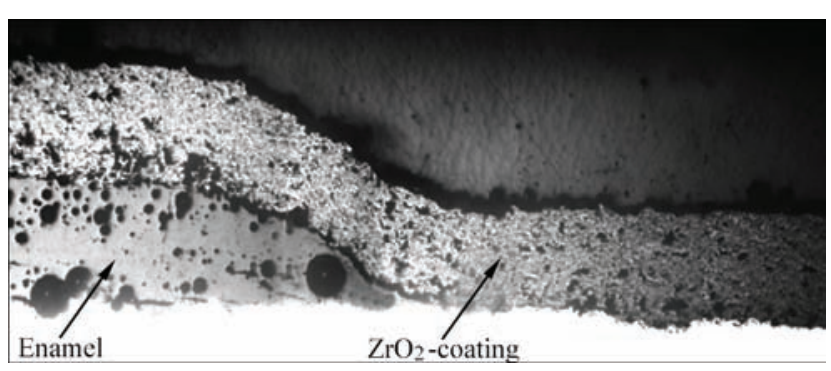

Figure 4. Microstructure $(\times 150)$ of $\mathrm{ZrO}_{2}$-coating produced with MPS on specimen simulating enamel coating defect

epoxy-resin, which was used as a compound for impregnation. It is characterized with the possibility to penetrate in the cavities of casting and coating microdefects. After $\mathrm{ZrO}_{2}$-coating was sprayed on the test specimens a triple impregnation of the coating by Dichtol with intermediate drying was performed. The specimens received after impregnation did not show spot corrosion under the similar test conditions (Figure 5).

Received results allowed determining process parameters and developing the following technological recommendations on restoration of the local damages of enamel coatings using microplasma spraying method:

- preparation of product surface include gas-abrasive treatment (corundum) and degreasing with organic solvents;

- parameters of spraying mode: $I=45 \mathrm{~A} ; V_{\mathrm{pg}}=1 \mathrm{l} /$ $\min ; h=160 \mathrm{~mm} ; G_{\mathrm{p}}=1 \mathrm{~g} / \mathrm{min}$;

- transverse displacement of the plasmatron in movement along larger diagonal should not exceed 4 $\mathrm{mm}$ and $3 \mathrm{~mm}$ in movement along smaller diagonal;

- after spraying the coating is subjected to triple impregnation by Dichtol (Germany), one-component fluid material based on epoxy-resin, with intermediate drying during $1.5 \mathrm{~h}$.

Approbation of the developed technology of coating restoration using microplasma spraying method was carried out under production conditions for repair of the local damages of enamel coating on inner surface of V-630 reactor, which is used in produc-

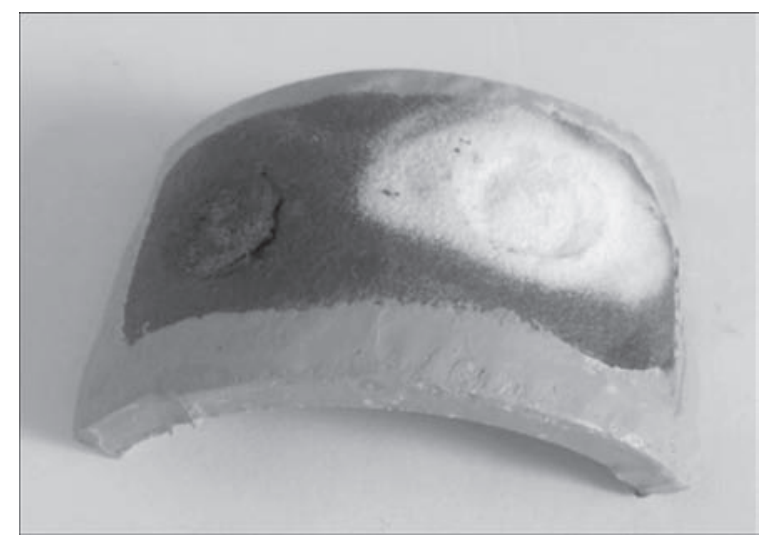

Figure 5. Specimen with defect of enamel coating after restoration using MPS method and uniformity testing 

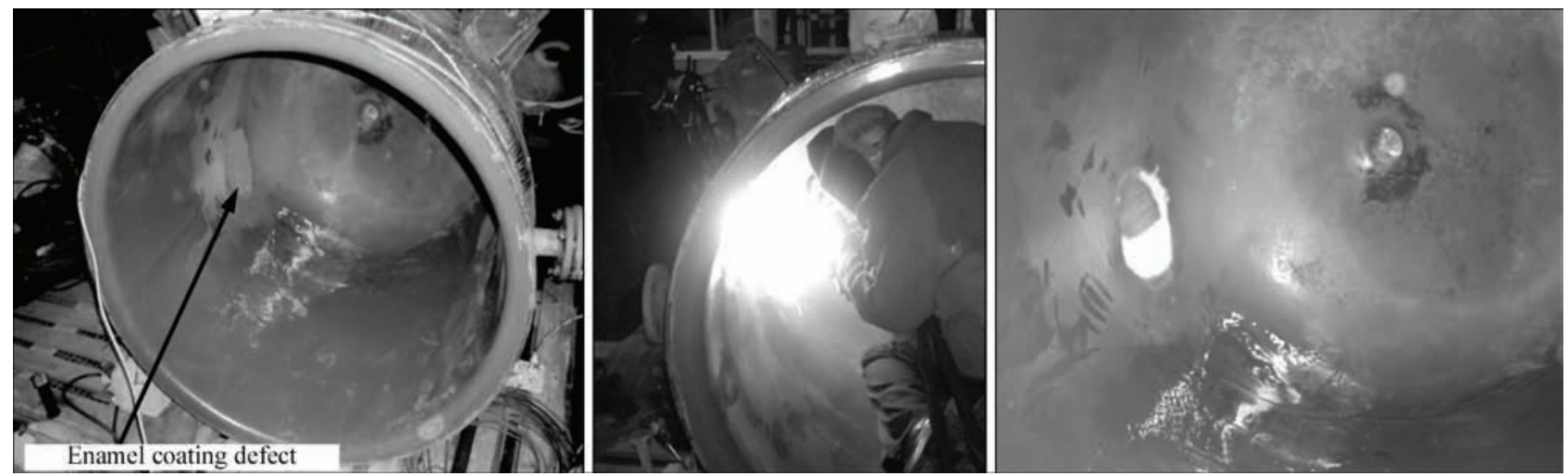

Figure 6. Process of restoration of local damages of enamel coating of V-630 reactor using microplasma spraying method under production conditions

tion of medical products at CJSC «Kharkovreachim» (Kharkov) (Figure 6).

Currently, the reactor restored using MPS method is under testing.

Further realization of the developed technology will be carried out in cooperation with LLC «Emal-service», the leading enterprise in Ukraine on repair and restoration of enameled equipment.

\section{Conclusions}

1. The requirements were determined to plasma coatings designed for repair of damaged enamel layer, and selection of the spraying materials for such coatings was performed. Tantalum was taken as a sublayer material and zirconium oxide was a base layer material.

2. It is determined that $\mathrm{ZrO}_{2}$-coating with the densest microstructure (porosity 1.2-1.9\%) is formed at increased values of current $I=40-45$ A. The lowest porosity equal $1.2 \%$ is observed in the coating produced using $I=45 \mathrm{~A} ; V_{\mathrm{pg}}=1 \mathrm{l} / \mathrm{min} ; h=160 \mathrm{~mm} ; G_{\mathrm{p}}=$ $=1 \mathrm{~g} /$ min mode.

3. It is shown that application of tantalum-based sublayer allows increasing adhesion strength of zirconium based coating by $25 \%$ (in absolute values from $6.11 \pm 1.32 \mathrm{MPa}$ to $8.14 \pm 2.16 \mathrm{MPa}$ ).

4. Evaluation of through porosity of the coatings by testing the permeability for outdoor environment (water was used as a model medium) was carried out. The method was proposed for increase of coating uniformity by exopy-resin impregnation. Received specimens showed water impermeability.

5. Performed approbation of the developed technology under production conditions showed possibility of application of microplasma spraying technology for repair of local damages of enamel coating including on inner surfaces of reservoirs.

1. (1972) Enameling of metallic products. Ed. by V.V. Vargina. Leningrad: Mashinostroenie.
2. Petzold, A. (1990) Enamel and enameling: Refer. Book. Moscow: Metallurgiya.

3. Lobanov, L.M., Maksimovich, B.I., Neiesa, I.V. (1991) Materials, equipment and technology of deposition of corrosion-resistant coatings on steel metallic structures. In: Strengthening and protection of surfaces by thermal and vacuum deposition: Transact. Kiev, 104-107.

4. Lyublinsky, E.Ya. (1991) Thermal coatings in shipbuilding. Strengthening and protection of surfaces by thermal and vacuum spraying. In: Proc. of $3^{\text {rd }}$ Int. Sci.-Techn. Conf. Kiev, 154-159.

5. Morozov, V.N., Narkevich, N.K., Tretyakova, I.A. et al. (1993) Method of repair of damaged glass-enamel coatings. USSR author's cert. 1813796. Int. Cl. C 23 D 13/02.

6. Kudinov, V.V., Ivanov, V.M. (1981) Plasma deposition of refractory coatings. Moscow: Mashinostroenie.

7. Berzynsh, I.A., Zelenkevich, O.A., Zozulya, A.I. et al. (1980) Application of plasma spraying in repair of enameled equipment at SPA Biokhimreaktiv. Teoriya i Praktika Gazotermicheskogo Naneseniya Pokrytij, 2, 118-120.

8. Kupriyanov, I.L., Korotkina, M.G., Verstak, A.A. (1983) Study of protective properties of composite coatings for agricultural machine parts. In: Abstr. of Pap. of Sci.-Techn. Conf. on New Corrosion-Resistant Metallic Alloys, Nonmetallic and Composite Materials and Coatings. Kiev, 45-46.

9. Byoungchul Hwang, Ahn Jeehoon, Lee Sunghak (2002) Correlation of microstructure and wear resistance of ferrous coatings fabricated by atmospheric plasma spraying. Metall. and Mater. Transact. A, 33(9), 2933-2945.

10. Kolotyrkin, V.I., Knyazheva, V.M. (1991) Possibilities of high-energy treatment methods of metals surface for corrosion protection. Zashchita Metallov, 27(2), 179-196.

11. Safonova, A.A., Kramarenko, D.M., Eseleva, L.I. (1985) Application of metallized-polymer coatings for corrosion protection of metallic structures of equipment in domestic and foreign practice. Moscow: Mintsvetmet SSSR.

12. Verenkova, E.M., Trofimov, M.G., Frolov, A.S. et al. (1966) Heat-resistant electrically insulating ceramic materials and coatings. In: Proc. of $3^{\text {rd }}$ Sem. on Temperature-Resistant Protective Coatings, Leningrad, 215-222.

13. Reutovich, S.S., Shilova, O.A., Khamova, T.V. et al. (2001) Producing of protective heat-resistant material by method of electric arc plasma spraying using glass-ceramic powder materials. In: Temperature-resistant functional coatings: Book, 219-222.

14. Borisov, Yu., Borisova, A., Pereverzev, Yu. et al. (1997) Microplasma spraying. In: Proc. of the $5^{\text {th }}$ Europ. Conf. on Advanced Materials and Processes, Netherlands.

15. Borisov, Yu.S., Borisova, A.L. (1986) Plasma powder coatings. Kiev: Tekhnika.

Received 23.03.2017 


\title{
APPLICATION OF ADJUSTABLE ELECTRIC DRIVES WITH BRUSHLESS ELECTRIC MOTORS IN ARC WELDING
}

\author{
V.A. LEBEDEV ${ }^{1}$, G.V. ZHUK ${ }^{1}$ and I.V. LENDEL ${ }^{2}$ \\ ${ }^{1}$ Experimental Design-Technological Bureau of the E.O. Paton Electric \\ Welding Institute, NASU \\ 15 Kazimir Malevich Str., 03680, Kiev, Ukraine. E-mail: dktbpaton@gmail.com \\ ${ }^{2}$ E.O. Paton Electric Welding Institute, NASU \\ 11 Kazimir Malevich Str., 03680, Kiev, Ukraine. E-mail: office@paton.kiev.ua
}

\begin{abstract}
The paper deals with the possibility of application of electric drives with step and valve motors in welding equipment. Examples of performed developments of mechanized and automatic welding-surfacing equipment for various purposes are used to demonstrate the advantages of application of brushless motors as a set with computerized systems of control and regulation in different units to perform diverse technological functions. Effectiveness of application of step and valve electric drives for modulated and pulsed feed of electrode wire is particularly emphasized. Goods prospects for development of equipment with application of electric drives with step and valve electric motors are noted. 11 Ref., 8 Figures.
\end{abstract}

Ke ywords : arc welding-surfacing, mechanized equipment, control, electric drive, brushless electric motors

Constantly coming new tasks, set by industry for welding fabrication, require continuous attention of developers and designers to improvement of mechanized equipment for arc processes of welding and surfacing. Spheres of equipment application with the need for conducting the processes in different positions in space, different media and conditions, are expanding [1]. Prevalence of such equipment predetermines the high degree of economic effectiveness while obtaining new technical and technological advantages. In many cases new results can be achieved by upgrading mechanized equipment, its systems and realizing new technological processes on this base.

The objective of this work was assessment of the possibilities of obtaining effective results in welding-surfacing with application of a new generation of adjustable electric drives with electric motors of brushless type in different systems of mechanized and automatic equipment. Until recently, predominantly electric drives with brushless DC motors, and in small quantities also asynchronous three-phase electric motors, were used in systems of mechanized and automatic equipment for arc welding-surfacing.

The limit of possibilities of the influence of electric drives with commutator motors on the technological process, is realization on their base of modulated operation modes at feeding electrode wires with up to $2.0-2.5 \mathrm{~Hz}$ frequencies [2] and welding tool oscillations in the same range. All this is due to inertia properties of electric motors and respective motion converters. It is practically impossible to implement (c) V.A. LEBEDEV, G.V. ZHUK and I.V. LENDEL, 2017 controllable electrode metal transfer, using a feeding system with commutator motors without additional mechanical motion converters, as it requires ensuring the frequency of pulsed movement of electrode wire in the controlled mode in the range of $10-60 \mathrm{~Hz}$. No significant improvement of dynamic characteristics of such electric drives can be achieved even with very perfect systems of regulation. A significant disadvantage of application of such electric drives is presence of a commutator that considerably reduces equipment reliability characteristics (electric erosion, mechanical wear). This particularly acutely affects the design and performance of semi-automatic machines for wet underwater welding, where commutator assembly of electric motor operates in the liquid medium.

Three-phase asynchronous electric motors with modern systems of frequency control and regulation of different types having ample capabilities, are highly attractive for application in welding equipment. This can refer to systems of movement of welding tool, item being welded or surfaced. However, in electrode wire feeding system of mechanized equipment (semi-automatic machines for welding and surfacing), application of three-phase asynchronous electric motors $(380 \mathrm{~V})$ is practically impossible, because of the level of supply voltage. Our efforts to find the considered electric drives with safe power level on voltage failed, as there are certain difficulties in their development.

Proceeding from the above-said, comparative testing was used to search for the most effective electric drives, in order to apply them in mechanized and au- 


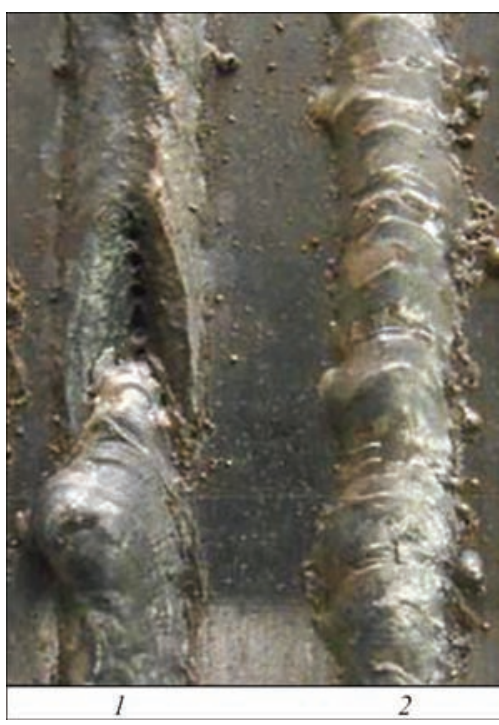

Figure 1. Appearance of deposited beads: 1 - regular wire feed; 2 - modulated feed

tomatic equipment for consumable electrode welding-surfacing, which would correspond to a range of capabilities, namely high values of dynamic characteristics; absence of contact assemblies (commutator assembly); shaft torque ensuring electric motor operation without an additional reducer; small weight and dimensional parameters; low cost and possibility of application for large-scale production in semi-automatic machines for various applications.

Comparative analysis showed that proceeding from the total set of parameters two types of electric drives can be applied, namely those based on step and on valve electric motors.

Let us consider the capabilities of adjustable electric drives with step and valve electric motors in different systems of welding equipment with subsequent assessment of the probability of their application. Here, the problem of reducer elimination should be solved. Actuator of welding equipment mechanism (feed roller) should be mounted directly on the shaft of brushless electric drive of any of the above types.

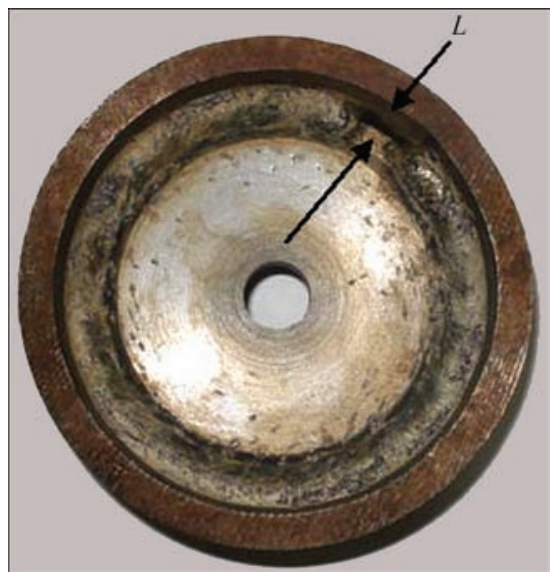

Figure 2. Appearance of pipe cap with welded-in plug: $L$ - real gap between the cap and pipe
Electric drive with step electric motor. As there are no manufacturers of this type of equipment in Ukraine, electric drives with step electric motors were selected as a set (electric motor and controller), batch-produced by a quite large number of companies. To minimize the cost, preference was given to electric motor with the required shaft torque for the respective mechanism of welding equipment, without built-in feedback system.

Electric drive with valve electric motor. In this case special development of Ukrainian experts was used. With the assistance of SC «EDTB of E.O. Paton Electric Welding Institute of NASU» they designed and manufactured an electric drive, where systems of control and regulation with specifically selected properties, have been implemented [3]. This electric drive provides maximum possible speed and minimum distortion of reproduction of the shape of assigned algorithm of electrode wire movement at acceptable weight and dimensional characteristics of both the electric motor, and the control module.

In actual developments of equipment for mechanized welding and surfacing of various objects, also during performance of wet underwater processes, computerized electric drive with bipolar step electric motor of Kinco and Schneider Electric Companies was used. We will give examples of several successful engineering solutions.

There is experience of application of electric drives with step electric motors in underwater automatic welding equipment for solving a number of problems. Electric drive was programmed to implement modulated modes of operation using an algorithm (level and time of pulse and pause) of electrode wire feed, specially selected from the conditions of weld pool solidification. It was also applied to perform welding tool oscillations with controllable parameters and producing a weld with the required characteristics at non-guaranteed gap size. Figure 1 presents the comparative results of bead deposition under water by the wet process. These beads were produced by a semi-automatic machine with step electric motor, on a vertical plane with regular and modulated feed of flux-cored wire of 1.6 mm diameter at 200-220 A current and 25-27 V voltage. Modulation was performed with specially, in this case, experimentally, selected parameters: pulse of $0.7 \mathrm{~s}$, pause of $0.5 \mathrm{~s}$. Note that performance of wet underwater welding or surfacing on a vertical plane is problematic. Application of modulated process allows an essential improvement of weld quality and facilitating the task of welder-diver.

Figure 2 presents the result of application of controllable oscillations of welding tool by step electric 
drive in an automatic machine, designed for deep-sea (more than $200 \mathrm{~m}$ ) wet underwater welding. Specially developed automatic machine with computerized control shown as a fragment in Figure 3 provided quality solution of the problem of welding caps to a pipe of small inner diameter [4] with the gap between pipe wall and plug in the range of $2-5 \mathrm{~mm}$, at currents of 180-200 A and voltage of 24-26 V.

Note that in the described units, electric motors without built-in systems of formation and transmission of signals of feedback by motor rotor position were applied, in order to avoid the influence of interference on operation of computerized electric drive.

It should be specially mentioned that when certain conditions are satisfied, step electric motors are capable of long-term operation in the medium of isolating, lubricating liquids of semi-automatic machines for wet underwater welding.

Semi-automatic machines with application of step electric motors are manufactured in small batches and used for welding and cutting in water facilities in fresh and sea water.

In our opinion, promising is the use of computerized electric drives to generate controllable oscillations of items being surfaced, in order to widen the surfacing zone, as well as ensure a favourable structure of deposited bead metal [5].

Highly attractive is the task of providing controllable pulsed movement of electrode wire with up to $50-60 \mathrm{~Hz}$ frequencies for solving a range of technical and technological problems, the results of which are given, for instance in [6].

Application of step electric motors for pulsed feed of electrode wire is described in [7]. It gives the results of experimental study of the technology of automatic submerged-arc welding of structural steel with application of the mechanism of electrode wire feed, based on step motor. Influence of parameters of pulsed wire feed mode on the process of drop formation at the electrode tip, deposition rate and deposited bead geometry, is noted. Strictly speaking, the produced rather good result is not the consequence of desired controlled pulsed feed. It is based on the impact on electrode metal drop of a packet of feed pulses generated by step electric motor, which is indicated by oscillograms characteristic for this process (Figure 4). We can state that the obtained process is a certain variant of transition from modulation to pulsed feed of electrode wire.

Experimenting with different types of step electric motors produced in series and having built-in regulators of rotation frequency, with comprehensive approach to weight and dimensional characteristics, traction capabilities, frequency properties, so far has

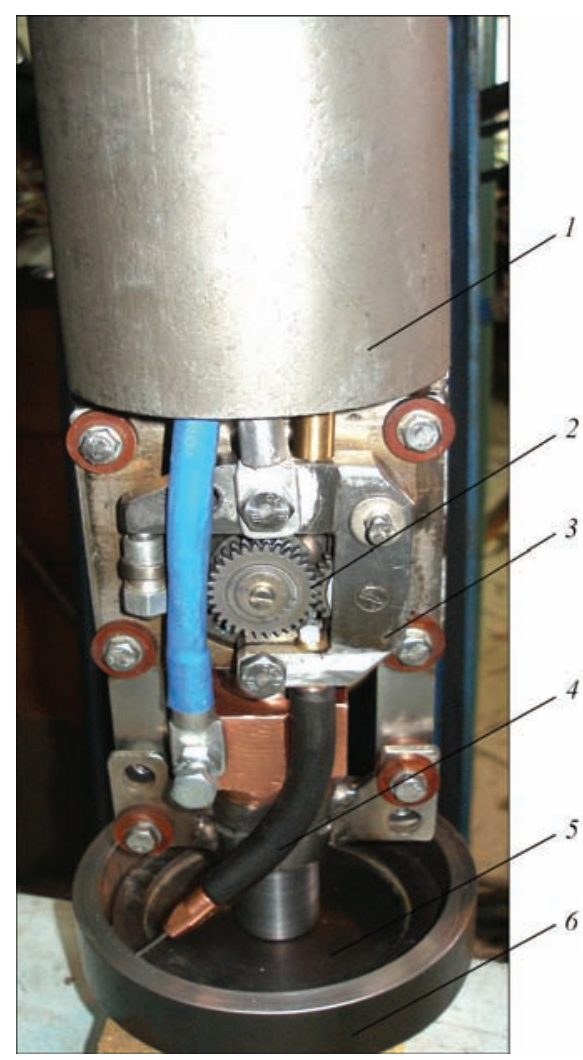

Figure 3. Welding assembly of the apparatus for deep-sea welding: 1 - body; 2 - feed mechanism; 3 - oscillation mechanism; 4 - welding torch; 5 - plug; 6 - pipe fragment

not led to selection of an optimum variant to achieve controllable pulsed feed of electrode wire. Work in this direction is going on.

The problem of providing controllable pulsed feed of electrode wire can be solved in its entirety now only at application of specially developed computerized electric drive with valve electric motor, having the shaft torque, sufficient for wire feeding even in

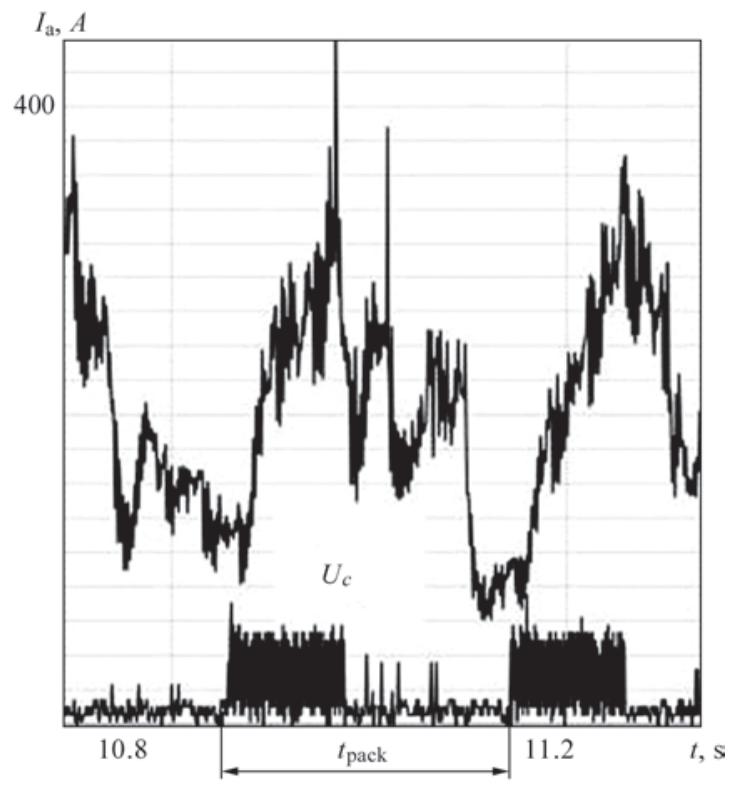

Figure 4. Oscillograms of current and control voltage in step motor in welding by pulse packets $\left(t_{\text {pack }}\right.$ - period of pulse packet action; $U_{c}$ - control voltage) 


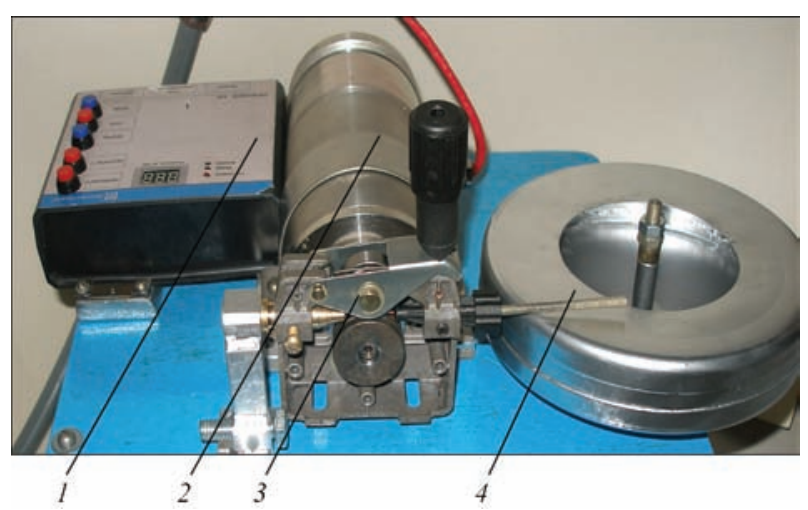

Figure 5. Pulsed feed mechanism based on valve electric drive: 1 - digital control block; 2 - valve motor; 3 - device for pressing press-down roller to feed roller; 4 - wire cassette

the pulsed mode [8]. Figure 5 shows a set of specially developed valve electric drive for welding equipment. Valve type electric motor can be built into feed mechanism of any welding equipment. Weight-dimensional characteristics of this assembly are 1.5-2.9 times lower than in the traditional units. Unlike electric drives with step motors, regulator of such an electric drive is synthesized purposefully to provide maximum speed with minimum overshoot at start and reverse. Oscillogram of speed of electrode wire pulsed movement, provided by the considered type of electric drive, in the feeding mode, is shown in Figure 6.

Results of application of electric drive with valve motor are essential improvements of practically all welding-surfacing indices. This pertains to bead formation, penetration, HAZ, weld metal structure and sanitary-hygienic characteristics.

As an illustration, Figure 7 gives macrosections of beads deposited in $\mathrm{CO}_{2}$ at different values of frequencies, amplitudes, relative duration of pulses of feeding Sv-08G2S wire at the same integral values of current and voltage of the process (160 A, $24 \mathrm{~V})$. Essential changes in bead geometry, and penetration depth at the change of controllable parameters of pulsed feed are obvious. Considerable saving of material and energy resources (lowering of electrode metal losses for spattering and power consumed for conducting the process) is achieved.

It is important to note that in this case pulsed feed provided the welding process with controlled short-circuiting.

Valve motor is fitted with an incremental sensor of rotor position, the signal of which is fed into computerized electric drive through channels protected from interference.

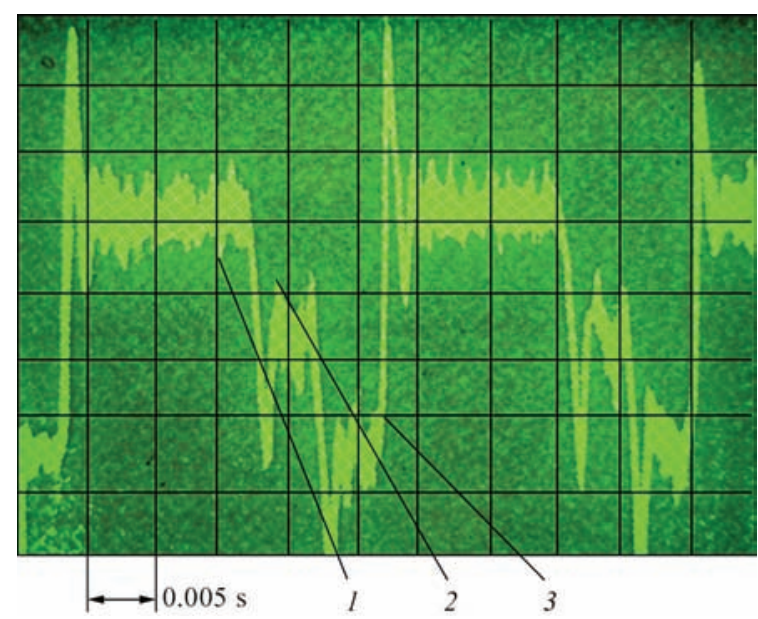

Figure 6. Oscillogram of pulsed feed rate: 1 - pulse; 2 - pause; 3 - reverse

Valve electric drive for welding equipment has the capability of introducing various feedback signals by arc process parameters that both significantly expands the functional capabilities of the unit, and simplifies setting up pulsed feed parameters.

By entering and processing the results of experimental studies using oscillograms, it was found that change of the step of displacement in the pulse in keeping with the following relationship, will be the most effective for changing the integral speed of wire feed:

$$
I_{\mathrm{w}}=k_{1} v_{\mathrm{f}}=k_{1} f_{\mathrm{p}} h,
$$

where $h$ is the feed step in the pulse; $k_{1}$ is the coefficient, determining the dependence between welding current $I_{\mathrm{w}}$ and feed rate $v_{\mathrm{f}} ; f_{\mathrm{p}}$ is the frequency of pulsed feed.

This is exactly the step change that was accepted in realization of dependence $U_{w}=f\left(I_{w}\right)$, and parameter $U_{w}$ is taken as feedback signal. This engineering solution, essentially, is one of the kinds of synergetic control of arc welding process by analogy with pulsed arc power sources with synergetic control [9], but already based on algorithms of pulsed electrode wire feed [10].

A new welding process is being developed now, based on application of valve electric drive. This process with electrode wire feed dosed by arc process parameters is realized both with short-circuiting and without it. The method allows conducting welding-surfacing process with flux-cored self-shielded and gas-shielded electrode wires with controlled transfer of electrode metal drops.

The problem of providing the welding process with simultaneous use of pulsed algorithms of func-

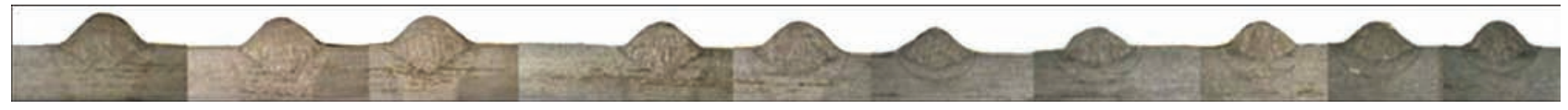

Figure 7. Microsections of deposited beads at pulsed feed of electrode wire 
tioning of welding current sources and mechanism with pulsed feed of electrode wire remains urgent.

Such electric drives are applied to ensure other movements of welding tool. Automatic welding-surfacing machine shown in Figure 8, is an example of application of valve electric drive with provision of two-axis displacement of the support with the welding tool and electrode wire feed mechanism. Such an automatic machine can perform programmable displacements in the horizontal or vertical plane by signals of built-in incremental sensors [11].

\section{Conclusions}

1. Experience of application of valve and step electric drives in welding equipment gives an indication of their high efficiency and rationality of wide application in mechanized and automatic welding equipment. Continuous work should be performed on its improvement as regards design and control system, with the purpose of their simplification, reducing their cost, and further improvement of their reliability, for instance, in operation with long lines of signal transmission.

2. The most effective application of electric drives with brushless motors are electrode wire feed mechanisms, where quite significant results have been achieved as regards bead formation, penetration, HAZ, solving energy- and resources-saving problems.

3. Application of electric drives based on valve and step electric motors enables automation of welding operations, in particular, under the water at $200 \mathrm{~m}$ and greater depth.

4. Results achieved in application of step and valve electric drives in welding equipment, are the base for further efforts on improvement of equipment and technology for mechanized and automatic arc welding.

1. Paton, B.E. (2008) Selected works. Kiev: PWI.

2. Kuznetsov, V.D., Skachkov, I.O., Krasnoshapka, V.V. (1993) Application of direct current drive for pulse filler wire feed. Avtomatich. Svarka, 9, 53-54.

3. Lebedev, V., Rymsha, V., Lendel, I. (2014) BLDC electric drive in the mechanism of pulse feed of electrode wire. The $J$. Electromechanic and Computer Syst., 92(16), 26-31.

4. Maksimov, S.Yu., Lebedev, V.A., Lendel, I.V. (2013) Sealing of heat exchangers pipes using «wet» welding at the depth of 200 m. Voprosy Materialovedeniya, 1, 199-204.

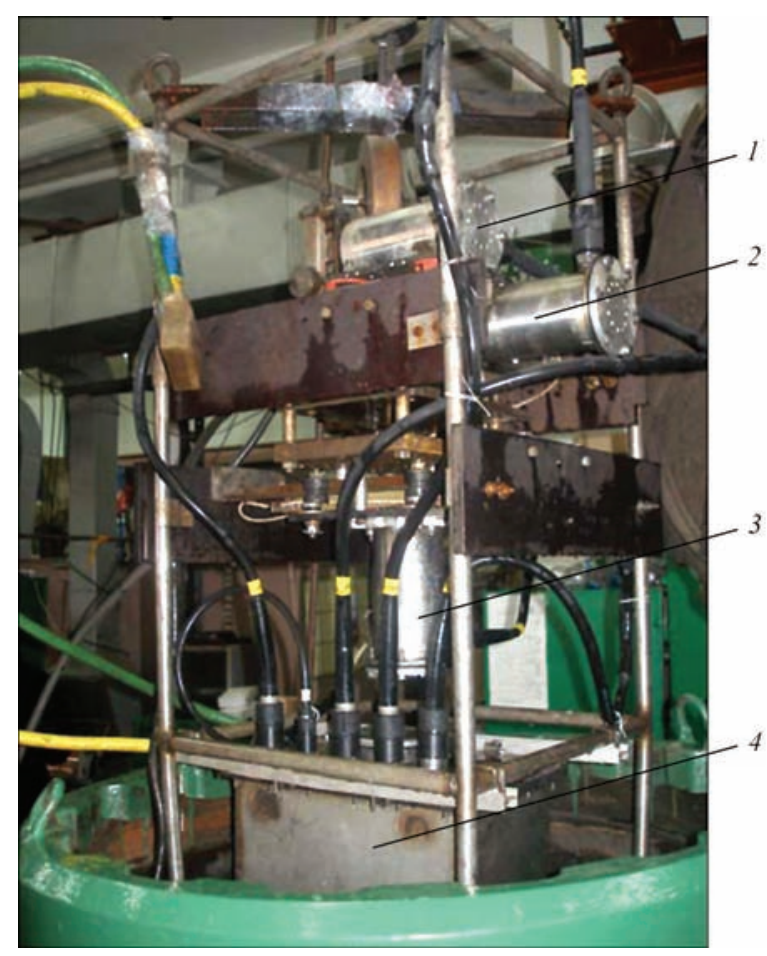

Figure 8. Automatic machine for welding-surfacing under the water with electric motors of mechanisms of: 1 - longitudinal; 2 - transverse displacement; 3 - electrode wire feed; 4 - immersible control block

5. Lebedev, V.O., Maksimov, S.Yu., Lendel, I.V. Universal manipulator with possibility of low-frequency vibratory processing of weld pool. Utility model pat. 80823, Ukraine. Int. Cl. 20113.01 B 23 K 13/00.

6. Lebedev, V., Reisgen, U., Lendel, I. (2016) Study of technological opportunities of GMA welding and surfacing with pulse electrode wire feed. Welding in the World, February, 9.

7. Levedev, V.A., Dragan, S.V., Trunin, K.K. (2016) Automatic submerged-arc welding with pulse electrode wire feed by step motor. Svarochn. Proizvodstvo, 2, 27-34.

8. Lebedev, V.A., Guly, M.V. (2014) High-speed valve electric drive for mechanized arc welding equipment. Mekhatronika. Avtomatizatsiya. Upravlenie, 6, 47-51.

9. Voropaj, N.M., Ilyushenko, V.M., Lankin, Yu.N. (1999) Peculiarities of pulsed arc welding with synergic control of mode parameters (Review). Avtomatich. Svarka, 6, 25-32.

10. Lebedev, V.A. (2016) Mechanized synergic welding with pulse electrode wire feed. Naukoyomkie Tekhnologii v Mashinostroenii, 2, 19-24.

11. Lebedev, V.A., Maksimov, S.Yu. (2015) New generation mechanized equipment for wet underwater welding and cutting of metal structures. Montazhnye i Spets. Raboty v Stroitelstve, 10, 30-32. 


\title{
ARC SURFACING OF LAYERS OF METAL OF VARYING COMPOSITION AND HARDNESS
}

\author{
V.V. PEREMITKO and A.I. PANFILOV \\ Dnieper State Technical University \\ 2 Dneprostroyevskaya, 51918, Kamenskoye, Ukraine. E-mail: welding@dstu.dp.ua
}

\begin{abstract}
In arc surfacing over the layer of alloying charge, the conditions for producing layers with varying composition and structure in the zones of separate beads were determined. On the deposited surface the carbon-containing fibres were preliminarily deposited in bands, the width and distance between which were selected from the conditions of positioning the end of the electrode with displacement relative to the edge of the bands. To fix the fibres, a primer was used, into which the iron powder and aerosol $\mathrm{SiO}_{2}$ were added. During the experiments a number of deposited layers, the eccentricity in the arrangement of bands relative to the axis of electrode wire, as well as the induction of external magnetic field were varied. The difference in hardness of the metal across the width of the deposited beads (up to HRC 9-12) and the successively deposited layers (up to HRC 15-25) was established. The hardness reaches its maximum values at the eccentricity $c=4 \mathrm{~mm}$ and induction $B=40-80 \mathrm{mT}$ and also at $c=10-12 \mathrm{~mm}$ and $B$ up to $40 \mathrm{mT}$. The increase in hardness is observed with increase in the amount of deposited layers. The metallographic analysis recorded an increase in the fraction of hardening structures (in the form of acicular bainite and martensite) from 15-22 to 25-35\% in the second layer and more than $50 \%$ in the third one 13 Ref., 1 Table, 10 Figures.
\end{abstract}

Ke y word s : arc surfacing over alloying charge, deposited metal, hardness, microstructure of deposited metal, controlling magnetic field, carbon-containing fibre

It is known that the wear of many parts of machines and mechanisms in the process of operation bears a selective character [1-4]. Nevertheless, as a rule,

when such parts are restored applying the methods of surfacing, the selective character of wearing their surfaces is not taken into account [5-7]. The positive

(1)
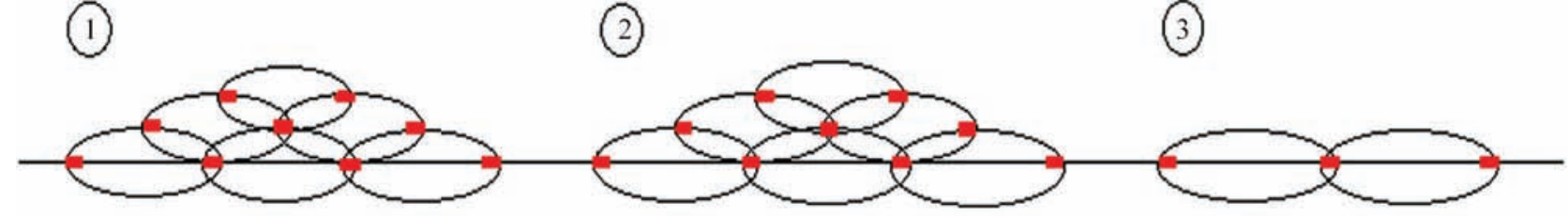

(4)

(5)

(6)

(7)

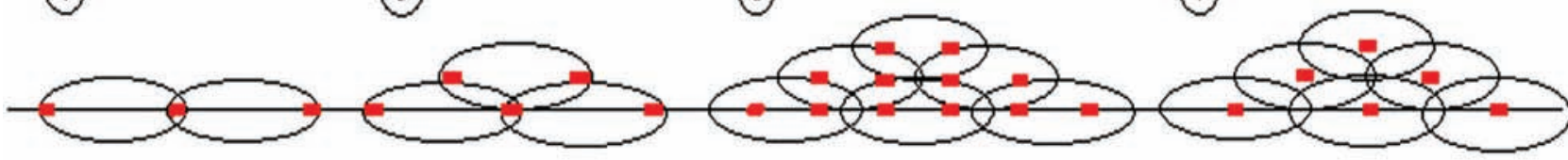

(8)

(9)

(10)

(11)

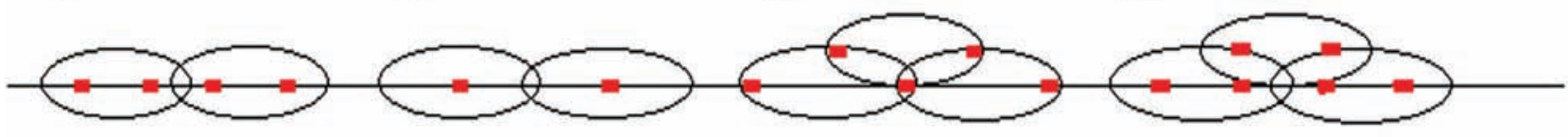

(12)

(13)

(14)

(15)

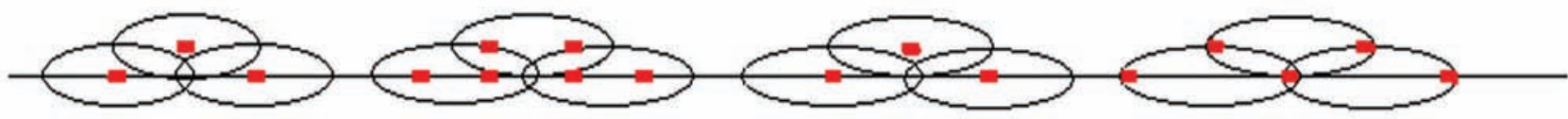

Figure 1. Scheme of arrangement of carbon-containing fibres on all specimens (1-15) with the specified eccentricity (locations of fibres arrangement are indicated by dots) 

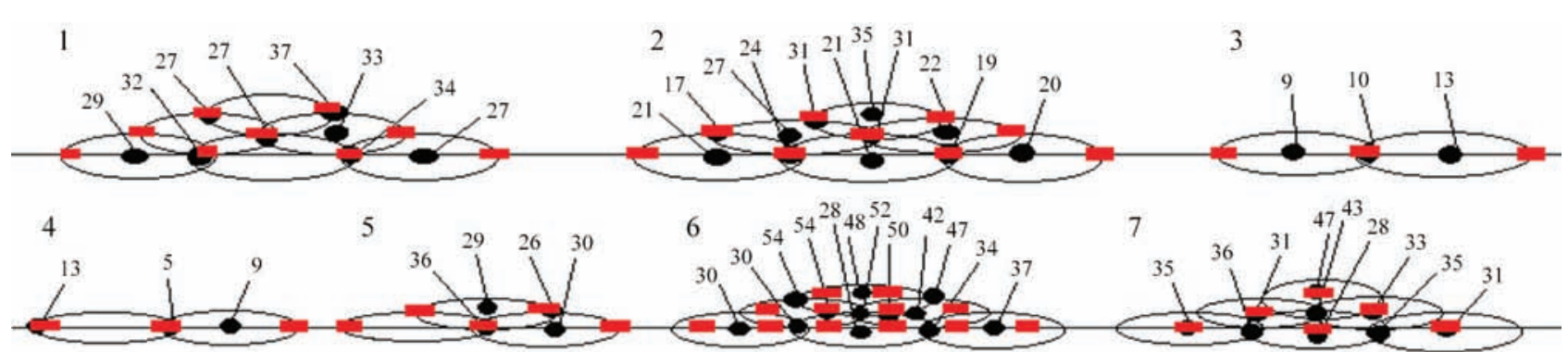

8

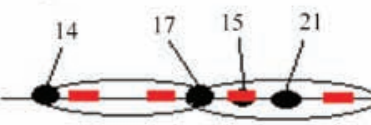

12

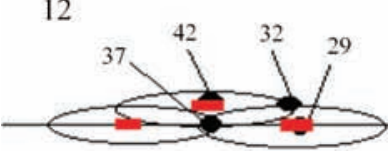

9

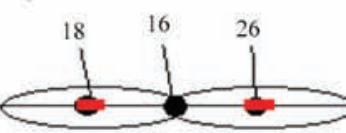

13

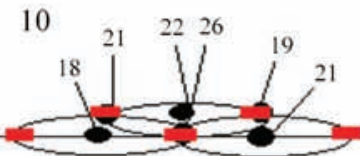

14
11

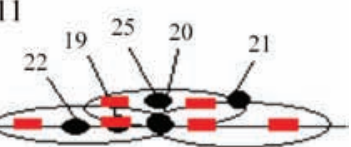

15

Figure 2. Hardness HRC in the zones of deposited beads (measuring places are indicated with dots, description of grey and black dots see in the text)

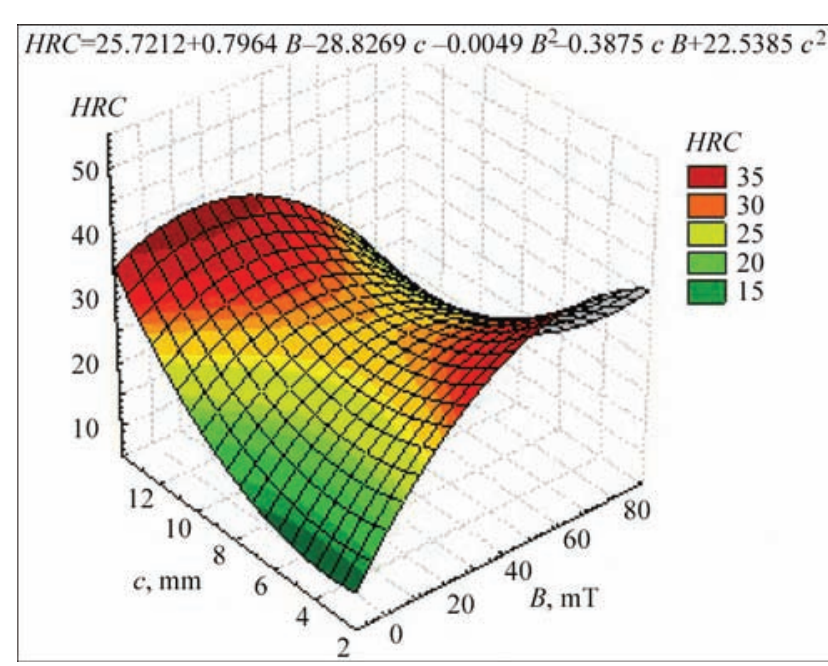

Figure 3. Dependence of hardness $H R C$ of the deposited metal on the value of magnetic induction $B$ and eccentricity $c$

experience of some researchers [8-11] on producing deposited layers with properties varying in depth and in zones of the surface, give grounds to consider this

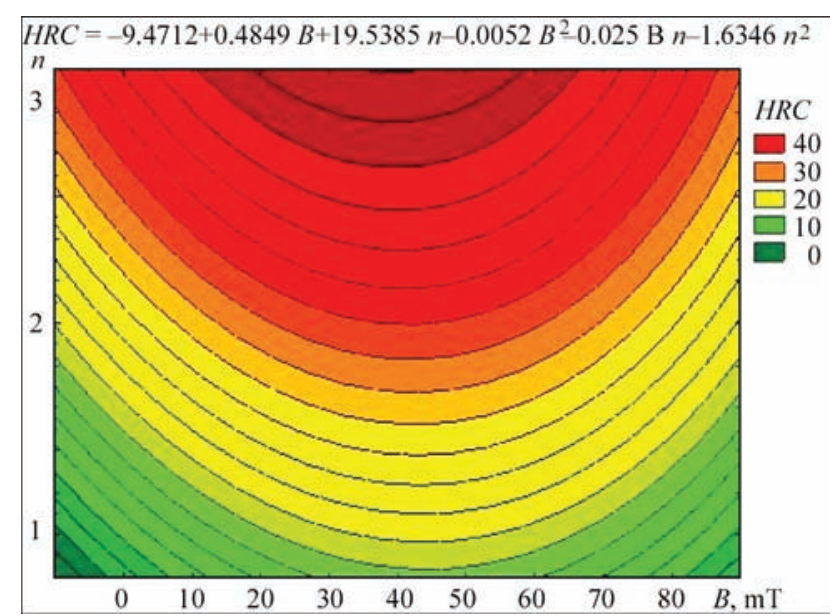

Figure 4. Dependence of hardness $H R C$ of the deposited metal on the number $n$ of deposited layers and magnetic induction $B$
Experiment matrix

\begin{tabular}{|c|c|c|c|}
\hline $\begin{array}{c}\text { Specimen } \\
\text { number }\end{array}$ & $\begin{array}{c}\text { Number } \\
\text { of layers } n\end{array}$ & $\begin{array}{c}\text { Magnetic } \\
\text { induction } B, \mathrm{mT}\end{array}$ & $\begin{array}{c}\text { Eccentricity } \\
c, \mathrm{~mm}\end{array}$ \\
\hline 1 & 3 & 80 & 8 \\
\hline 2 & 3 & 0 & 8 \\
\hline 3 & 1 & 80 & 8 \\
\hline 4 & 1 & 0 & 8 \\
\hline 5 & 2 & 40 & 8 \\
\hline 6 & 3 & 40 & 4 \\
\hline 7 & 3 & 40 & 0 \\
\hline 8 & 1 & 40 & 4 \\
\hline 9 & 1 & 40 & 0 \\
\hline 10 & 2 & 40 & 8 \\
\hline 11 & 2 & 80 & 4 \\
\hline 12 & 2 & 80 & 0 \\
\hline 13 & 2 & 0 & 4 \\
\hline 14 & 2 & 0 & 0 \\
\hline 15 & 2 & 40 & 8 \\
\hline
\end{tabular}

experience as a promising way for improvement of serviceability of contact friction pairs during their restoration.

In this work the task was put to deposit metal with varying composition and structure in the zones of separate beads, separate layers and in the places of overlapping the neighboring beads and layers applying arc surfacing.

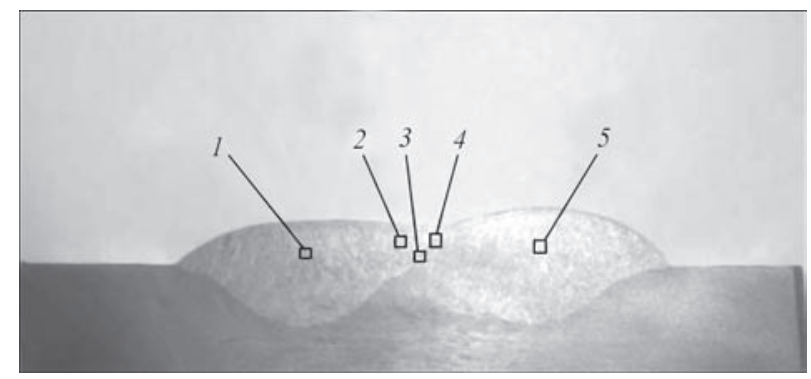

Figure 5. Specimen No.5 (surfacing with external magnetic field $B=40 \mathrm{mT}$, eccentricity $c=8 \mathrm{~mm}$ ); $1-5-$ investigated points 

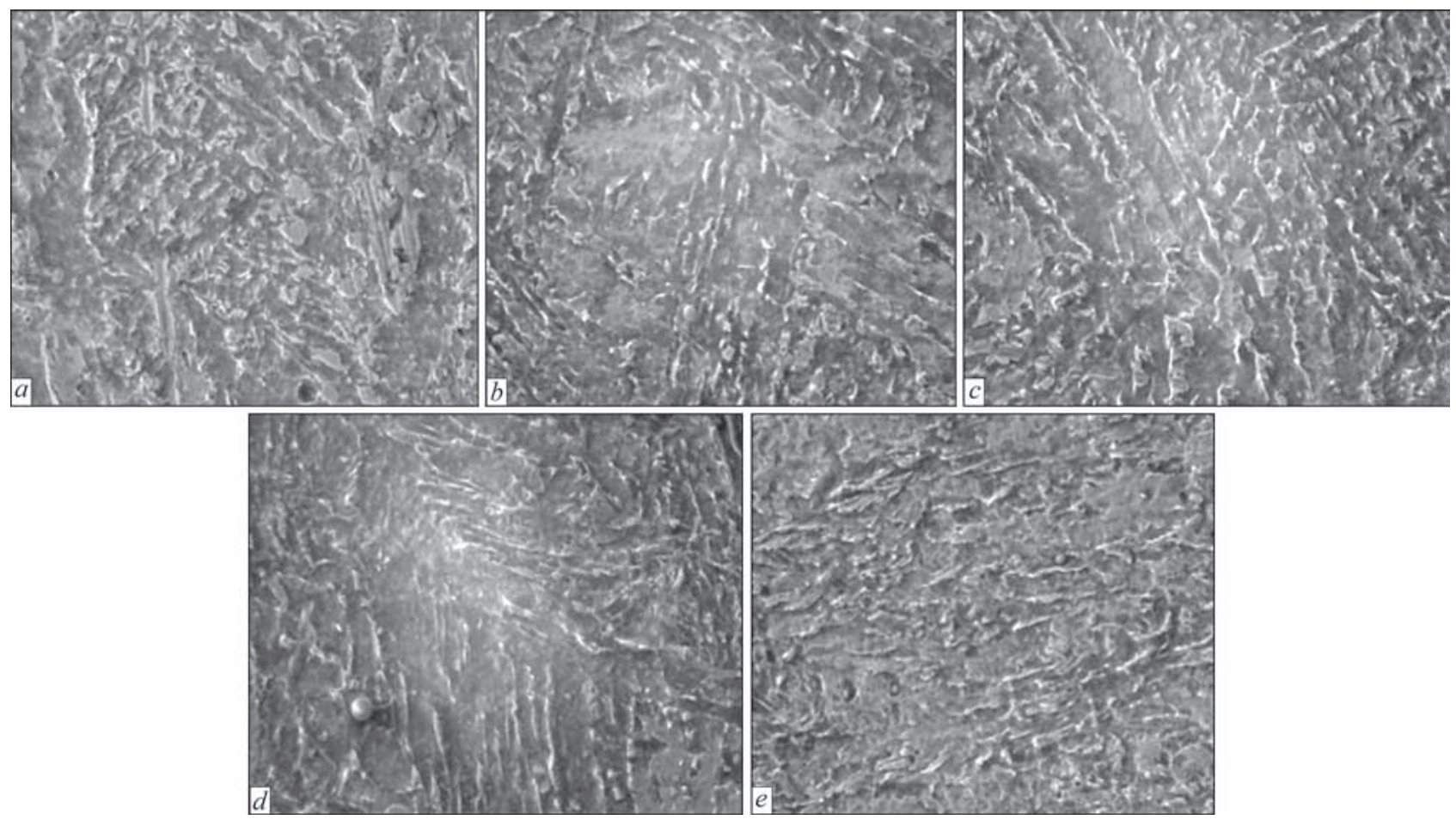

Figure 6. Microstructure $(\times 400)$ of the deposited metal of specimen No.5: $a-e$ - points $1-5$ according to Figure 5, respectively

In the experiments the method of arc surfacing over the layer of alloying charge was used, which, under certain conditions, provides an effective preservation of materials, additionally introduced into the surfacing pool, from their complete dissolution [12, 13].

The carbon-containing fibres ( $\mathrm{T}$ 700SC Torey) were preliminarily applied on the deposited surface in bands, the width $a$ and the distance $b$ between which were selected from the condition of positioning the electrode wire end with displacement $c$ relatively to the edge of the mentioned bands (Figure 1). As a material fixing the arrangement of carbon-containing fibres, a primer was used, to which iron powder (15-25 wt.\%) and aerosil (0.3-0.6 wt.\%) were added. The values of the parameters $a, b$ and $c$ were also selected from the condition of formation of beads with overlapping.

In the experiments, the automatic welding machine of the type ADS-1000 and the universal rectifier VDU-506, as a power source, were used.

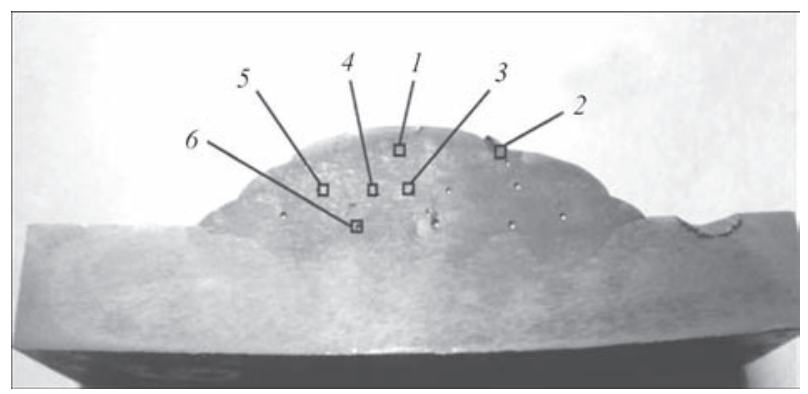

Figure 7. Specimen No.6 (surfacing with external magnetic field $B=40 \mathrm{mT}$, eccentricity $c=4 \mathrm{~mm}) ; 1-6$ - investigated points
The surfacing was performed on the specimens of flat shape of steel 20 under the flux AN-348A using the wire Sv-08A of $3 \mathrm{~mm}$ diameter. The surfacing mode was the following: current - 400-420 A, voltage - 32-36 V, wire feed speed - $160 \mathrm{~m} / \mathrm{h}$, surfacing speed $-12-16 \mathrm{~m} / \mathrm{h}$, surfacing pitch $-6-8 \mathrm{~mm}$, the current is direct of reverse polarity.

To control the crystallization of bead metal, the longitudinal magnetic field was used [12]. The coil, which provided axial magnetic field, was attached to the torch nozzle through the layer of electrical insulation. To measure the hardness, the specimens of $15 \mathrm{~mm}$ thickness were cut from the deposited semi-products in the meter TK-2.

To reduce the number of experiments, a central non-compositional planning of the second order was performed for three factors: eccentricity in arrangement of the electrode wire relative to the edge of the bands of previously applied additional components (from 0 to half of the bead width, about $6 \mathrm{~mm}$ ); number of layers of deposited metal (up to three); induction of external magnetic field (from 0 to $80 \mathrm{mT}$ ) (Table).

Figure 2 shows the results of measurements of hardness in the places of preliminary fixation of additional components (grey), as well as in the places of additional measurements (black dots).

The difference in the metal hardness across the width of deposited layers should contribute to increasing the wear resistance due to formation of periodic waviness of the contacting surfaces and, as a result, to reducing their slipping, for example, in case of rotational working travel of the parts. 

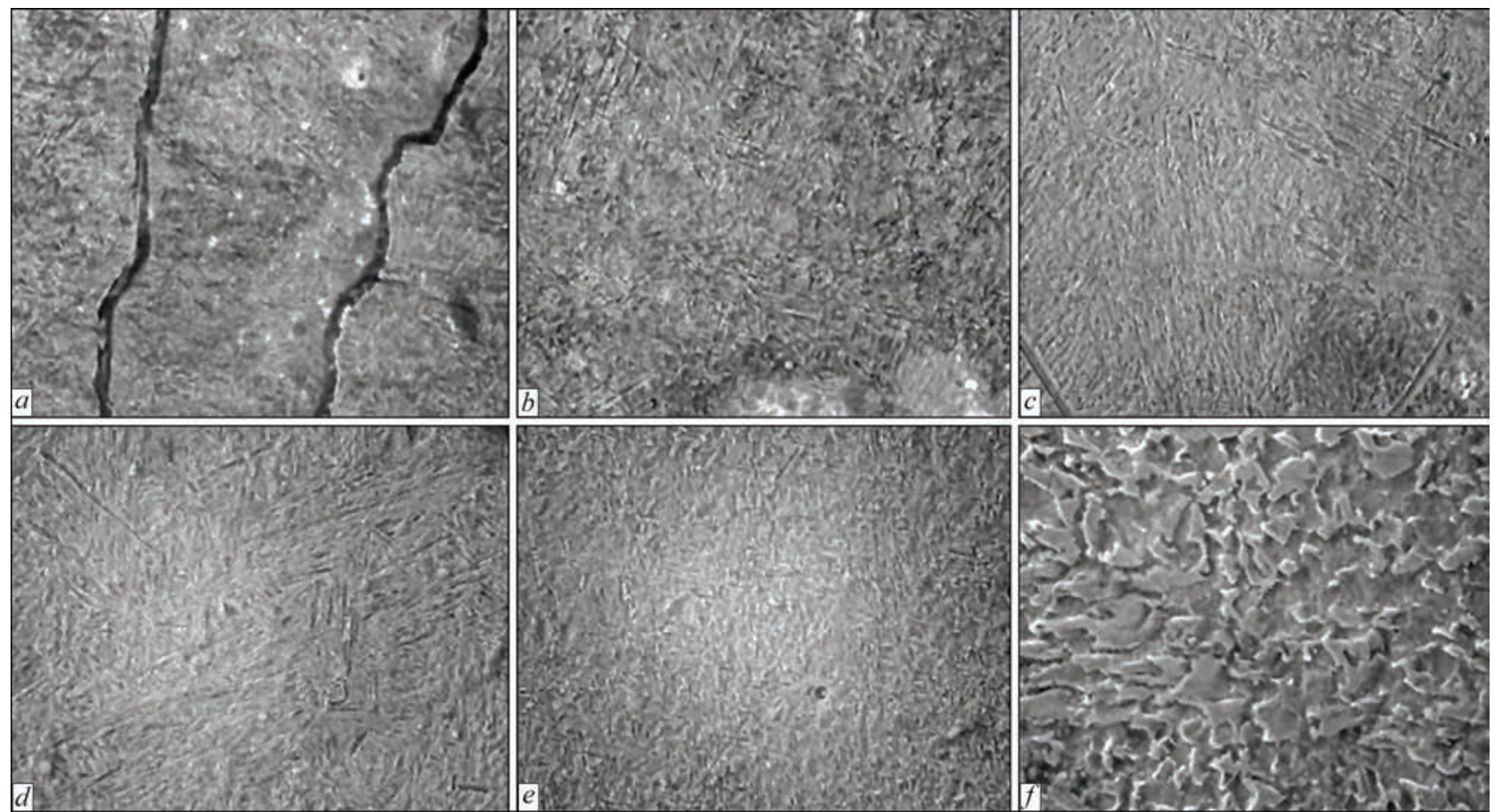

Figure 8. Microstructure $(\times 400)$ of the deposited metal of specimen No.6: $a-f$ - points $1-6$ according to Figure 7 respectively

The processing of experimental data was carried out with the help of the program StatSoftStatistica 6.0. The obtained dependencies between the surfacing parameters are shown in Figures 3, 4.

As is seen from Figure 3, the hardness reaches the maximum values at arrangement of carbon-containing fibre with the eccentricity of $4 \mathrm{~mm}$ and the magnetic induction of $40-80 \mathrm{mT}$, as well as with the eccentricity of 10-12 $\mathrm{mm}$ and magnetic induction of up to $40 \mathrm{mT}$.

The maximum hardness is observed in the case of three-layer surfacing at the induction values of external magnetic field of $40 \mathrm{mT}$ (Figure 4).

The microstructure of deposited metal was examined in the scanning electron microscope REM-106I-Selmi.

Illustrative are the results of metallographic examination of the specimen No.5 (Table; Figures 5, 6), which was deposited with the fixation of carbon-containing material and application of external magnetic field.

The analysis of microstructure of the specimen No.5 shows that throughout the entire cross-section

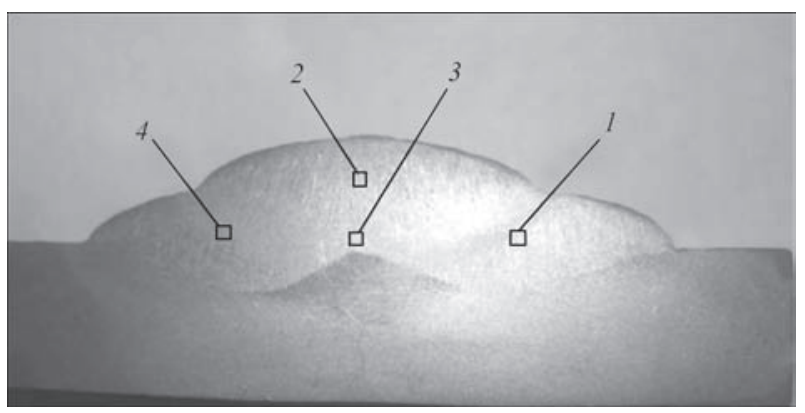

Figure 9. Specimen No.14 (surfacing without applying magnetic field, eccentricity $c=0 \mathrm{~mm}$ ) of deposited beads the grain refinement is observed, which is the result of the effect of external magnetic field. In the places of overlapping the beads (correspond to the places of location of carbon-containing material), a significant increase in the fraction of hardened phases is recorded, a number of which is 25-40\%. The hardness drop for these zones reaches HRC 20.

On the specimen No.6 (Table; Figures 7, 8), produced according to the scheme of three-layer surfacing, the appearance of cracks was noted, which are a consequence of increasing the residual stresses and growth of carbon content not only in the zones of separate beads, but also across the layers of deposited metal.

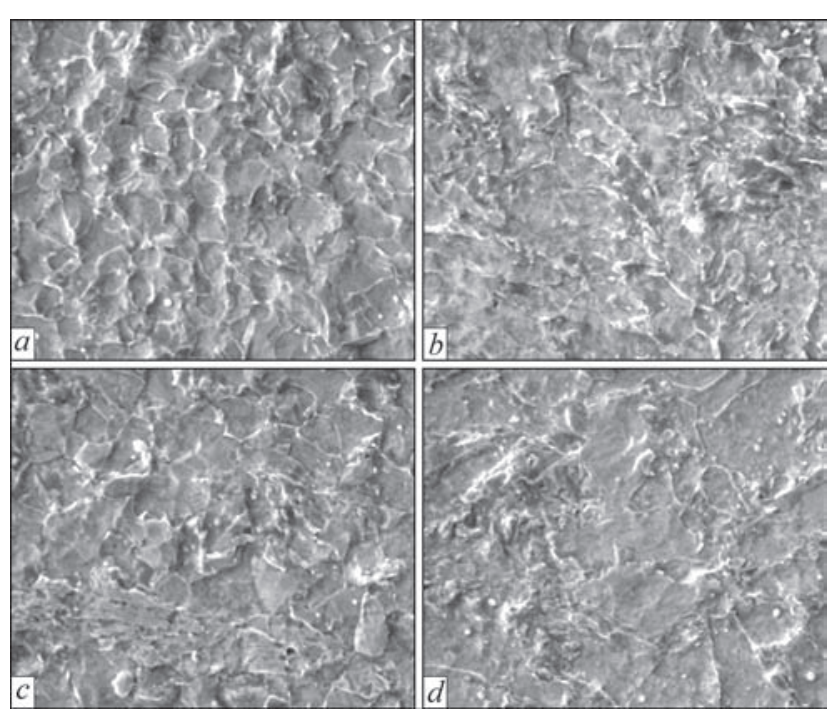

Figure 10. Microstructure $(\times 600)$ of the deposited metal of specimen No.14: $a-d$ - points 1-4 according to Figure 9 
In particular, in the microstructure of the third layer of the deposited metal (Figure 7, point 1), the fraction of martensite is maximal and exceeds $50 \%$. In the microstructure of the deposited metal in the place of overlapping the second and the third layers (Figure 7, point 2), an increased content of hardening structure in the form of acicular martensite is also observed. In the deposited metal of the second layer (points 3 and 4), the structure is also hardening and consists of bainite and martensite.

Figure 9 shows macrosection of the specimen No. 14 , indicating the places in which the microstructure of deposited metal was investigated (Figure 10). The surfacing of this specimen was performed without using of magnetic field and with zero eccentricity.

In this case, the difference in the grain number in the selected points is almost absent. The values of hardness differ insignificantly. Obviously, a uniform distribution of introduced materials over the volume of beads with equalization of carbon content occurs.

\section{Conclusions}

1. The possibility of producing layers of deposited metal with varying structure and properties in arc surfacing along the charge preliminary applied to the deposited surface and the action of external magnetic field was experimentally confirmed.

2. In case of preliminary application of carbon-containing material on the deposited surface, an increase in the concentration of carbon from layer to layer was revealed. This is confirmed by increase in the fraction of hardening structures in the deposited metal, which increases from $15-22$ to $25-35 \%$ in the second layer and to more than $50 \%$ in the third one.
The hardening structures are represented by acicular bainite and martensite.

3. The dependences for predicting hardness of the metal deposited during preliminary application on the surface were obtained applying separate bands of carbon-containing and modified materials.

1. Garkunov, D.N. (1989) Tribo-engineering. Moscow: Mashinostroenie.

2. Kostetsky, B.I. (1975) Reliability and service life of machines. Kiev: Tekhnika.

3. Kragelsky, I.V., Dobychin, M.N., Kombalov, V.S. (1977) Calculation principles on friction and wear. Moscow: Mashinostroenie.

4. Vlasov, V.M. (1987) Working capacity of strengthened rubbing surfaces. Moscow: Mashinostroenie.

5. Frumin, I.I. (1961) Automatic electric arc surfacing. Kharkov: Metallurgizdat.

6. Tylkin, M.A. (1971) Improvement of life of metallurgical equipment parts. Moscow: Metallurgiya.

7. Ryabtsev, I.A., Kondratiev, I.A. (1999) Mechanized electric arc surfacing of metallurgical equipment parts. Kiev: Ekotekhnologiya.

8. Leshchinsky, L.K., Gulakov, S.V., Stepnov, K.K. et al. (1985) New design rolls with deposited layer increase operating efficiency of mills. In: Surfacing. Experience and efficiency of application. Kiev: PWI, 17-20.

9. Gulakov, S.V., Golovachev, M.V., Alengos, N.N. (1990) Automated equipment for arc surfacing of working layer with regulated distribution of properties. In: Equipment and materials for surfacing. Kiev: PWI, 14-17.

10. Sokolov, G.N., Lysak, V.I. (2005) Surfacing of wear-resistant alloys on press dies and tool for hot deforming of steels. Volgograd: RPK Politekhnik.

11. Savulyak, V.I., Zabolotny, S.A., Shenfeld, V.I. (2010) Surfacing of high-carbon coatings using the carbon fibers. Problemy Trybologii, 1, 66-70.

12. Peremitko, V.V. (2014) Wear-resistant arc surfacing over the layer of alloying charge. The Paton Welding J., 8, 54-57.

13. Peremitko, V.V., Nosov, D.G. (2015) Optimization of modes of submerged arc surfacing over the layer of alloying charge of caterpillar machine running gear parts. Ibid., 5/6, 44-46.

Received 16.04.2017 
INFLUENCE OF PREHEATING PARAMETERS AND LOCAL HEAT TREATMENT ON STRUCTURE AND PROPERTIES OF DISPERSION-STRENGTHENED JOINTS OF SILICON-CONTAINING TITANIUM ALLOYS MADE BY ELECTRON BEAM WELDING

\author{
S.V. AKHONIN, E.L. VRZHIZHEVSKY, V.Yu. BELOUS and I.K. PETRICHENKO \\ E.O. Paton Electric Welding Institute, NASU \\ 11 Kazimir Malevich Str., 03680, Kiev, Ukraine. E-mail: office@paton.kiev.ua
}

\begin{abstract}
Titanium alloys have high strength and corrosion resistance in a broad temperature range. When developing promising alloys, it is necessary to increase both working temperatures of parts and components of future engines, and their specific strength. The work is a study of the influence of preheating and local heat treatment on the structure and properties of EB welded joints of experimental silicon-containing titanium alloys, namely pseudo $\alpha$-alloy Ti-5.6Al2.2Sn-3.5Zr-0.4Mo-1V-0.6Si and $(\alpha+\beta)$-alloy Ti-4.3Al-4.4Sn-6Zr-1.6Mo-0.7V-4.3Nb-0.4Si. Welded joints of dispersion-strengthened titanium ( $\alpha+\beta$ )-alloy Ti-4.3Al-4.4Sn-6Zr-1.6Mo-0.7V-4.3Nb-0.4Si have higher ultimate strength, reaching $1277 \mathrm{MPa}$ that corresponds to $90 \%$ of that of the alloy proper. Long-term strength $\sigma_{100}$ at $600{ }^{\circ} \mathrm{C}$ temperature of welded joint of Ti-4.3Al-4.4Sn-6Zr-1.6Mo-0.7V-4.3Nb-0.4Si titanium alloy is equal to about $260 \mathrm{MPa}$ that is on the level of $93 \%$ of long-term strength of base metal. 12 Ref., 4 Figures, 3 Tables.
\end{abstract}

Keywords: titanium, titanium alloy, dispersion strengthening, electron beam welding, structure, properties, strength, long-term strength

Titanium alloys have high strength and corrosion resistance in a broad temperature range. In development of competitive engines, it is necessary to increase both working temperatures of parts and components of future engines and their specific strength [1]. This can be achieved, first of all, through improvement of alloying of titanium alloy. High-temperature titanium alloys, such as VT3, VT9, VT8 are traditionally included into the group of pseudo $\alpha$-alloys. Over the last years, however, investigations are performed also in the direction of development of two-phase high-temperature $(\alpha+$ $\beta$ )-titanium alloys, for instance, high-temperature alloy VT25U [2], which has $\sigma_{t}=1080 \mathrm{MPa}$, at $20^{\circ} \mathrm{C}$, and $\sigma_{t}=784 \mathrm{MPa}$ at $550^{\circ} \mathrm{C}$, that exceeds the respective values of many high-temperature single-phase $\alpha$-alloys or pseudo $\alpha$-alloys [3]. In the case of dispersion-strengthened $(\alpha+\beta)$-titanium alloys, their strength is also higher, making them potentially more promising for application in engine construction [4, 5]. Silicon as an alloying element improves high-temperature strength of titanium alloys due to blocking the movement of dislocations. However, silicon solubility in $\alpha$-titanium is very low on the level of tenth fractions of a percent (less than $0.2 \%$ at $600{ }^{\circ} \mathrm{C}$ ). Even small changes of silicon concentration can lead to a change of the properties of both base metal (BM), and their welded joints. An essential disadvantage of dispersion-strengthened titanium alloys is complexity of welding titanium, associated with initiation of cold cracks in welded joints. Therefore, elec- tron beam welding (EBW) of such alloys requires application of additional technological operations, such as preheating and post weld heat treatment. Complication of the process of manufacturing parts from high-temperature titanium alloys requires improvement of the technology of their welding, particularly, of titanium alloys, additionally doped by silicon.

The objective of the work is determination of the influence of preheating and local heat treatment in EBW chamber on the properties of welded joints of experimental titanium alloys, doped with silicon.

Studied were the properties of EB welded joints of two types of titanium alloys, which belong to pseudo $\alpha$-alloys and $(\alpha+\beta)$-alloys: alloy 1 (Ti-5.6Al-2.2Sn$3.5 \mathrm{Zr}-0.4 \mathrm{Mo}-1 \mathrm{~V}-0.6 \mathrm{Si}$ - pseudo $\alpha$-alloy with coefficient of $\beta$-phase stabilization $K_{\beta}=0.1$ ); alloy 2 (Ti-4.3Al-4.4Sn-6Zr-1.6Mo-0.7V-4.3Nb-0.4Si two-phase $(\alpha+\beta)$-alloy of martensitic type with $K_{\beta}=$ $=0.33$ ).

Ingots were produced in skull electron beam installation ISV-004 [6]. Table 1 gives the composition of both the alloys. Produced ingots were rolled to $13 \mathrm{~mm}$ thickness. After rolling the plates were annealed at the temperature of $800^{\circ} \mathrm{C}$ for $1 \mathrm{~h}$ to stabilize the structure and relieve stresses.

Welding of samples of $150 \times 70 \times 13 \mathrm{~mm}$ size was performed in one pass in ELA60/60 unit. Three different preheating operations up to 200,300 and $400{ }^{\circ} \mathrm{C}$ were performed for each of the studied alloys, and 
Table 1. Chemical composition of silicon-containing dispersion-strengthened titanium alloys

\begin{tabular}{|c|c|c|c|c|c|c|c|c|}
\hline \multirow{2}{*}{ Alloy } & \multicolumn{7}{|c|}{ Alloying element content, \% } & \multirow{2}{*}{$K_{\beta}$} \\
\cline { 2 - 18 } & $\mathrm{Al}$ & $\mathrm{Sn}$ & $\mathrm{Zr}$ & $\mathrm{Mo}$ & $\mathrm{V}$ & $\mathrm{Nb}$ & 0.6 & 0.1 \\
\hline 1 & 5.6 & 2.2 & 3.5 & 0.4 & 1.0 & - & 0.4 & 0.33 \\
\hline 2 & 4.3 & 4.4 & 6.0 & 1.6 & 0.7 & 4.3 & 0.3 \\
\hline
\end{tabular}

temperature was monitored with thermocouples, attached from the weld root side. Detailed procedure is published in work [7]. Welding was performed in the following mode: $U_{\text {acc }}=60 \mathrm{~kW}, I_{\text {beam }}=80 \mathrm{~mA}, V=$ $=7 \mathrm{~mm} / \mathrm{s}$. Appearance of welded joint of experimental $(\alpha+\beta)$-titanium alloy with dispersion strengthening, made by EBW with preheating and subsequent local electron beam heat treatment, is given in Figure 1.

Defects, most often observed in welded joints of both the alloys, included cold cracks, these cracks forming both in weld upper part, and in the heat-affected zone (HAZ). Local heat treatment directly after welding is an effective technological measure to prevent cold cracking in EBW [8]. Therefore, to produce crack-free sound joints local heat treatment (LHT) of the made joints was performed directly after welding in EB chamber. LHT included heating up to $900{ }^{\circ} \mathrm{C}$ and soaking for $5 \mathrm{~min}$. After LHT the joint has no cold cracks.

Experimental alloy 1 in the condition after rolling and subsequent annealing has platelike structure with silicide concentration on plate boundaries (Figure 2, a) that is associated with the fact that silicon content in this alloy is above the limit of its solubility in $\alpha$-phase. As is known, maximum solubility of silicon in $\alpha$-phase is equal to $0.45 \%$ at the temperature of $860{ }^{\circ} \mathrm{C}$, and minimum temperature is less than $0.2 \%$ at $600{ }^{\circ} \mathrm{C}$ [9]. In addition, silicon solubility in titanium can decrease in the presence of other alloying elements, such, as for instance, aluminium $[10,11]$. Investigations of the structure of the welded joints showed that weld metal of experimental alloy 1 in as-welded and LHT condition consists of primary $\beta$-grains elongated in the direction of heat removal with platelike $\alpha$-phase in the grain volume. After welding silicide particles are localized both along the boundaries of $\beta$-grains, and in the grain volume (Figure $2, c$ ). Size of platelike $\alpha^{\prime}$-phase is equal to $0.3-1.5 \mu \mathrm{m}$, and that of silicide precipitates is $0.1-0.2 \mu \mathrm{m}$. After heat treatment silicide particles are located predominantly along the boundaries of $\alpha$-plates (Figure 2, d), and in BM. Large equiaxed grains of $\beta$-phase form in the HAZ near-weld zone after heating up to temperatures exceeding polyamorphous transformation temperatures (PTT). At cooling to temperatures below PTT $\beta \rightarrow \alpha^{\prime}$-transformation with formation of platelike $\alpha^{\prime}$-phase takes place in the volume of primary $\alpha$-grains, as well as in the weld (Figure $3, a)$. After heat treatment silicides also predominantly fringe the boundaries of $\alpha$-plates (Figure $3, b$ ).

Work [12] shows that structural-phase state of metal of fusion zone of welded joint on titanium alloy 1 is characterized by formation of platelike $\alpha$ - and $\beta$-structures of an elongated shape. Here, phase precipitates of intermetallics of diverse stoichiometric composition are formed, such as $\mathrm{Ti}_{3} \mathrm{Si}$; $\mathrm{Ti}_{5} \mathrm{Si}_{3}$; (Ti, $\mathrm{Zr})_{5}(\mathrm{Si}, \mathrm{Al})_{3}$; (Ti,Zr) $)_{2}(\mathrm{Si}, \mathrm{Al})$ and TiSi. These intermetallic phases differ essentially both by dimensions and by their distribution. Mean diameter of intermetallic precipitates is equal to $0.1-0.2 \mu \mathrm{m}$. Phase precipitation sites also feature formation of dense dislocation clusters in these zones. Presence of strongly elongated structural-phase formations promotes lowering of ductility of welded joint metal and increase of cracking susceptibility, respectively [12].

Experimental alloy 2 belongs to $(\alpha+\beta)$-alloys of martensitic type. Silicon content in this alloy is somewhat higher than the limit of its solubility in $\alpha$-phase. BM of alloy 2 has thin plate structure (Figure $4, a$ ). Weld of this alloy consists of primary $\beta$-grains of different shape (Figure 4, b). Metastable martensite $\alpha^{\prime}$-phase is detected in primary grain volume (Figure $4, c)$. Very fine particles of titanium silicides are observed against the background of acicular structure, which are located both on the boundaries and in the grain volume (Figure $4, d$ ).
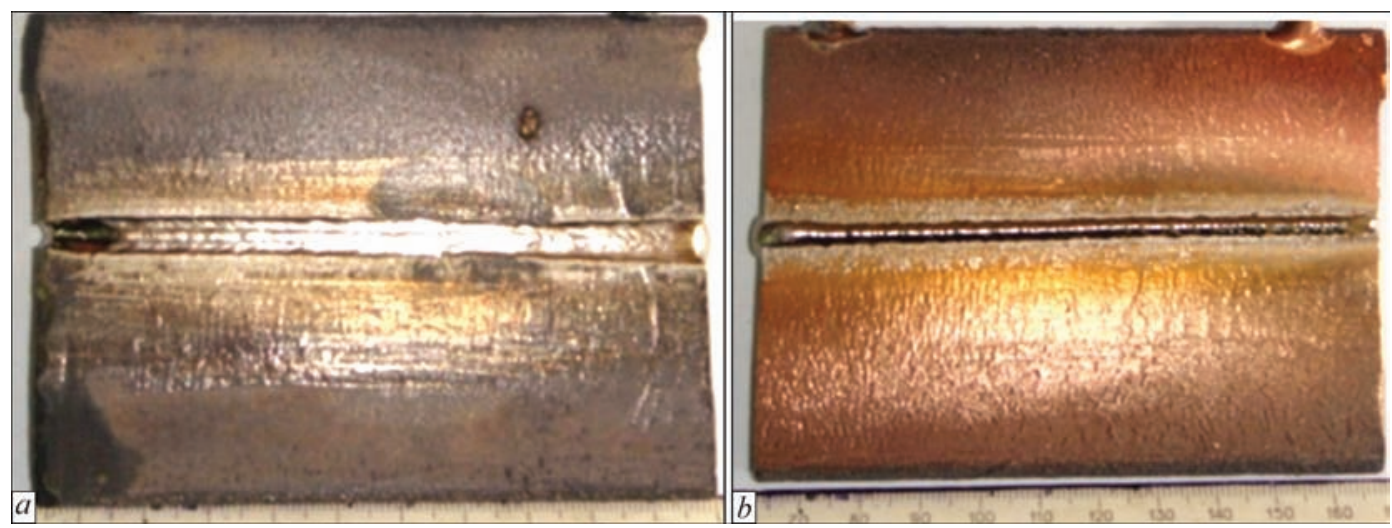

Figure 1. Appearance of welded joint of titanium alloy 2 with electron beam preheating at $200^{\circ} \mathrm{C}$ temperature: $a$ - face; $b$ - weld root 


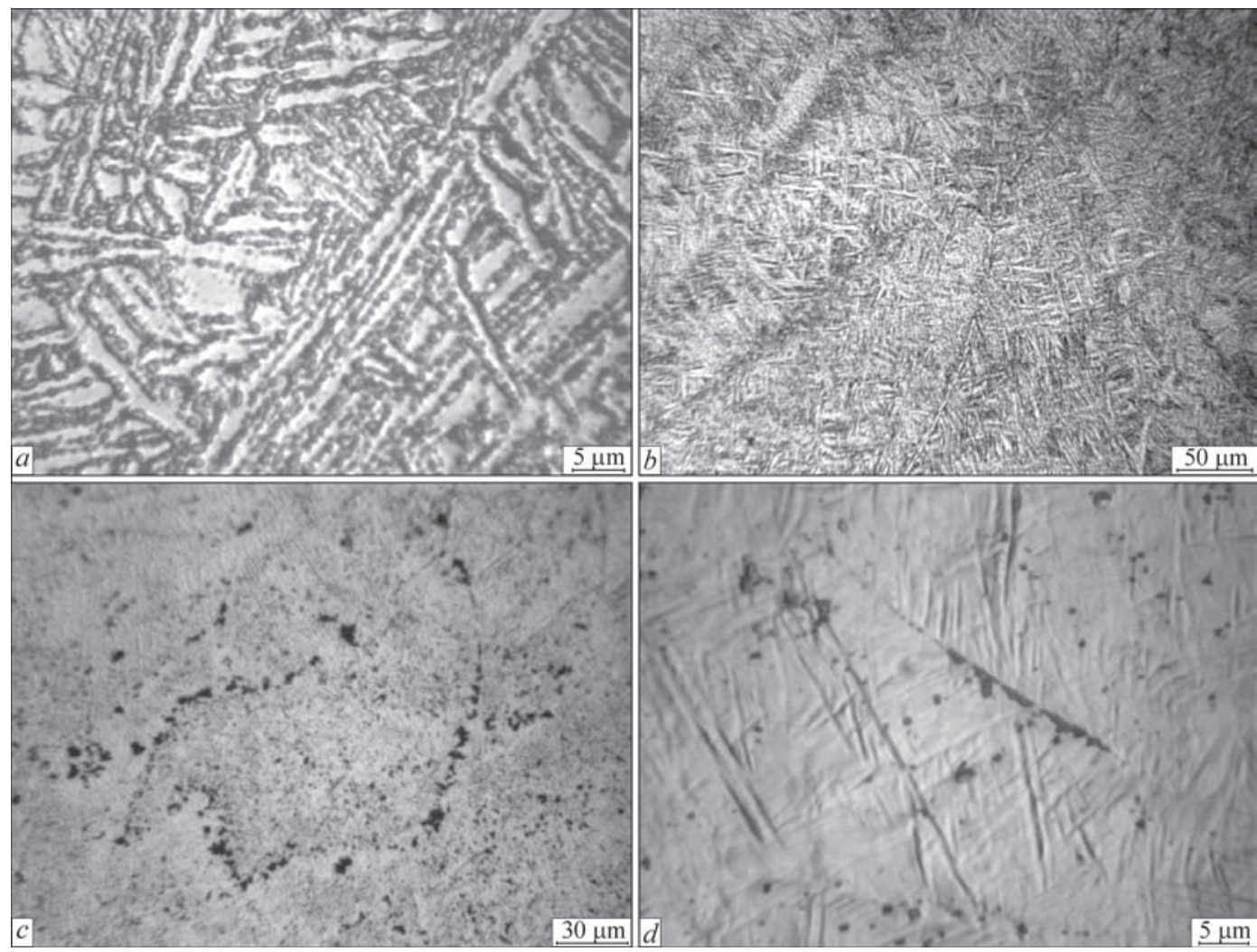

Figure 2. Microstucture of BM ( $a$ ) and metal of EB weld of dispersion-strengthened titanium alloy $1(b-d)$

Three structurally-different regions can be distinguished in the HAZ of alloy 2. Hear-weld zone consists of equiaxed polyhedral primary $\beta$-grains with acicular morphology of $\alpha^{\prime}$-phase (Figure 3,c).
Located farther from the weld is HAZ region where partial recrystallization with formation of fine equiaxed grains proceeds. Located near BM is HAZ region which was heated to temperatures below PTT
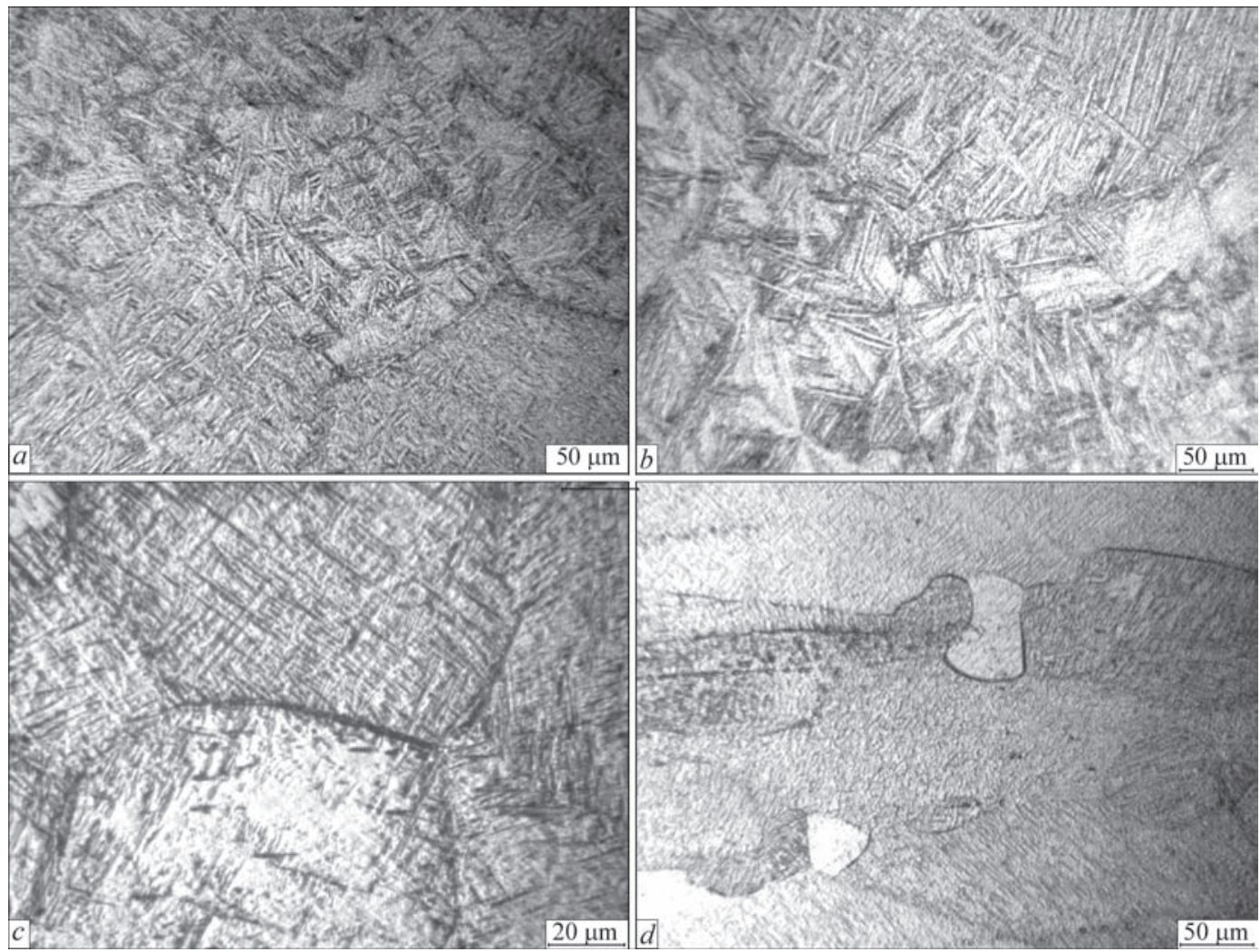

Figure 3. Microstructure of HAZ metal of EBW joints of dispersion-strengthened titanium alloys: $a, b-$ alloy 1 ; $c, d-$ alloy 2 ( $a$, $c$, $d$ - after welding; $b$ - after LHT) 


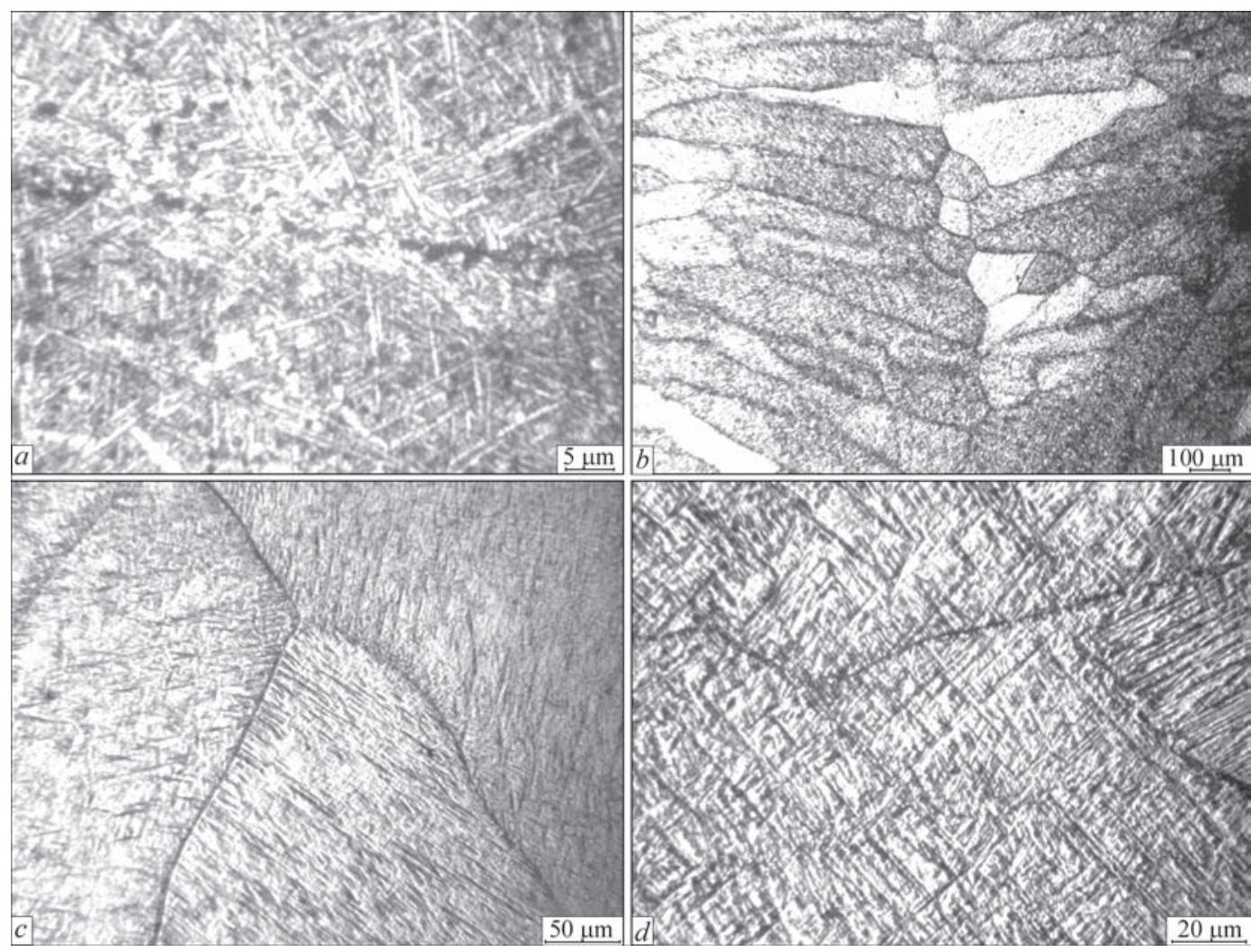

Figure 4. Microstructure of BM ( $a$ ) and metal of EB weld of dispersion-strengthened titanium alloy $2(b-d)$

and recrystallization temperature, and which inherits BM structure, but has low etchability. In some local areas of the HAZ fine equiaxed grains are surrounded by eutectics (Figure 3, d) with high silicon content. Microstructure in the fusion zone is represented, similar to pseudo $\alpha$-alloy, by platelike $\alpha$ - and $\beta$-phases of martensite type. On the whole, structure of weld and HAZ metal of alloy 2 is more uniform and finely-dispersed, compared to alloy 1 . As shown in [12], the main difference in HAZ structure of these alloy joints consists in smaller dimensions of $(\alpha, \beta)$-constituents and intermetallic phases. So, dimensions of platelike structures are equal to $0.2-0.5 \mu \mathrm{m}$, and mean diameter of intermetallic precipitates is equal to $0.01-0.06 \mu \mathrm{m}$, that is $2-3$ times smaller in the cross-section, compared to the respective zone of pseudo $\alpha$-alloy. Silicide and intermetallic phase distribution is more uniform through the entire metal volume.

Thus, dispersion-strengthened titanium alloy 2 has smaller dimensions of $(\alpha, \beta)$-components, as well as silicide and intermetallic phases, compared to alloy 1 , but presence of elongated platelike structures will

Table 2. Mechanical properties of base metal and EB welded joints of dispersion-strengthened titanium alloys

\begin{tabular}{|c|c|c|c|c|c|c|}
\hline Material & $\begin{array}{c}\text { Preheating tempera- } \\
\text { ture, }{ }^{\circ} \mathrm{C}\end{array}$ & $-\begin{array}{c}\text { Temperature }\left({ }^{\circ} \mathrm{C}\right) \\
\text { LHT duration (min) }\end{array}$ & $\sigma_{y}, \mathrm{MPa}$ & $\sigma_{\mathrm{t}}, \mathrm{MPa}$ & $\begin{array}{c}\text { Impact toughness } \\
K C V, \mathrm{~J} / \mathrm{cm}^{2}\end{array}$ & Remark \\
\hline \multirow{8}{*}{ Alloy 1} & - & - & 1106.4 & 1208.2 & 9.05 & Base metal \\
\hline & - & - & - & 1309.7 & - & Brittle fracture \\
\hline & 200 & - & - & 1187.6 & 5.4 & Same \\
\hline & 200 & $900 ; 10$ & 810.5 & 1182.9 & 5.3 & $»$ \\
\hline & 300 & - & - & 1167.7 & 5.1 & $»$ \\
\hline & 300 & $900 ; 10$ & 743.3 & 1089.0 & 4.9 & $»$ \\
\hline & 400 & - & - & 1192.0 & 4.4 & $»$ \\
\hline & 400 & $900 ; 10$ & 789.8 & 1132.8 & 3.4 & $»$ \\
\hline \multirow{8}{*}{ Alloy 2} & - & - & 1329.2 & 1422.2 & 4.2 & Base metal \\
\hline & - & - & - & 1360.2 & 2.2 & Brittle fracture \\
\hline & 200 & - & - & 1293.0 & 4.7 & Same \\
\hline & 200 & $900 ; 10$ & - & 1277.8 & 4.6 & $»$ \\
\hline & 300 & - & - & 1241.6 & 4.8 & $"$ \\
\hline & 300 & $900 ; 10$ & - & 1219.8 & 4.5 & $"$ \\
\hline & 400 & - & - & 1329.7 & 4.5 & $»$ \\
\hline & 400 & $900 ; 10$ & - & 1274.9 & 1.8 & $»$ \\
\hline
\end{tabular}


promote, even though to a smaller degree, lowering of ductility and appearance of susceptibility to crack formation in the welded joint, that is indicative of the need for local postweld heat treatment.

Analysis of mechanical characteristics of welded joints of both the alloys is given in Table 2. Strength of welded joints of alloy 2 is higher by $8 \%$ than that of alloy 1 joints at practically equal impact toughness of samples with a sharp notch. Increase of preheating temperature up to 300 and $400{ }^{\circ} \mathrm{C}$ is not favourable for welded joint properties, but leads to lowering of impact toughness of joints of both the alloys.

Thus, performed studies led to the conclusion that $200{ }^{\circ} \mathrm{C}$ is the optimum preheating temperature for EBW of alloy 2. In this case, welded joint strength is on the level of $90 \%$ of BM strength.

As welded joints of dispersion-strengthened titanium alloy 2 have a more uniform structure with $2-3$ times smaller dimensions of $(\alpha, \beta)$-components and silicide phases, as well as higher mechanical properties, long-term strength studies of both the alloy proper and its welded joints were performed for this alloy. Testing was conducted according to GOST 10145-81 «Metals. Method of testing for long-term strength». This required making standard samples of MI-83 type with a cylindrical part of $5.0 \mathrm{~mm}$ diameter, which were placed into the grips of tensile testing machine MP-3G (GOST 1533-81). Sample testing temperature was $600^{\circ} \mathrm{C}$ and was maintained constant with the accuracy of $\pm 2^{\circ} \mathrm{C}$. Table 3 shows the obtained results.

Analysis of the obtained results allowed plotting the following dependence: load $(\sigma, \mathrm{MPa})$ - time to fracture $(\tau, h)$, and making the following conclusions: long-term strength $\sigma_{100} \mathrm{BM}$ of titanium alloy 2 with dispersion strengthening is equal to about $280 \mathrm{MPa}$, long-term strength $\sigma_{100}$ of welded joint of titanium alloy 2 is equal to about $260 \mathrm{MPa}$.

Thus, conducted investigations led to the conclusion that long-term strength of welded joint of titanium alloy 2 with dispersion strengthening, produced by EBW with preheating at the temperature of $200^{\circ} \mathrm{C}$ and LHT by the electron beam in the welding chamber at the temperature of $600{ }^{\circ} \mathrm{C}$ is on the level of $93 \%$ of BM long-term strength.

\section{Conclusions}

1. Welded joints made by EBW of dispersion-strengthened titanium pseudo $\alpha$-alloy Ti-5.6Al-2.2Sn-3.5Zr$0.4 \mathrm{Mo}-1 \mathrm{~V}-0.6 \mathrm{Si}$ have dimensions of $\alpha^{\prime}$-phase in the range of $0.3-1.5 \mu \mathrm{m}$, silicide inclusions - of $0.1-0.2 \mu \mathrm{m}$, ultimate strength of the joints reaching $1182 \mathrm{MPa}$ that is equal to $97 \%$ of that of the alloy proper.

2. Welded joints of dispersion-strengthened titanium $(\alpha+\beta)$-alloy Ti-4.3Al-4.4Sn-6Zr-1.6Mo-0.7V$4.3 \mathrm{Nb}-0.4 \mathrm{Si}$ have high ultimate strength reaching $1277 \mathrm{MPa}$, that corresponds to $90 \%$ of that of the al-
Table 3. Long-term strength of titanium alloy 2 and its welded joints at $600{ }^{\circ} \mathrm{C}$ temperature

\begin{tabular}{|c|c|c|c|c|}
\hline Sample type & Load $\sigma, \mathrm{MPa}$ & $\begin{array}{c}\text { Time to frac- } \\
\text { ture, } \tau, \mathrm{h}\end{array}$ & $\begin{array}{c}\text { Relative } \\
\text { elongation } \\
\delta, \%\end{array}$ & $\begin{array}{c}\text { Reduction in } \\
\text { area } \psi, \%\end{array}$ \\
\hline Base metal & 650 & 2.15 & 9.2 & 18.6 \\
\hline Same & 600 & 3.10 & 14.6 & 39.2 \\
\hline$»$ & 450 & 19.00 & 26.9 & 50.6 \\
\hline$»$ & 400 & 19.30 & 22.0 & 61.6 \\
\hline$»$ & 350 & 26.30 & 26.4 & 54.9 \\
\hline$»$ & 300 & 58.00 & 21.3 & 69.7 \\
\hline Welded joint & 260 & 87 & 11.9 & 18.3 \\
\hline Same & 260 & 120 & 9.2 & 6.75 \\
\hline$»$ & 300 & 37 & 10.4 & 13.9 \\
\hline
\end{tabular}

loy proper, and 2-3 times smaller dimensions of ( $\alpha+$ $\beta)$-components and intermetallic phases. They, however, are prone to cracking and require performance of local postweld heat treatment.

3. Optimal preheating temperature in EBW of high-temperature titanium $\alpha$-alloy Ti-5.6Al-2.2Sn$3.5 \mathrm{Zr}-0.4 \mathrm{Mo}-1 \mathrm{~V}-0.6 \mathrm{Si}$ and $(\alpha+\beta)$-alloy Ti-4.3Al4.4Sn-6Zr-1.6Mo-0.7V-4.3Nb-0.4Si is equal to $200^{\circ} \mathrm{C}$.

4. Long-term strength $\sigma_{100}$ at $600^{\circ} \mathrm{C}$ temperature of welded joint of titanium alloy Ti-4.3Al-4.4Sn-6Zr$1.6 \mathrm{Mo}-0.7 \mathrm{~V}-4.3 \mathrm{Nb}-0.4 \mathrm{Si}$ is equal to about $260 \mathrm{MPa}$, that is on the level of $93 \%$ of BM long-term strength.

1. Mukhin, V.S. (2007) Principles of technology of machine building (aircraft engine building). Ufa: UGATU.

2. Ilienko, V.M., Shalin, R.E. (1995) Titanium alloys for aircraft gas-turbine engines. Titan (VILS), 1/2, 25.

3. Iliin, A.A., Kolachev, B.A., Polkin, I.S. (2009) Titanium alloys. Composition, structure, properties: Refer. Book. Moscow: VILS-MATI.

4. Ivanov, V.I., Yasinsky, K.K. (1996) Efficiency of application of heat-resistant alloys based on $\mathrm{Ti}_{3} \mathrm{Al}$ and $\mathrm{TiAl}$ intermetallics for operation at temperatures of $600-800{ }^{\circ} \mathrm{C}$ in aerospace engineering. Tekhnologiya Lyogkikh Splavov, 3, 12-25.

5. Solonina, O.P., Glazunov, S.G. (1996) Heat-resistant titanium alloys: Refer. Book. Moscow: Metallurgiya.

6. Levitsky, N.I., Matvinets, E.A., Lapshuk, T.V. et al. (2012) Producing complex-doped titanium alloys by method of electron beam skull melting. Metall i Lityo Ukrainy, 4, 6-9.

7. Vrzhizhevsky, E.L., Sabokar, V.K., Akhonin, S.V. et al. (2013) Influence of local heat treatment at EBW of titanium alloys with silicide strengthening on mechanical properties of weld metal. The Paton Welding, J., 2, 20-23.

8. Lyasotskaya, V.S., Lysenkov, Yu.T., Gerasimenko, A.V. et al. (1985) Influence of local heat treatment on structure and properties of VT6ch alloy welded joints. Avitsionnaya Promyshlennost, 11, 57-59.

9. Anoshkin, N.F., Sigalov, Yu.M. (2002) Titanium alloys with higher heat resistance. Tekhnologiya Lyogkikh Splavov, 1, 38-50.

10. Zvikker, U. (1979) Titanium and its alloys. Moscow: Metallurgiya.

11. Kornilov, I.I., Budberg, P.B. (1961) State diagrams of binary and ternary systems. Moscow: VINITI.

12. Markashova, L.I., Akhonin, S.V., Grigorenko, G.M. et al. (2012) Structure and properties of welded joints on titanium alloys containing silicon additions. The Paton Welding J., 11, 6-15. 


\title{
PATON PUBLISHING HOUSE
}

\author{
www.patonpublishinghouse.com
}

\section{SUBSCRIPTION}

\section{The ifitiolonal \\ Автоматическая B P}

"The Paton Welding Journal» is Published Monthly Since 2000 in English, ISSN 0957-798X.

"Avtomaticheskaya Svarka» Journal (Automatic Welding) is Published

Monthly Since 1948 in Russian, ISSN 005-111X.

«The Paton Welding Journal» is Cover-to-Cover Translation of

Avtomaticheskaya Svarka» Journal into English.

If You are interested in making subscription directly via Editorial Board, fill, please, the coupon and send application by Fax or E-mail.

The cost of annual subscription via Editorial Board is $\$ 348$ for «The Paton Welding Journal» and $\$ 180$ for «Avtomaticheskaya Svarka» Journal.

«The Paton Welding Journal» can be also subscribed worldwide from catalogues subscription agency EBSO.

\section{SUBSCRIPTION COUPON \\ Address for journal delivery \\ Term of subscription since \\ Name, initials \\ Affiliation \\ Position \\ Tel., Fax, E-mail}

20

till

20

We offer the subscription all issues of the Journal in pdf format, starting from 2009.

The archives for 2009-2014 are free of charge on www.patonpublishinghouse.com site.
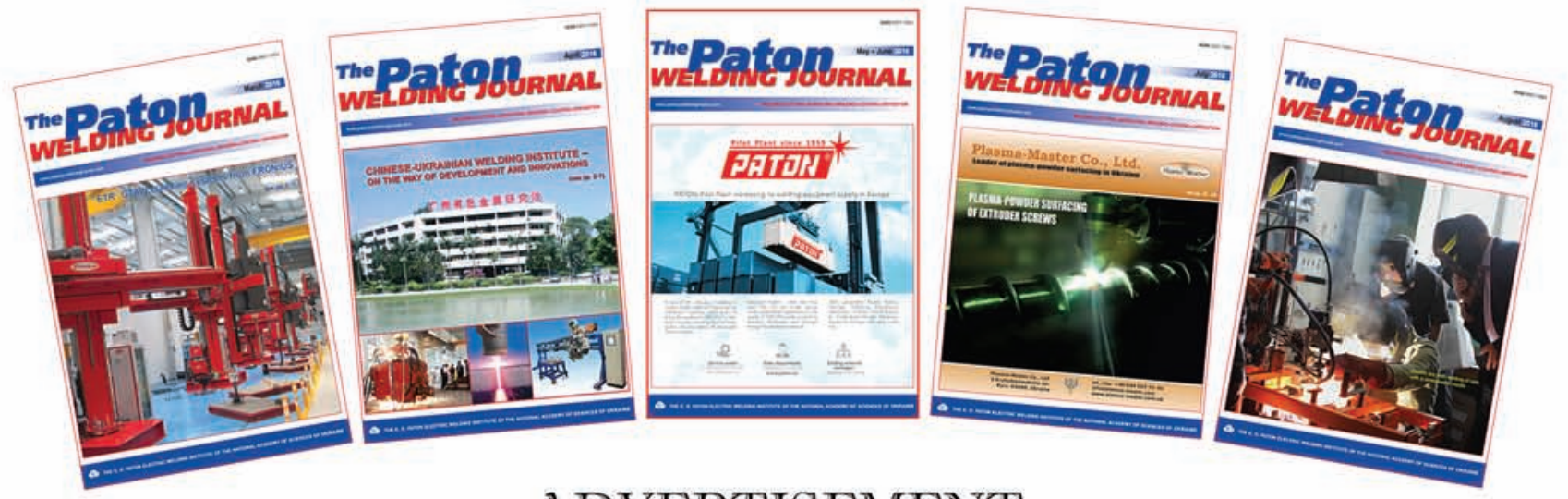

ADVERTISEMENT

in "Avtomaticheskaya Svarka" and "The Paton Welding Journal"

External cover, fully-colored:

First page of cover $(190 \times 190 \mathrm{~mm})-\$ 700$

Second page of cover $(200 \times 290 \mathrm{~mm})-\$ 550$

Third page of cover

$(200 \times 290 \mathrm{~mm})-\$ 500$

Fourth page of cover

$(200 \times 290 \mathrm{~mm})-\$ 600$
Internal cover, fully-colored: First/second/third/fourth page of cover $(200 \times 290 \mathrm{~mm})-\$ 400$

Internal insert: Fully-colored $(200 \times 290 \mathrm{~mm})$ $\$ 340$

Fully-colored (double page A3) $(400 \times 290 \mathrm{~mm})-\$ 500$
- Article in the form of advertising is $50 \%$ of the cost of advertising area

- When the sum of advertising contracts exceeds $\$ 1001$, a flexible system of discounts is envisaged

Size of journal after cutting is $200 \times 290 \mathrm{~mm}$

Editorial Board of Journal «Avtomaticheskaya Svarka» and \& The Paton Welding Journal» E.O. Paton Electric Welding Institute of the NAS of Ukraine International Association «Welding» 